FY 2005

\title{
THE ROLE OF RELUCTANCE IN PM MOTORS
}

Prepared by:

Oak Ridge National Laboratory

Mitch Olszewski, Program Manager

Submitted to:

Energy Efficiency and Renewable Energy

FreedomCAR and Vehicle Technologies

Vehicle Systems Team

Susan A. Rogers, Technology Development Manager

June 2005 
NATIONAL LABORATORY

MANAGED BY UT-BATTELLE

FOR THE DEPARTMENT OF ENERGY
Engineering Science and Technology Division

\section{THE ROLE OF RELUCTANCE IN PM MOTORS \\ P. J. Otaduy - ORNL \\ W. C. Johnson - UTK}

Publication Date: June 2005

Prepared by the

OAK RIDGE NATIONAL LABORATORY

Oak Ridge, Tennessee 37831

managed by

UT-BATTELLE, LLC

for the

U.S. DEPARTMENT OF ENERGY

Under contract DE-AC05-00OR22725 
This report was prepared as an account of work sponsored by an agency of the United States Government. Neither the United States Government nor any agency thereof, nor any of their employees, makes any warranty, express or implied, or assumes any legal liability or responsibility for the accuracy, completeness, or usefulness of any information, apparatus, product, or process disclosed, or represents that its use would not infringe privately owned rights. Reference herein to any specific commercial product, process, or service by trade name, trademark, manufacturer, or otherwise, does not necessarily constitute or imply its endorsement, recommendation, or favoring by the United States Government or any agency thereof. The views and opinions of authors expressed herein do not necessarily state or reflect those of the United States Government or any agency thereof. 


\section{CONTENTS}

Page

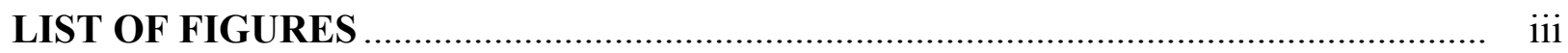

INTRODUCTION

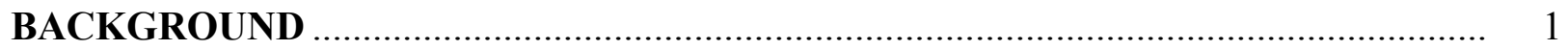

ANALYSIS SHOWING THE RELATIVE BENEFIT OF FLUX WEAKENING

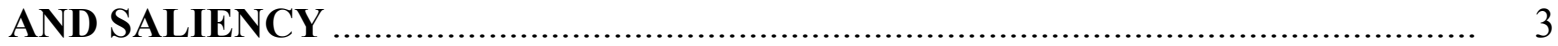

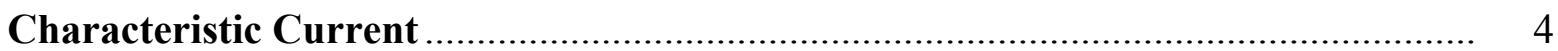

Summary of Reluctance Analysis ............................................................................... 6

ANALYSIS AND COMPARISON OF THREE PM MOTORS THAT PRODUCE

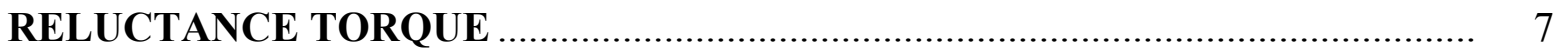

Methodology Used for Analysis and Comparison .................................................... 9

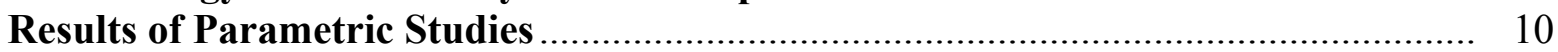

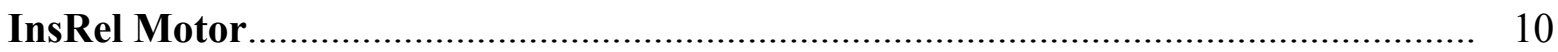

V-Shaped IPM Type-4 Results ................................................................... 20

U-Shaped Dual-Layer IPM Type-6 Results......................................................... 28

Comparison of Best of Each Topology ................................................................. 36

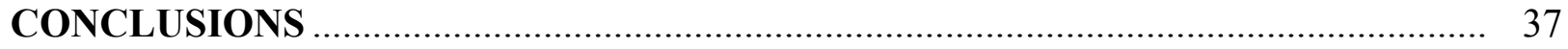

REFERENCES

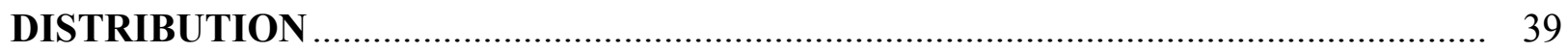




\section{LIST OF FIGURES}

Figure

Page

1 Standard RMS phasor diagram of a PM motor without flux weakening. ................ 2

2 Standard RMS phasor diagram of a PM motor with flux weakening ..................... 4

3 Inset surface mounted PM motors:

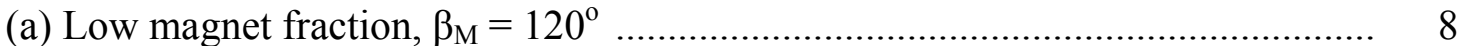

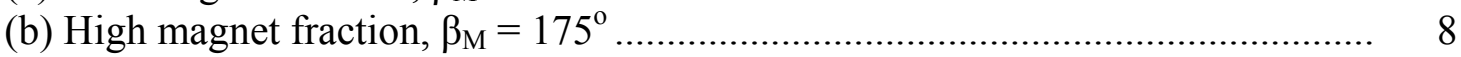

$4 \quad$ V-shaped IPM motors (type 4):

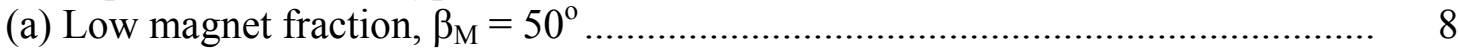

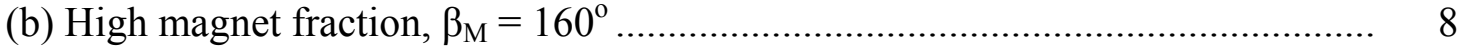

$5 \quad$ U-shaped IPM motors (type 6):

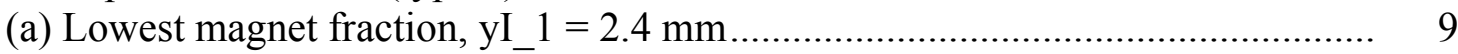

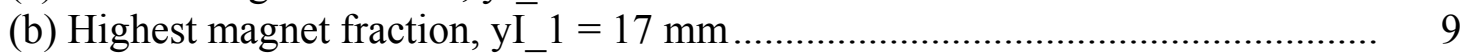

6 Amount of PM material in terms of cross-sectional surface area as a function of $\beta_{M}$ or $y I \_1$ for each of the three rotor configurations .................................... 10

7 Inset PM motor torque and efficiency as a function of speed for a range of magnet pitches:

(a) Compact view for the full range of speeds ...................................................... 11

(b) Expanded view for a reduced set of speeds for the inset PM motor.................. 11

8 Relationship between torque, magnet pitch, $\beta_{\mathrm{M}}$, and speed for the inset PM motor:

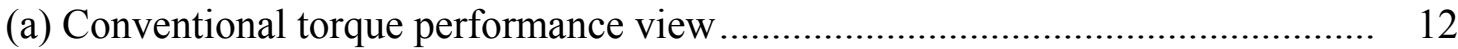

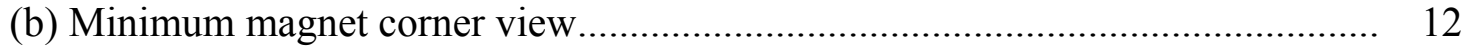

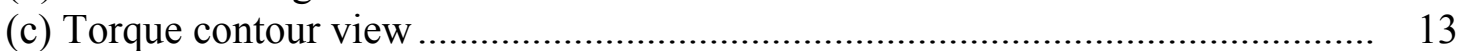

9 Relationship between magnet pitch, $\beta_{\mathrm{M}}$, speed, and advance for the inset PM motor:

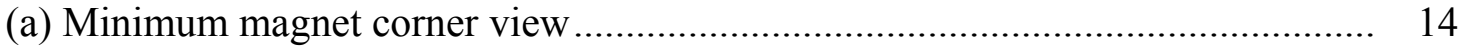

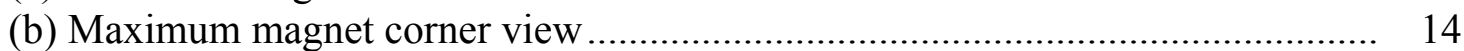

10 Relationship between $\beta_{\mathrm{M}}$, speed, and maximum power for the inset PM motor:

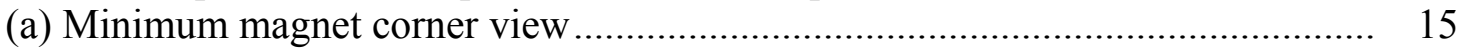

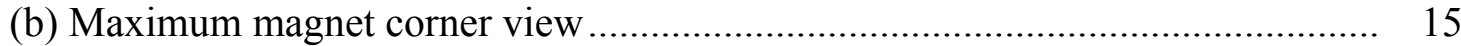

11 Relationship between magnet pitch, $\beta_{\mathrm{M}}$, speed, and percentage of reluctance torque for the inset PM motor

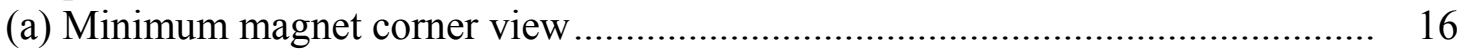

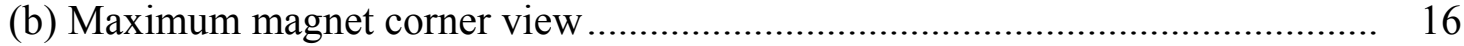

12 CPSR as a function of magnet pitch, $\beta_{\mathrm{M}}$, for the inset PM motor type................... 17

13 Relationship between normalized torque, speed, and relative magnet cost for the inset PM motor:

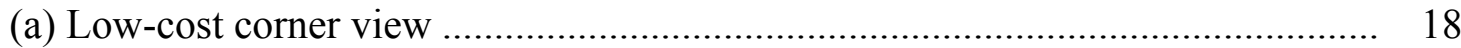

(b) Normalized torque contour view ......................................................... 18 
Figure

\section{LIST OF FIGURES (cont'd)}

14 Comparison of selected optimal (magnet pitches, $\beta_{\mathrm{M}}=105,115$, and $125^{\circ}$ with highest CPSR) inset PM motor performance with surface-mounted PM motor $\left(\beta_{\mathrm{M}}=180^{\circ}\right)$ :

(a) Torque performance view …………......................................................... 19

(b) Power performance view ............................................................................ 19

15 V-shaped IPM motor torque and efficiency as a function of speed for a range of magnet pitches:

(a) Compact view for the full range of speeds ...................................................... 20

(b) Expanded view for a reduced set of speeds .................................................. 20

16 Relationship between magnet pitch, $\beta_{\mathrm{M}}$, speed, and torque for the V-shaped IPM motor:

(a) Conventional torque performance view........................................................... 21

(b) Minimum magnet corner view................................................................... 21

(c) Maximum magnet corner view ..................................................................... 22

17 Relationship between magnet pitch, $\beta_{\mathrm{M}}$, speed, and advance for the V-shaped IPM motor:

(a) Minimum magnet corner view ......................................................................... 23

(b) Maximum magnet corner view ..................................................................... 23

18 Relationship between magnet pitch, $\beta_{\mathrm{M}}$, speed, and maximum power for the V-shaped IPM motor:

(a) Minimum magnet corner view .......................................................................... 24

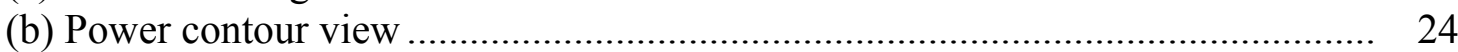

19 Relationship between magnet pitch, $\beta_{\mathrm{M}}$, speed, and percentage of reluctance torque for the V-shaped IPM type-4 motor .......................................................... 25

$20 \quad$ CPSR as a function of magnet pitch, $\beta_{\mathrm{M}}$, for the V-shaped IPM motor.................... 25

21 Relationship between normalized torque, speed, and relative cost for V-shaped IPM motor:

(a) Low-cost corner view

(b) Normalized torque contour view ................................................................ 26

22 Comparison of selected optimal (magnet pitches, $\beta_{\mathrm{M}}=104,110$, and $116^{\circ}$ with highest CPSR) V-shaped IPM motor performance with surface-mounted PM motor $\left(\beta_{\mathrm{M}}=180^{\circ}\right)$ :

(a) Torque comparison view............................................................................... 27

(b) Power comparison view.......................................................................... 27

23 Torque and efficiency as a function of speed over a range of magnet pitches for the motor with dual-layer U-shaped IPMs:

(a) Compact view for the full range of speeds ...................................................... 29

(b) Expanded view for a reduced set of speeds ..................................................... 30

24 Relationship between magnet amount, yI-1, speed, and torque for the motor having dual-layer U-shaped IPMs:

(a) Conventional torque performance view ............................................................. 30

(b) Minimum magnet material corner view ………….......................................... 30 
Figure

\section{LIST OF FIGURES (cont'd)}

25 Relationship between magnet material, yI_1, speed, and advance for the motor having dual-layer U-shaped IPMs:

(a) Minimum magnet material corner view .................................................... 31

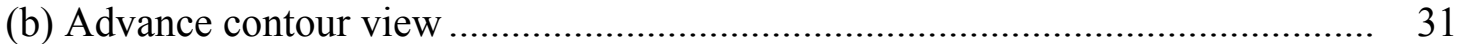

26 Relationship between magnet amount, yI_1, speed, and power for the motor having dual-layer U-shaped IPMs:

(a) Minimum magnet material corner view....................................................... 32

(b) Maximum magnet material corner view .................................................. 32

27 Relationship between magnet amount, yI_1, speed, and percentage of reluctance torque for the motor having dual-layer U-shaped IPMs ....................... 33

28 CPSR as a function of magnet amount, yI_1, for the motor having dual-layer U-shaped IPMs

29 Speed and normalized cost and torque for the motor having dual-layer U-shaped IPMs:

(a) View from low-cost corner

(b) Torque contour plot

30 Performance comparison of IPM motor having double-layer U-shaped magnets with surface-mounted PM motor having only PM torque:

(a) Torque performance comparison

(b) Power performance comparison

31 Performance comparison of four motors with varying degrees of reluctance:

(1) surface-mounted PM motor producing only PM torque; (2) inset PM/reluctance motor with magnet pitch, $\beta_{M}=125^{\circ}$; (3) V-shaped IPM motor with $\beta_{M}=116^{\circ}$; and (4) double-layer U-shaped IPM with yI_1 $=22.4 \mathrm{~mm}$

(a) Torque performance comparison ............................................................ 36

(b) Power performance comparison ......................................................... 36 


\section{INTRODUCTION}

The international research community has lately focused efforts on interior permanent magnet (IPM) motors to produce a traction motor for hybrid electric vehicles (HEV). One of the beneficial features of this technology is the additional torque produced by reluctance. The objective of this report is to analytically describe the role that reluctance plays in permanent magnet (PM) motors, to explore ways to increase reluctance torque without sacrificing the torque produced by the PMs, and to compare three IPM configurations with respect to torque, power, amount of magnet material required (cost), and percentage of reluctance torque. Results of this study will be used to determine future research directions in utilizing reluctance to obtain maximum torque and power while using a minimum amount of magnet material.

\section{BACKGROUND}

Once a PM machine is built, the strength and number of magnets in the rotor and the number of poles and turns in the coils of the stator remain constant; thus, the amount of PM-generated magnetic flux linked by the coils of the stator remains fixed. As a result, the back-electromotiveforce (back-emf) voltage induced by the PMs increases linearly with the speed of the rotor.

As the rotor speed increases the back-emf voltage rises, which results in a rapid reduction in the available voltage, (the difference between the supply voltage and the back-emf). When there is no longer any voltage available to drive current into the stator, the maximum speed has been reached.

Reluctance is a property used in magnetic circuits that accounts for the ratio of geometric length to area and the magnetic properties of a medium, such as permeability, $\mu$, in which a magnetic flux flows. The expression for reluctance is $R=l /(\mu \mathrm{A})$, where $l$ is the length of the flux path and $A$ is the area normal to the flux. Reluctance relates magnetic flux to magnetomotive force in a manner similar to the way that resistance and inductance relate current to voltage in an electric circuit. Since the externally controllable measurement parameters of a motor are electric, it is customary to study the performance of motors in terms of electric rather than magnetic quantities. The relationship between magnetic reluctance and electric inductance is complex except for the simplest of cases, like that of a coil wrapped with $N_{t}$ turns of wire around a magnetic path of reluctance, $R$. This simple relationship is

$$
\mathcal{L}=N_{t}^{2} / R .
$$

As Eq. (1) shows, electric inductance is proportional to the inverse of magnetic reactance. Consequently, high inductance corresponds to low reluctance.

Two distinct reference axes exist in most motors, the direct axis (d-axis) and the quadrature axis (q-axis). They are perpendicular in terms of electric degrees. Physically, they correspond to those rotor positions that yield the maximum and minimum amounts of magnetic flux linked in the stator coils. In PM motors, the d-axis corresponds to the center of a rotor's PM, while the q-axis corresponds to the midpoint in the space separating a PM from its closest PM of different polarity. These axes are identified later in this report in Fig. 3 through Fig. 5. 
Figure 1 shows the electric root-mean-square (RMS) phasor diagram representative of all PM motors driven by sinusoidal voltages with the stator current in phase with the PM motor's backemf. Note that it is customary to show RMS phasor diagrams with the rotor in the d-axis position because the PM's magnetic flux linked by the stator coils is at a maximum, thus generating the highest back-emf. The meaning of the symbols used in this figure, and in the rest of this report, are as follows:

$R$ represents the ohmic resistance of the stator coils

$L$ their inductance

$\omega$ is the electrical frequency (= number-of-pole-pairs times rotor's cycles per second times $2 \pi$ ) subsequently referred to as "rotor speed"

$V$ represents the terminal's RMS voltage

$I$ represents the stator's RMS current

$\lambda_{p m}$ represents the flux linked by the stator coils originated by the PM

$\Lambda_{p m}$ represents the RMS value of $\lambda_{\mathrm{pm}}$ (in the open literature this is also identified as $\left.\Psi_{\mathrm{m}}\right)$

$\lambda_{r}$, represents the component of flux linked by the stator coils originated by the current circulating in the stator

$E_{p m}$ and $E_{r}$ represent the RMS back-emf associated to the PM and the reaction magnetic fluxes, respectively

$\alpha$ represents the angle between the terminal voltage and current

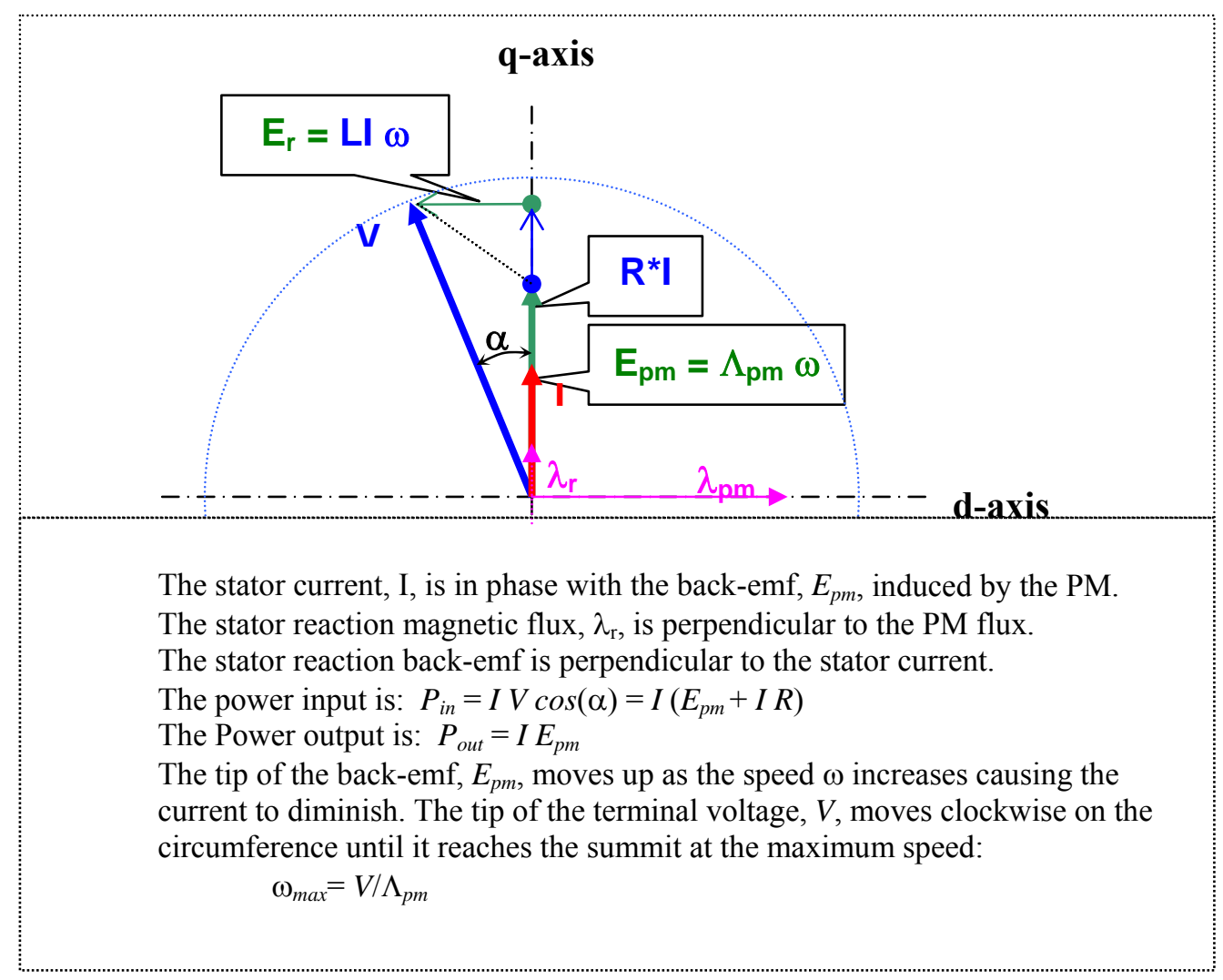

Fig. 1. Standard RMS phasor diagram of a PM motor without flux weakening. 
As shown in the extensive caption of Fig. 1, higher-strength PMs reduce the maximum speed of operation.

Since locomotion applications tend to prefer motors with wide ranges of speed to eliminate the need for or reduce the complexity of gear-boxes, it is important to find ways to increase the speed range of PM motors. One obvious possibility is to use a multilevel voltage source where available voltage would increase with rotor speed. Drive costs, already the major component of a PM drive system, may limit this approach to two stages, with the higher stage enabled at the higher speeds. Presently, improvements in stator and rotor topologies together with control approaches have enabled better overall performance/cost potential.

Comment: I think motor cost $/ \mathrm{kW}$ are higher than drive (inverter) costs $/ \mathrm{kW}$

\section{ANALYSIS SHOWING THE RELATIVE BENEFIT OF FLUX WEAKENING AND SALIENCY}

In PM motors, optimal torque production occurs when the back-emf voltage and the stator current are in phase. When they are not, the current component normal to the back-emf produces a magnetic field that opposes or reinforces that of the PM, depending on its direction. The timedependent linked flux then includes stator reaction components in both the d- and the q-axes, such that

$$
\begin{gathered}
\lambda_{\mathrm{d}}=\lambda_{\mathrm{pm}}+\lambda_{\mathrm{rd}}=\lambda_{\mathrm{pm}}+L_{d} i_{d} \\
\lambda_{\mathrm{q}}=\lambda_{\mathrm{rq}}=L_{q} i_{q},
\end{gathered}
$$

where

$i_{q}$ is the current component in-phase with the PM's back-emf (q-axis direction)

which is the primary torque producing component of current,

$i_{d}$ is the current component normal to the back-emf (d-axis direction) which is the

flux producing component of current,

$\lambda_{r d}=L_{d} i_{d}$ represents the flux linkages created by the stator current's $i_{d}$ component,

$\lambda_{r q}=L_{q} i_{q}$ represents the flux linkages created by the stator current's $i_{q}$ component,

$L_{d}$ and $L_{q}$ are the inductances when the rotor is in the d-axis and q-axis positions.

Equation (2) shows that when $i_{d}$ is negative, the reaction field has a d-axis component opposing that of the PM, thereby weakening the flux. This in turn causes a reduction in the q-axis backemf voltage; consequently, higher $I_{q}$ currents at the same or higher speeds for the same total current would be possible, thus extending the motor's operating speed range. This extension is achieved at the cost of additional ohmic losses in the stator, but it reduces the angle, $\alpha$, between the stator's voltage, $V$, and current, $I$, thus improving the power factor.

Figure 2 shows the RMS phasor diagram describing the operation of a generic PM motor driven sinusoidally with flux-weakening since the current is in the negative d-axis direction. In it, the meaning of the symbols is the same as for Fig. 1, with terms added that represent $\mathrm{d}$ - and q-axis components $I_{d}, I_{q}, L_{d}, L_{q}, \lambda_{r d}, \lambda_{r q}, E_{r d}, E_{r q}$ of $I, L, \lambda_{r}$, and $E_{r}$, respectively. 


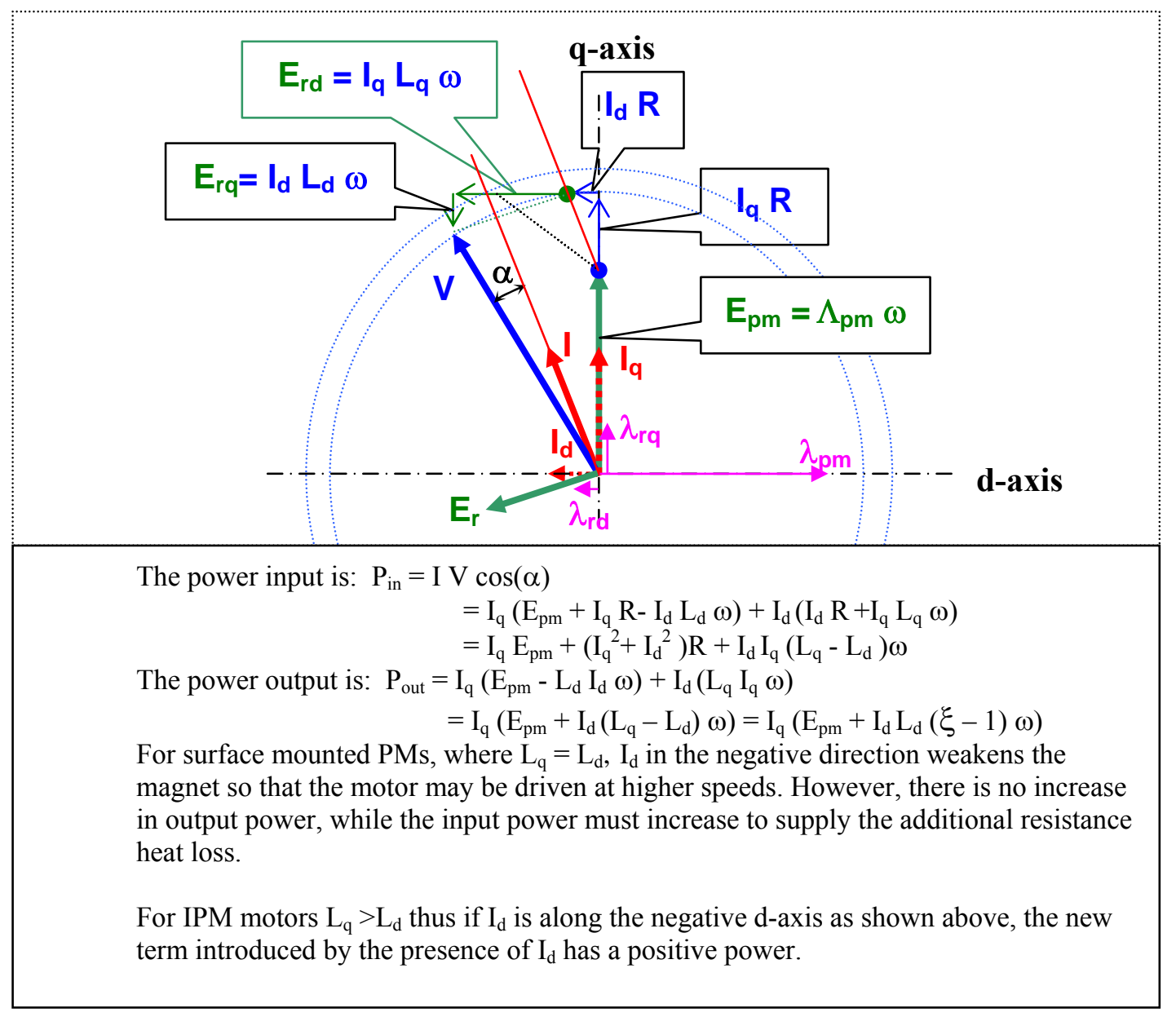

Fig. 2. Standard RMS phasor diagram of a PM motor with flux weakening.

As discussed in the caption of Fig. 2, in addition to flux weakening, extra mechanical power is produced when the saliency ratio, defined as

$$
\xi=L_{q} / L_{d}
$$

is larger than unity. In surface-mounted PM motors characterized by $\xi=1$, the stator reaction back-emf, $E_{r}$, is perpendicular to the stator current, $I$, and thus their vector product is zero. Hence, in surface-mounted PMs, $I_{d}$ has no effect in power production, although it increases the ohmic losses and improves the power factor.

\section{Characteristic Current}

The magnitude of the d-axis current needed to completely cancel the PM magnetic flux is often referred to as the motor's "characteristic current." In the open literature the characteristic current is also identified as $I_{x}(3)$. By setting $\lambda_{d}=0$, in Eq. (2) we obtain

$$
i_{c h}=\left|-i_{d}\right|=\lambda_{p m} / L_{d} .
$$


Surface-mounted PMs, for which $L_{q}=L_{d}$, operated with an amount $I_{c h}$ of d-axis current in the negative direction, would have no speed limit since the back-emf induced by the PM would be zero. Unfortunately, the inductance, $L_{d}$, is small in PM motors; consequently, the magnitude of the characteristic current is large, showing that large currents cause only small amounts of flux weakening.

The power output for a PM with an $I_{d}$ equal to the characteristic current, $I_{c h}$, in Eq. (4) injected in the negative direction would be

$$
\text { Pout }_{c h}=I_{q}\left(E_{p m}+\lambda_{p m} / L_{d}\left(L_{q}-L_{d}\right) \omega\right)=I_{q} E_{p m} L_{q} / L_{d}=I_{q} E_{p m} \xi
$$

IPM motors differ in that they have the PMs inserted in the body of the rotor. This not only provides mechanical support for the magnets and protects them from the environment and from demagnetization, but also makes the inductance of the rotor position dependent, so that $L_{d}<L_{q}$. Consequently, when an $I_{d}$ current is inserted in the negative direction shown in Fig. 2 to weaken the flux, extra mechanical power is generated in the motor. IPMs are thus considered as hybrids of PM and reluctance technologies. In addition, in IPMs the boundary between the rotor poles and the air-gap is high-permeability silicon steel. It allows phase-advance to give the PM flux a tangential component within the rotor pole, thus skewing the air-gap flux distribution to such a degree that stator teeth are saturated. This allows for an externally controlled variation in reluctance that is not possible in surface-mounted PM motors.

As shown in the caption of Fig. 2, the power output for any PM is

$$
P_{\text {out }}=I_{q}\left(E_{p m}+I_{d}\left(L_{q}-L_{d}\right) \omega\right)=I_{q}\left(E_{p m}+I_{d} L_{d} \omega(\xi-1)\right) .
$$

Thus, the torque expression,

$$
T=P_{\text {out }} / \omega=I_{q} E_{p m} / \omega+I_{d} I_{q}\left(L_{q}-L_{d}\right)=\text { Torque }_{P M}+\text { Torque }_{\text {Reluctance }},
$$

has two components. In IPMs, the reluctance term is not zero and contributes to the motor's output.

Equation (7) shows that the total torque output can be maintained while reducing the PM torque by compensating with an increase in the reluctance torque. When the strength of the PM flux is reduced, $\lambda_{p m}$ and the magnitude of the characteristic current are also reduced. This makes fluxweakening by insertion of negative current in the d-axis less costly and more practical.

Solving Eq. (6) for $E_{p m}$, substituting $E_{p m}=\Lambda_{p m} \omega$, and taking the partial derivative of $\Lambda_{p m}$ with respect to $\xi$ for fixed $P_{\text {out }}, \omega, I_{d}, I_{q}$, and $L_{d}$, we obtain the relationship between the change of PM strength needed and a change in the degree of saliency,

$$
\delta \lambda_{p m}=-I_{d} L_{d} \delta \xi .
$$


That is, an increase of saliency would result in a decrease in magnet strength required proportional to the product of $I_{d} \bullet L_{d}$, the values of the d-axis inductance and d-axis current component.

In terms of the characteristic current, Eq. (8) becomes

$$
\delta \lambda_{p m} / \lambda_{p m}=-I_{d} / I_{c h} \delta \xi,
$$

whose integral yields

$$
\lambda_{p m}=k e^{-} \frac{I_{d}}{I_{c h}} \xi
$$

where $k$ is an integration constant. This is an important relationship since it shows that the magnet strength needed diminishes exponentially with the degree of saliency and with the amount of d-axis current injected relative to the value of the characteristic current. Therefore, decreasing the value of the characteristic current and increasing the saliency are clear goals for improving PM motor performance.

\section{Summary of Reluctance Analysis}

(a) Equation (4) shows that to reduce the magnitude of a motor's characteristic current, one may (1) reduce the magnitude of the PM flux links, and/or (2) increase the value of the daxis inductance.

(b) Equation (6) shows that IPM motors are superior to surface-mounted motors for flux weakening since under flux-weakening conditions they provide extra mechanical power output because their saliency is larger than unity.

(c) Equation (8) shows the desirability of increasing (1) the saliency, and (2) the d-axis inductance in order to reduce the amount of PM flux linkage needed by a motor. This would further enhance the motor's flux-weakening capabilities and reduce the cost of PMs while maintaining the motor's power level.

(d) Equation (10) shows that for equal motor power output, the magnet strength needed diminishes exponentially with the degree of saliency and with the amount of d-axis current injected relative to the value of the characteristic current. Therefore, decreasing the value of the characteristic current and increasing the saliency should be clear goals for improving PM motor performance.

(e) Equation (3) shows that to increase the saliency ratio, $\xi$, one should increase the quadrature inductance, $L_{q}$. One could decrease the d-axis inductance, $L_{d}$, but it would be counterproductive because of (a) and (c) above, which call for an increase in $L_{d}$. 
(f) If $L_{d}$ is increased as recommended by (a) and (c) above, then a proportional or larger increase should be sought for $L_{q}$ in order to maintain or augment the saliency ratio as recommended by (d).

Please note that from Eq. (1) these findings can be rephrased in terms of reluctance merely by replacing the word "inductance" with the word "reluctance" together with the inverse of its preceding verb, "increase" or "decrease." For instance, "increase the inductance, $L_{d}$," would be replaced by "decrease the reluctance, $\mathbb{R}_{\mathrm{d} .}$."

Ways to reduce the PM flux linked by the stator coils include (1) decreasing the strength or volume of the PMs, (2) increasing the magnetic flux bypassing of the stator coils, and (3) reducing the number of coils and/or span of the stator coils.

Ways to create saliency include (1) replacing PM material in the surface-mounted PM motor with silicon steel, as in the case of the inset PM motor; (2) embedding the PMs in the rotor, as in IPM motors; and (3) placing magnetic flux barriers, as in the multi-layered IPM designs.

\section{ANALYSIS AND COMPARISON OF THREE PM MOTORS THAT PRODUCE RELUCTANCE TORQUE}

We have investigated three PM motors that exhibit varying amounts of reluctance. The inset PM was assessed for the impact of trading PM for iron; the V-shaped single-layer IPM was assessed for the impact of embedding the PMs in the iron and of trading PM for iron; and the U-shaped multilayered IPMs were assessed for the effect of changing the amount of PM material in an embedded PM design. For each design, the performance vs. amount of PM material was studied to determine the optimal configuration. Parametric computations of performance were performed using the SPEED Consortium's brushless direct current (BLDC) computer simulator for each design. The topologies, methodologies, and results obtained are presented and discussed in the next section.

Three IPM motor configurations, which exhibit different reluctance properties, have been parametrically characterized for comparison of torque, power, and amount of magnet material. Figures 3-5 show two variations of their structures with two different distributions of PM and iron.

Figures 3(a) and 3(b) correspond to the inset type motor, whose magnets are flush with the rotor surface. In the parametric calculations for this motor, the angular pitch, Beta $\mathrm{M}\left(\beta_{\mathrm{M}}\right)$, of the PM is varied from a low value of $5^{\circ}$ to a high value of $175^{\circ}$ in $10^{\circ}$ increments. The degrees are with respect to one complete electrical cycle, which includes a north and a south pole. In Fig. 3(a) one quadrant represents a $360^{\circ}$ electrical cycle, which includes 12 stator teeth. The angular pitch, $\beta_{\mathrm{M}}$, is the angle in electrical degrees subtended by the magnet. In Fig. 3(a) this includes four teeth, which leads to $360^{\circ} \times 4 / 12=120^{\circ}$. Note that as the pitch of the magnets decreases, the width of the iron web between the magnets increases. Also note that for the highest pitch, the expected behavior is that of a surface-mounted PM motor. 


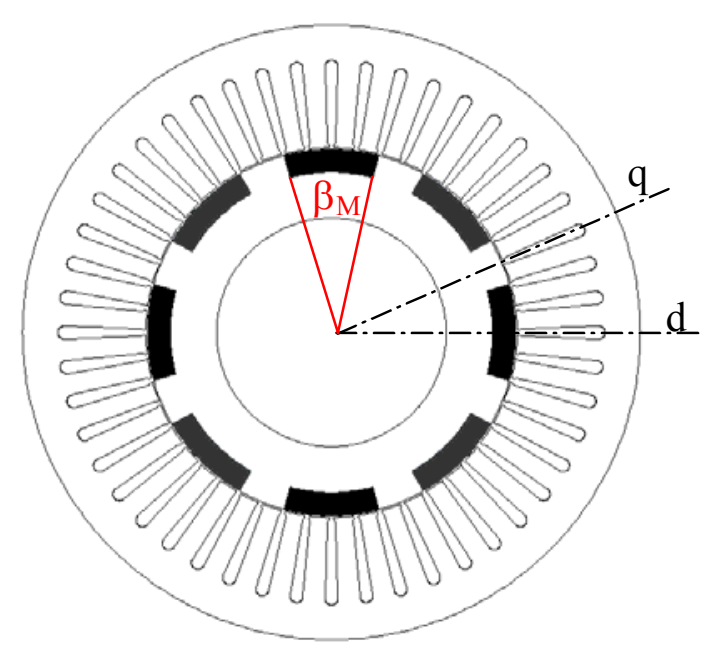

(a) Low magnet fraction, $\beta_{\mathrm{M}}=120^{\circ}$.

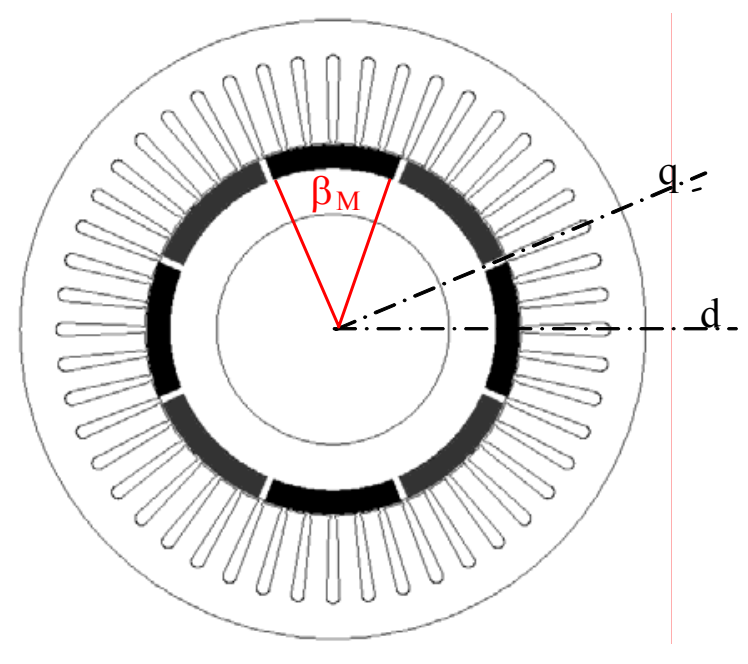

(b) High magnet fraction, $\beta_{M}=175^{\circ}$.

Fig. 3. Inset surface mounted PM motors.

Figures 4(a) and 4(b) correspond to the V-shaped IPM motor. In the parametric calculations for this motor, the lower radial position of the PMs is kept constant while the angular pitch of the $\mathrm{PM}$ at the rotor's surface is varied from a low value of $50^{\circ}$ to a high value of $175^{\circ}$ in $10^{\circ}$ increments. Note that as the pitch of the magnets decreases, the width of the iron web between the magnets increases. In this design we have reluctance variations on account of the iron web, as in the inset type motor, but in addition we have the soft-PM effect of iron pole-caps that allow control of the shape of the distribution of flux crossing the air-gap.

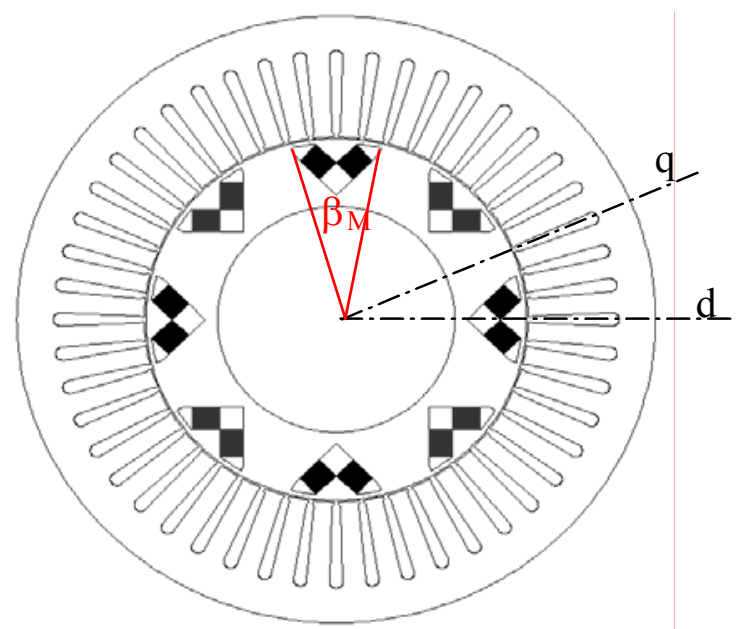

(a) Low magnet fraction, $\beta_{\mathrm{M}}=\mathbf{5 0}$.

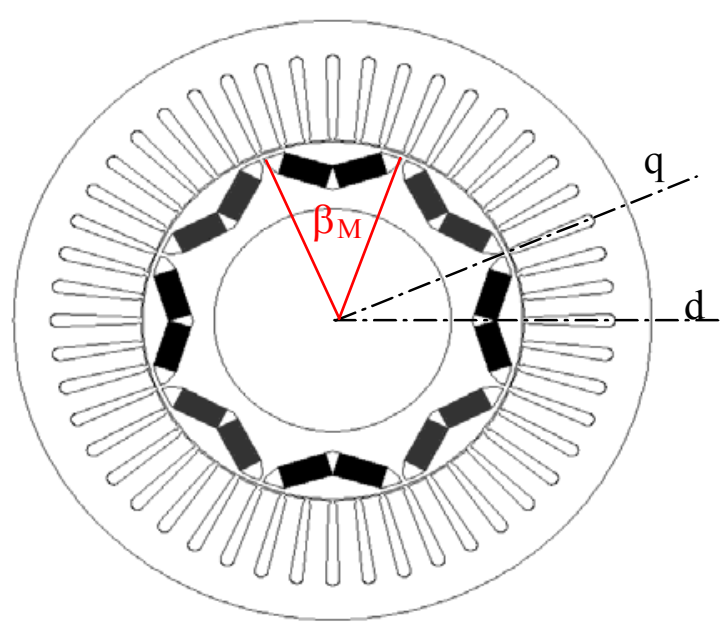

(b) High magnet fraction, $\beta_{M}=160^{\circ}$.

Fig. 4. V-shaped IPM motors (type 4).

Figures 5(a) and 5(b) correspond to the dual-layer U-shaped IPM motor. In the parametric calculations for this motor, the angular pitch of the PM at the rotor's surface and the lower radial position of the PMs are kept constant, while the length of the lower magnets in the two layers of U-shaped PMs is varied proportionally. The length of the innermost layer's magnet, yI_1, is 
varied from a low value of $2.4 \mathrm{~mm}$ to a high value of $17 \mathrm{~mm}$ in $0.73-\mathrm{mm}$ increments. Note that the width of the iron web at the air-gap boundary remains constant, while the amount of magnetic material increases with the value of yI_1.

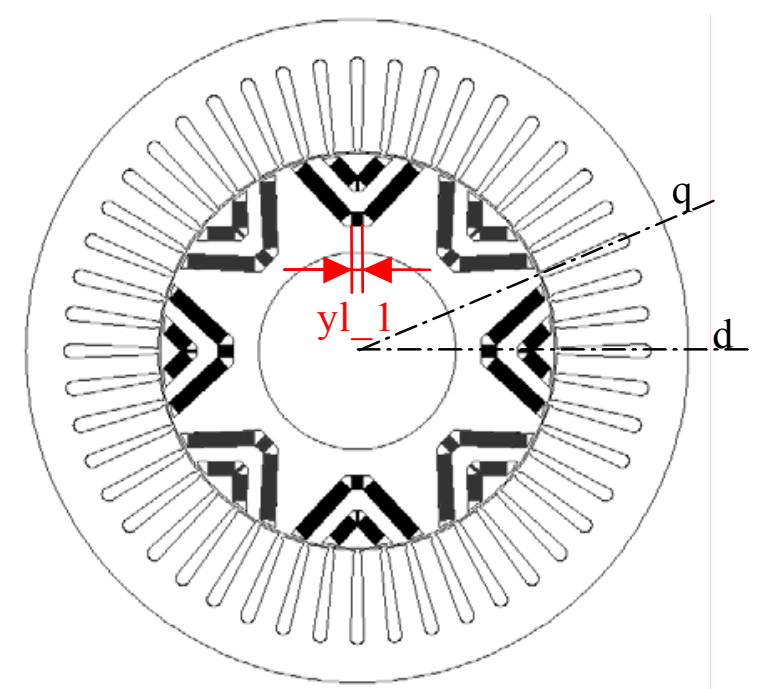

(a) Lowest magnet fraction, yI_1 $=2.4 \mathrm{~mm}$.

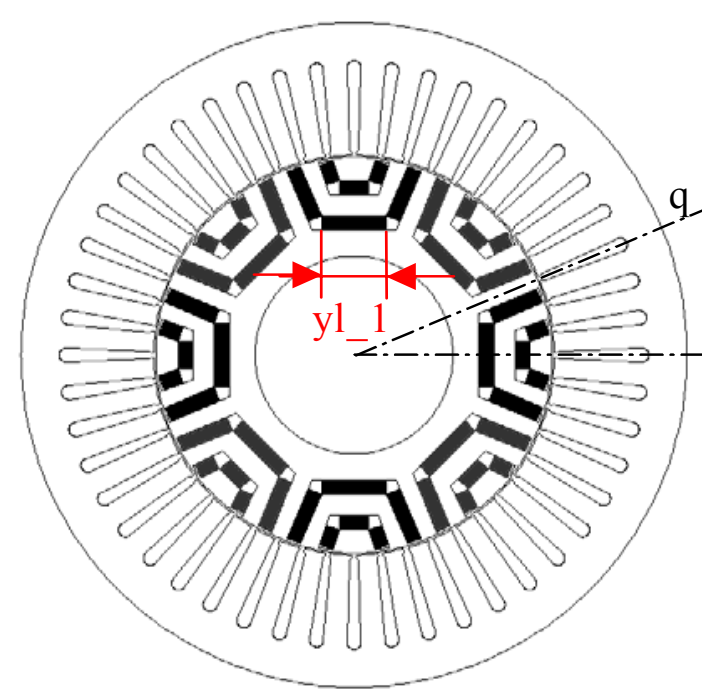

(b) Highest magnet fraction, yI_1 $=17 \mathrm{~mm}$.

Fig. 5. U-shaped IPM motors (type 6).

\section{Methodology Used for Analysis and Comparison}

Each motor topology was explored using the BLDC motor simulation software, a product of the SPEED Consortium. All of the motors have the same stator and overall rotor dimensions. The same operating conditions, such as max current and voltage, were used for all to provide the basis for comparative analysis.

The simulation software computed the PM and reluctance torques, power output, current peak and RMS, back-emf, etc., characterizing the performance of the motors. The analysis excluded thermal flux and mechanical stress analysis, although these would be of interest for further study.

For each of the three topologies, parametric studies were performed which nested a range of advance angles within a range of speeds for each magnet configuration. The magnet-to-iron ratio was varied by means of the PM angular pitch parameters, $\beta_{M}$ or yI_1, as appropriate. Figure 6 shows how the amount of PM material varies with the varying parameter, $\beta_{M}$ or $y I \_1$, in each motor type. Note that Beta $M=\beta_{M}$ in the figures. There is a large difference between the three topologies. At each speed there is an optimal phase advance, which determines the fluxweakening current component, for torque production that is not necessarily the same as for optimum motor efficiency. The results presented here correspond to the phase advance that computed the highest torque. 


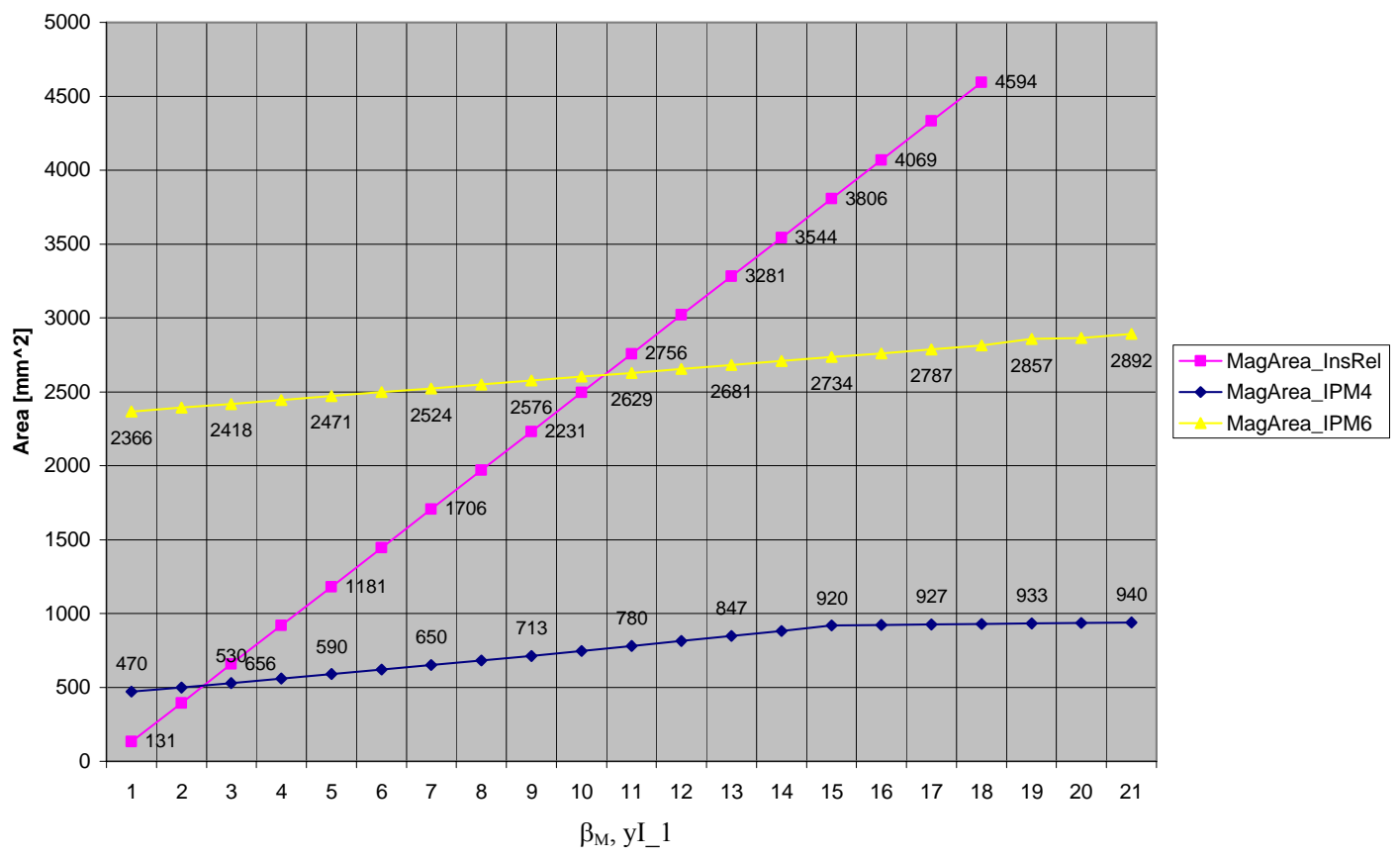

Fig. 6. Amount of PM material in terms of cross-sectional surface area as a function of $\beta_{M}$ or $y I \_1$ for each of the three rotor configurations.

\section{Results of Parametric Studies}

The results from the analysis are shown graphically in Figs. 7-14 for the inset PM motor (InsRel), Figs. 15-22 for the V-shaped IPM (type 6) motor, and Figs. 23-31 for the dual-layer Ushape IPM (type 4) motor. Based upon these results, conclusions and recommendations for further research are made.

\section{InsRel Motor}

Figures 7(a) and 7(b) show the curves of torque and efficiency vs. $\beta_{M}$ for the full range of rotor speeds. As mentioned earlier, the points in the figure correspond to the phase advance that yields the peak torque for the speed and $\beta \mathrm{M}$ under consideration. Figure $7(\mathrm{~b})$ is a magnified version of Fig. 7(a) to better show the $\beta_{M}$ dependency. The curves show a parabolic-like dependence on the change in the magnet pitch value. Each parabolic curve describes the dependence on $\beta_{M}$ at the constant speed to its left in the x-axis. For example, at $100 \mathrm{rpm}$ the torque squares and the efficiency diamonds represent values of $\beta_{\mathrm{M}}$ from $5^{\circ}$ to $175^{\circ}$ in steps of $10^{\circ}$ from left to right. Note that as speed increases, the peaks move toward higher values of $\beta_{M}$. 


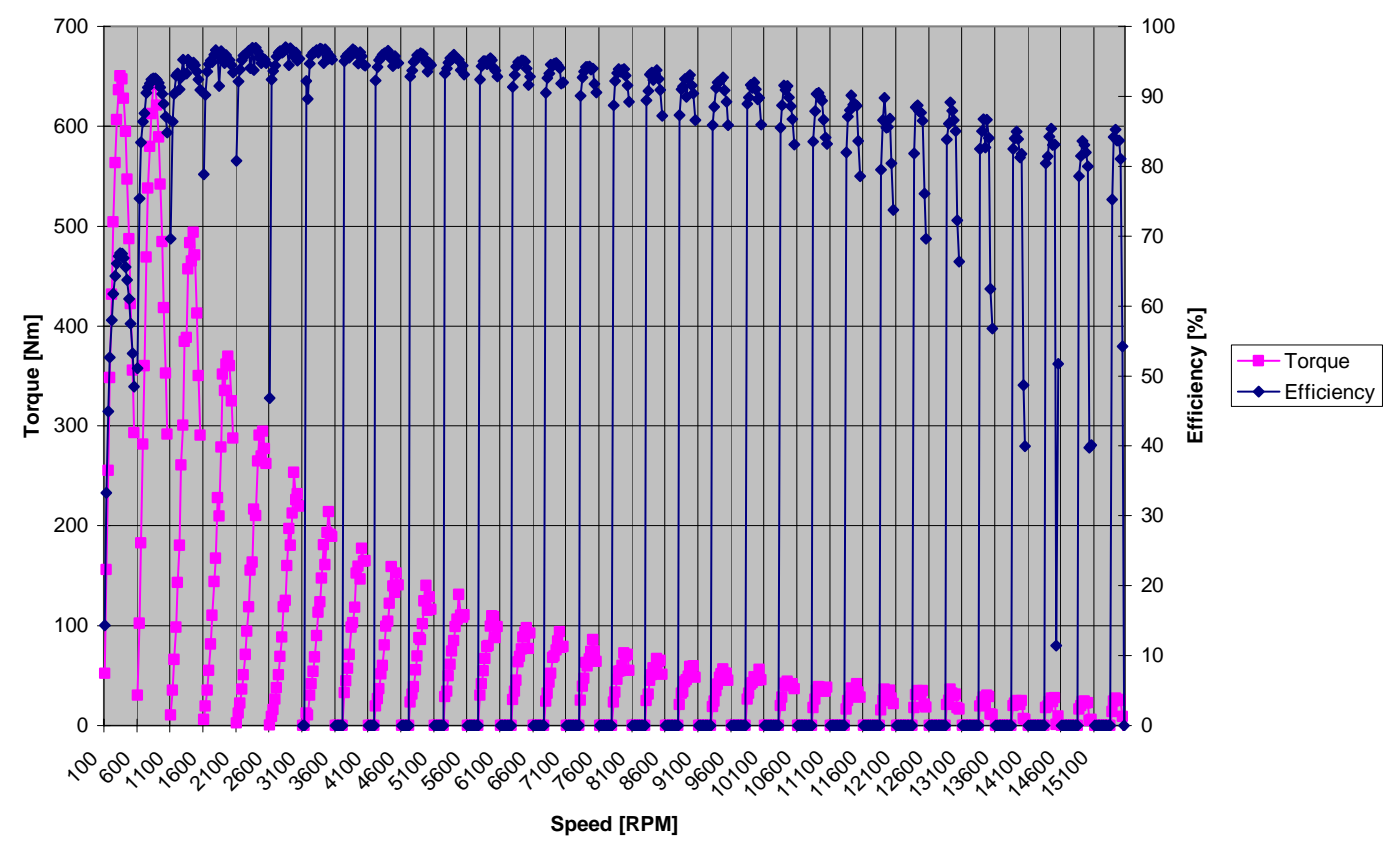

(a) Compact view for the full range of speeds

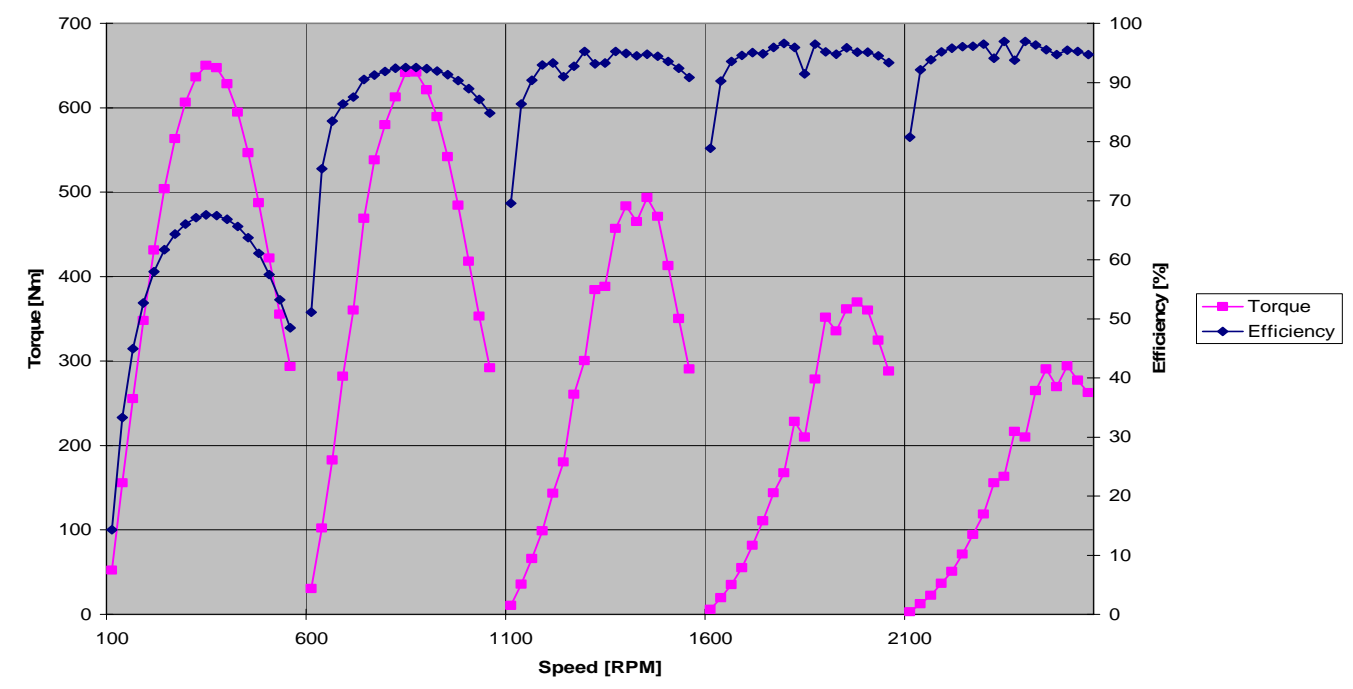

(b) Expanded view for a reduced set of speeds for the inset PM motor.

Fig. 7. Inset PM motor torque and efficiency as a function of speed for a range of magnet pitches.

Figures $8(a), 8(b)$, and $8(\mathrm{c})$ display in classical formats the same information relationships between $\beta_{\mathrm{M}}$, speed, and torque as Fig. 7. Figure 8(c) in particular facilitates the determination of the value of $\beta_{\mathrm{M}}$ required to achieve a level of torque through a given speed range. For instance, for a torque output above $50 \mathrm{~N}-\mathrm{m}$ over the entire speed range, the minimum amount of PM material needed corresponds to $\beta_{\mathrm{M}}=95^{\circ}$. 
Speed Variation Upon Torque

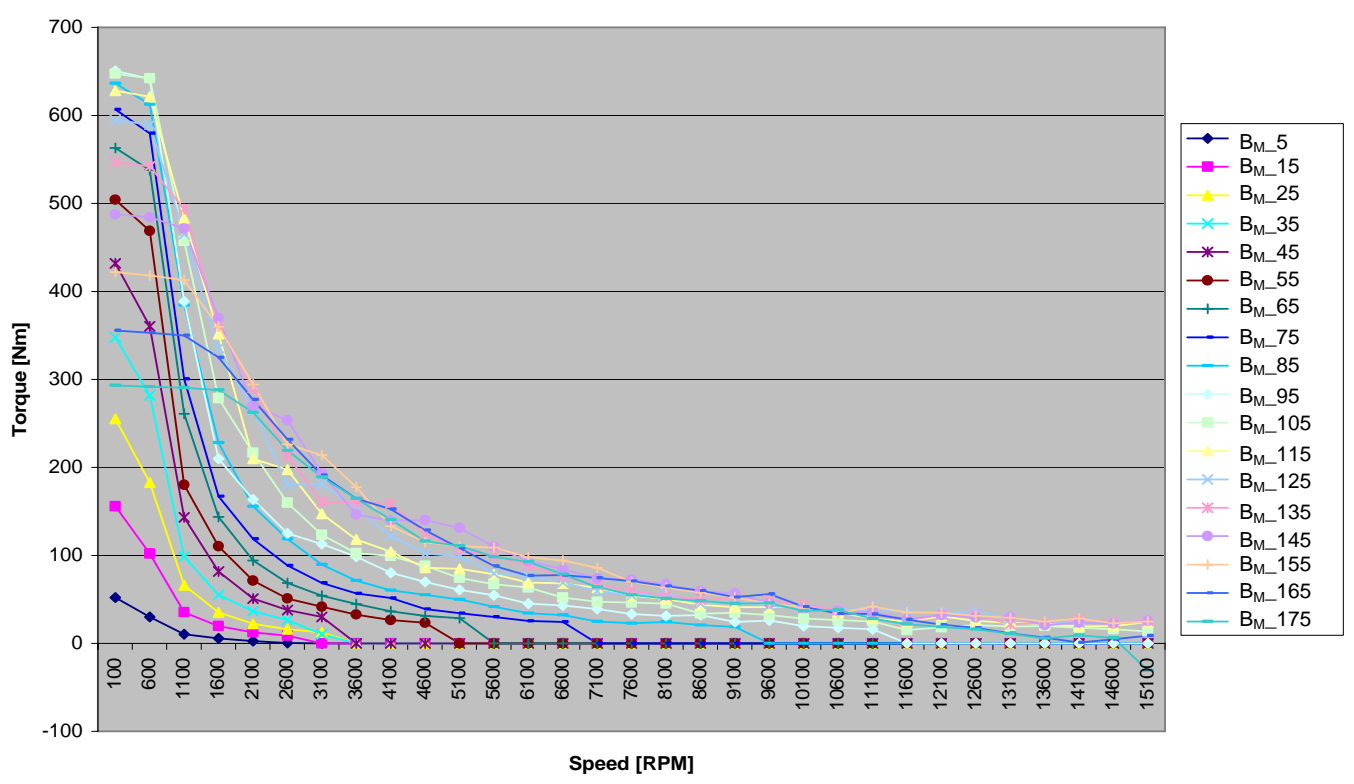

(a) Conventional torque performance view.

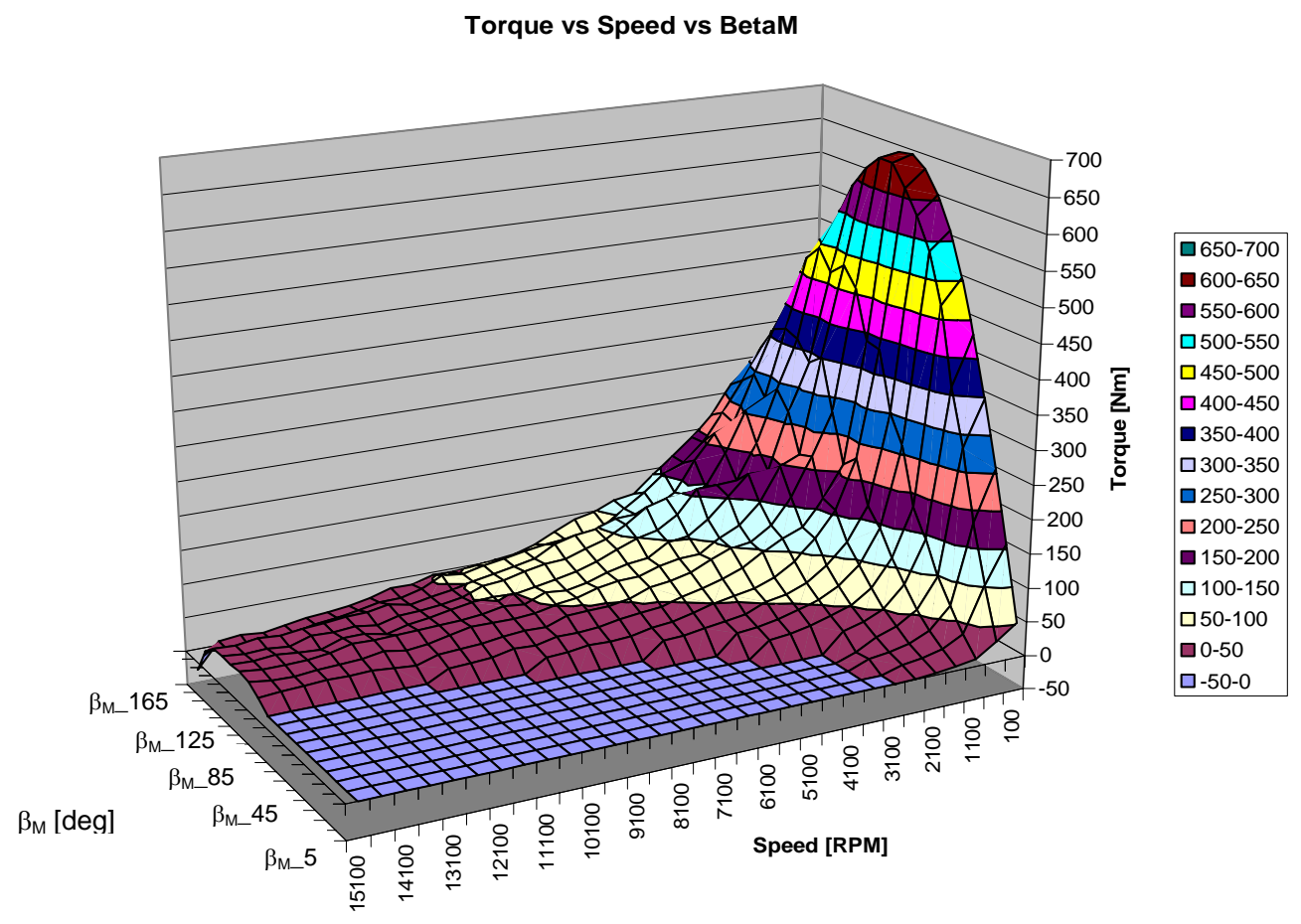

(b) Minimum magnet corner view.

Fig. 8. Relationship between torque, magnet pitch, $\beta_{M}$, and speed for the inset PM motor. 

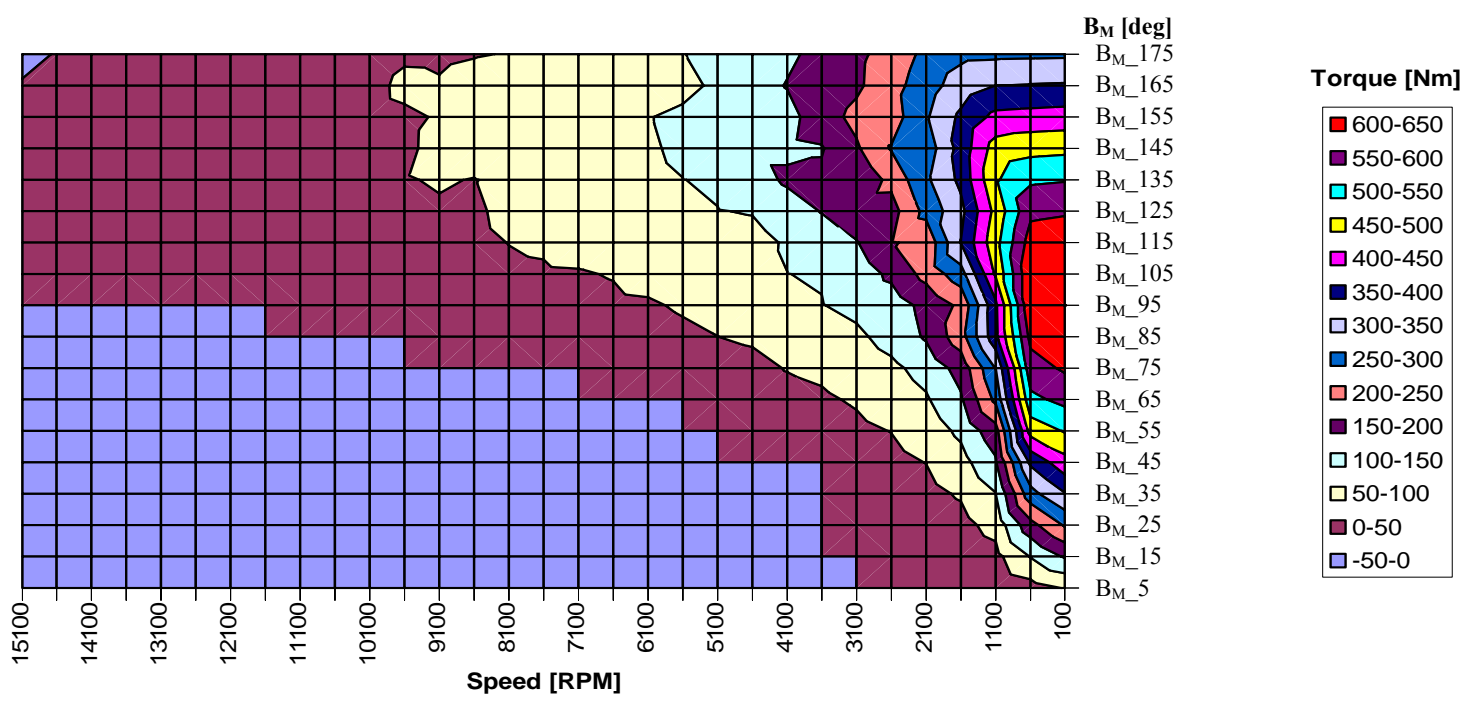

(c) Torque contour view.

Fig. 8. Relationship between torque, magnet pitch, $\beta_{\mathrm{M}}$, and speed for the inset PM motor (cont'd).

Similarly, the complete relationship between $\beta_{\mathrm{M}}$ and speed upon advance and upon power is shown below in Figs. 9(a), 9(b), 10(a), and 10(b), respectively.

The percentage of torque produced by reluctance is shown in Figs. 11(a) and 11(b).

The constant power speed ratio (CPSR) may be found using Figs. 8 and 10. From Fig. 8, the base speed is estimated as the speed when torque delivery begins to drop, which appears to be about $1100 \mathrm{rpm}$. From Fig. 10, the intersection of a power plane, whose value is the rated power with the surface, may be used to determine the maximum speed for which the motor is capable of delivering rated power by observing where the power falls below that plane. The CPSR is the ratio of the maximum useful speed to the base speed and is determined for each value of the magnet pitch, $\beta_{\mathrm{M}}$. For a threshold value of $40 \mathrm{~kW}$, the CPSR as a function of $\beta_{\mathrm{M}}$ is shown in Fig. 12. In it, one can see that a CPSR $=10$ can be obtained when $\beta_{\mathrm{M}}=125^{\circ}$. 


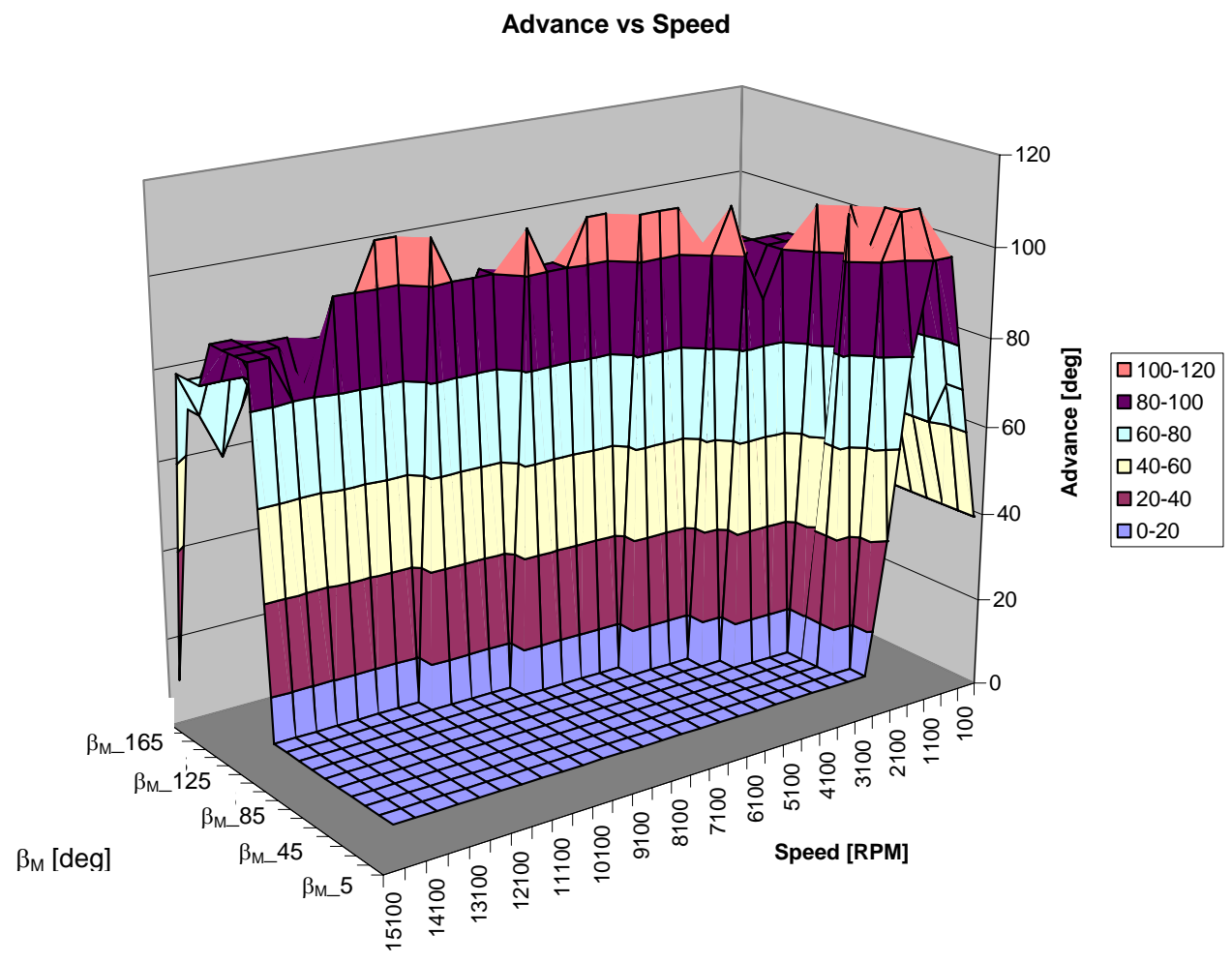

(a) Minimum magnet corner view.

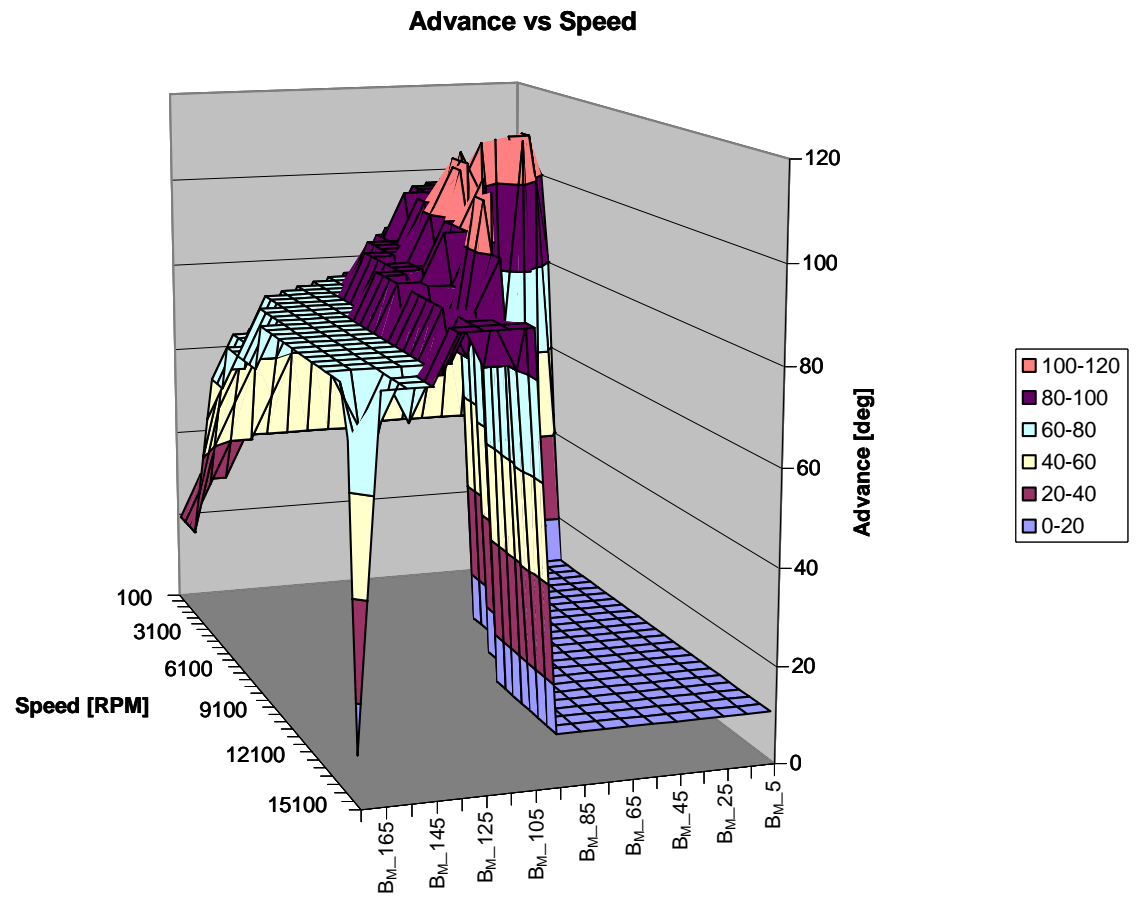

(b) Maximum magnet corner view.

Fig. 9. Relationship between magnet pitch, $\beta_{M}$, speed, and advance for the inset PM motor. 


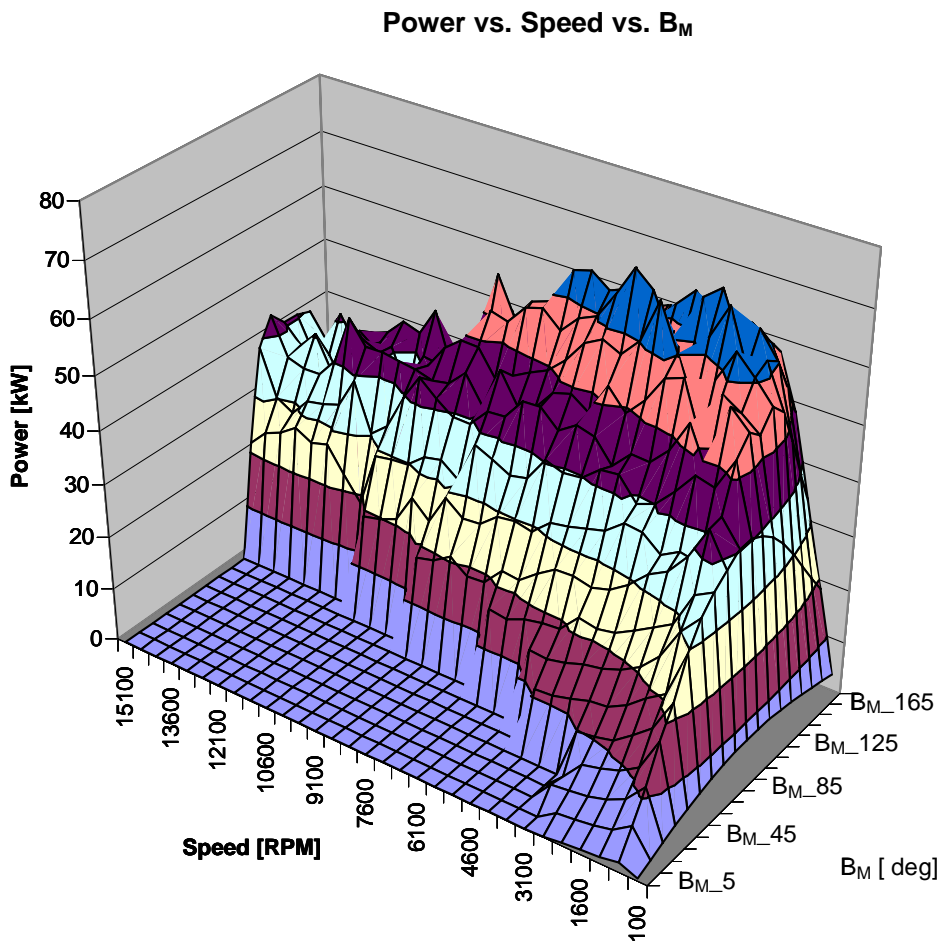

(a) Minimum magnet corner view.

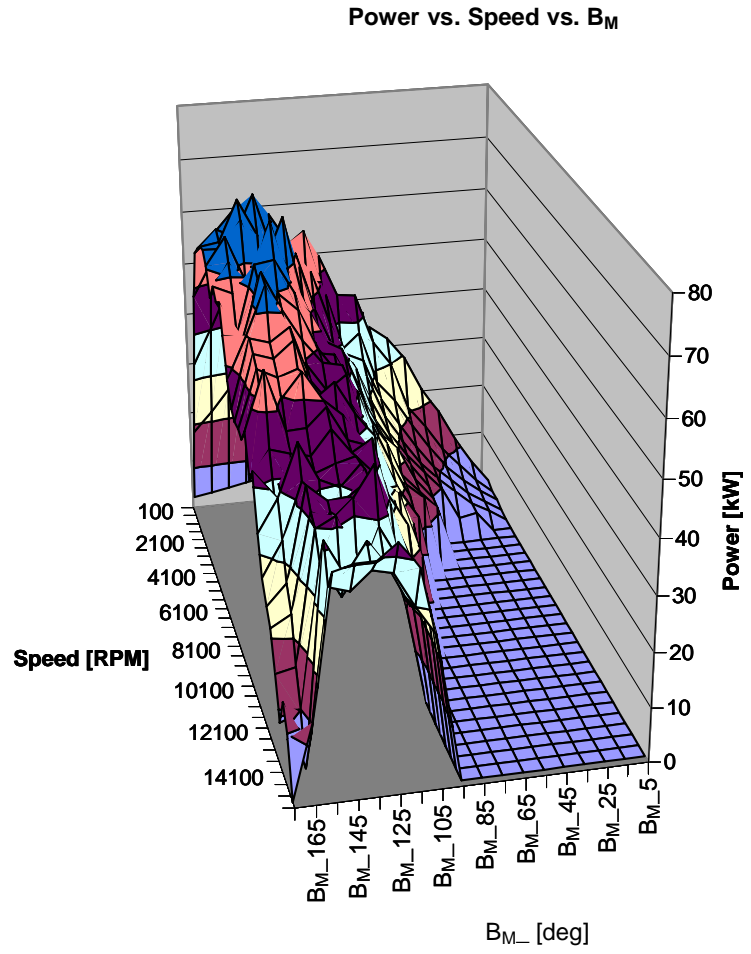

(b) Maximum magnet corner view.

Fig. 10. Relationship between $\beta_{M}$, speed, and maximum power for the inset PM motor. 


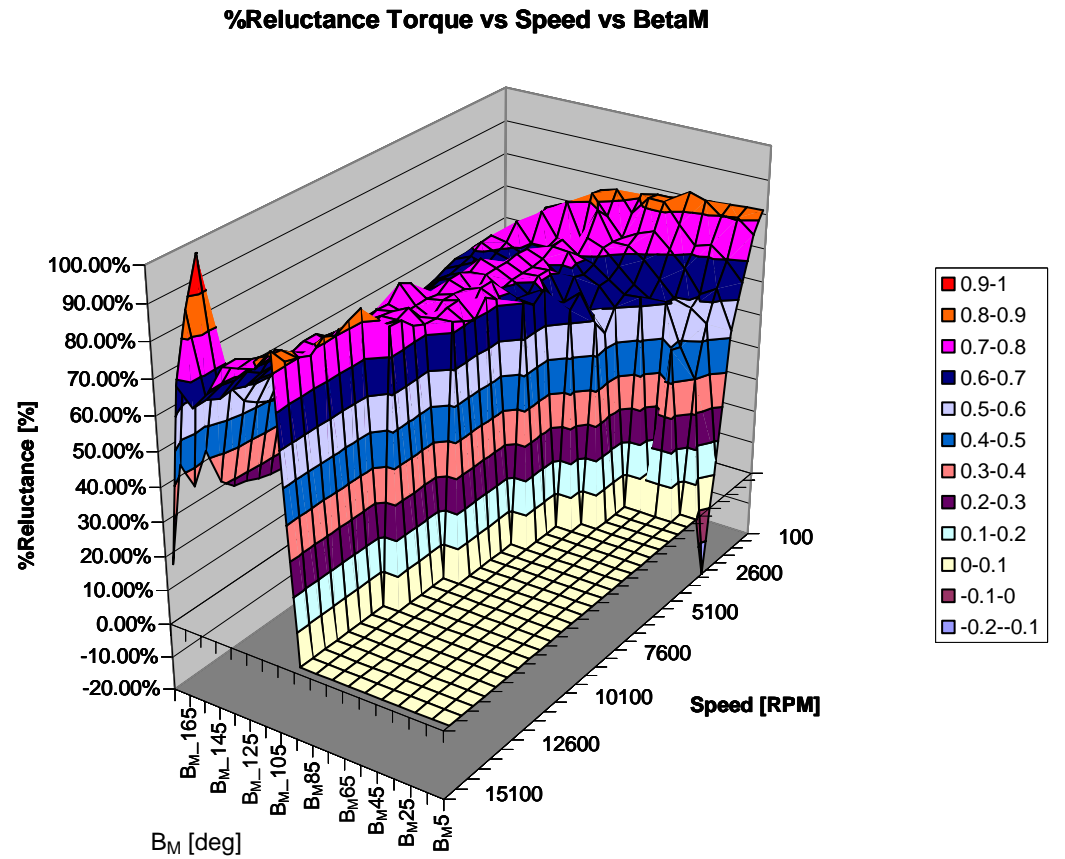

(a) Minimum magnet corner view.

\%Reluctance Torque vs. Speed vs. $B_{M}$

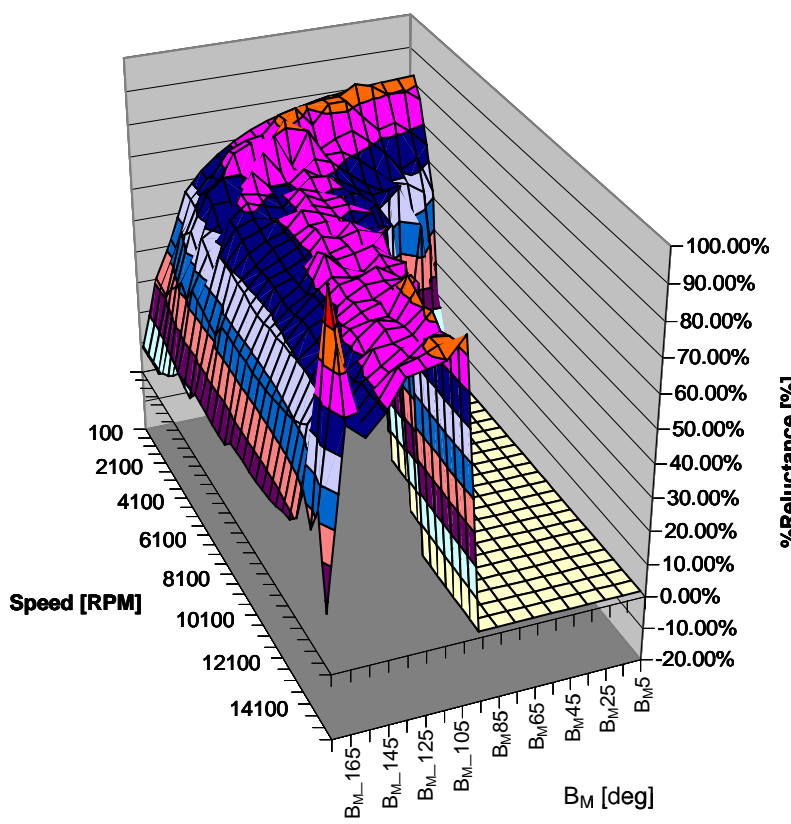

(b) Maximum magnet corner view.

Fig. 11. Relationship between magnet pitch, $\beta_{\mathrm{M}}$, speed, and percentage of reluctance torque for the inset PM motor. 


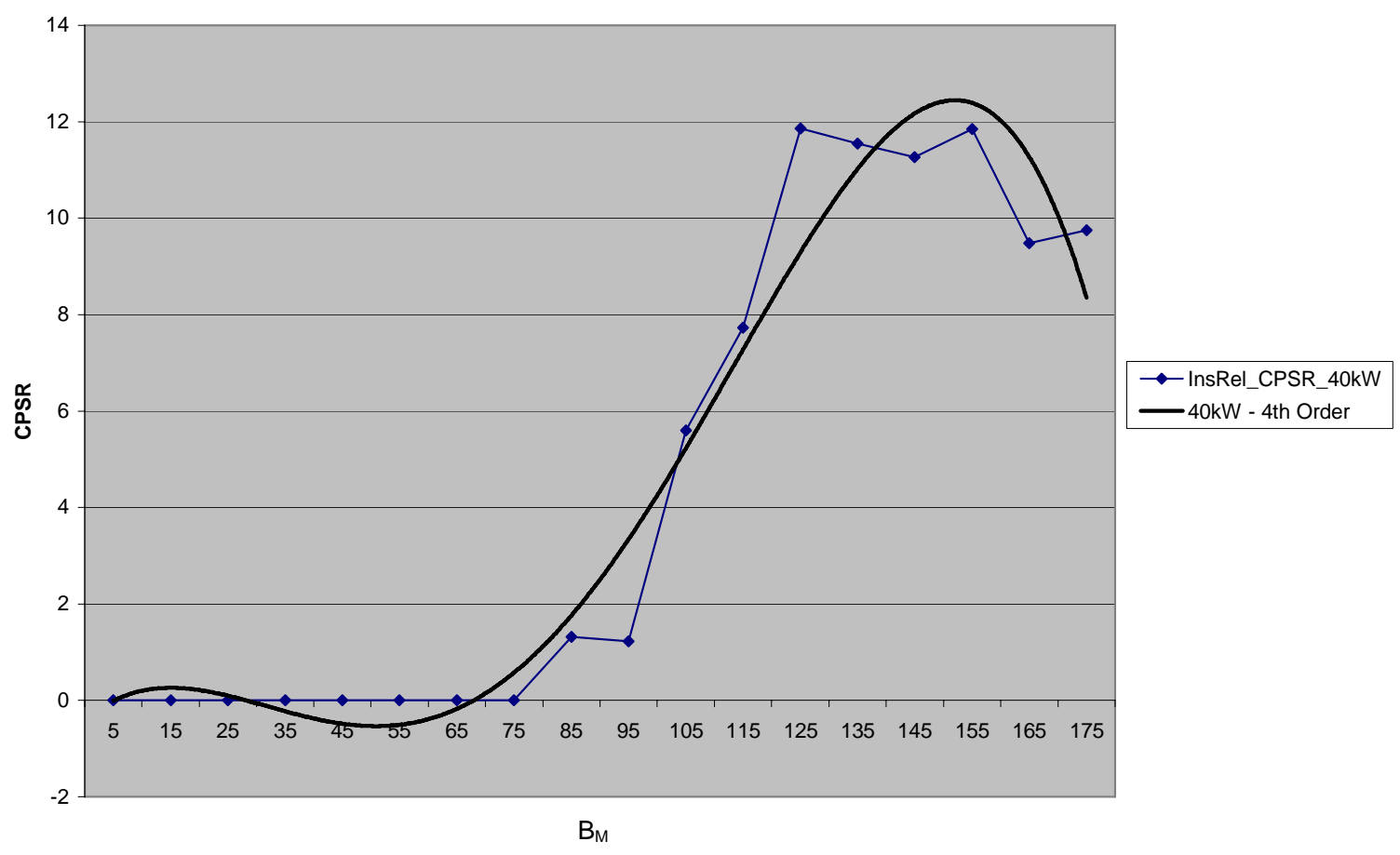

Fig. 12. CPSR as a function of magnet pitch, $\beta_{\mathrm{M}}$, for the inset PM motor type.

Assuming the magnet cost is proportional to the amount of magnet, and then the relative cost which may be used for cost comparisons, is the magnet area divided by the maximum magnet area. Using Fig. 6 and the U-shaped type 6 motor as an example, maximum magnet area is $2892 \mathrm{~mm}^{2}$, which occurs for yI $1=17 \mathrm{~mm}$ and would have a normalized cost of 1 . The minimum magnet area in this example is $2366 \mathrm{~mm}^{2}$, which occurs at yI_ $1=2.4 \mathrm{~mm}$ and has a normalized cost of 0.82 . Figures 13 (a) and 13(b) show graphically the cost for producing torque for each $\beta_{M}$ for the inset PM motor type over the entire speed range. Figure 13(b) shows that, in order to produce torque over the full speed range, the normalized cost incurred is between 0.59 and 1.0, which corresponds to values of $\beta_{M}$ between 95 and $175^{\circ}$. 


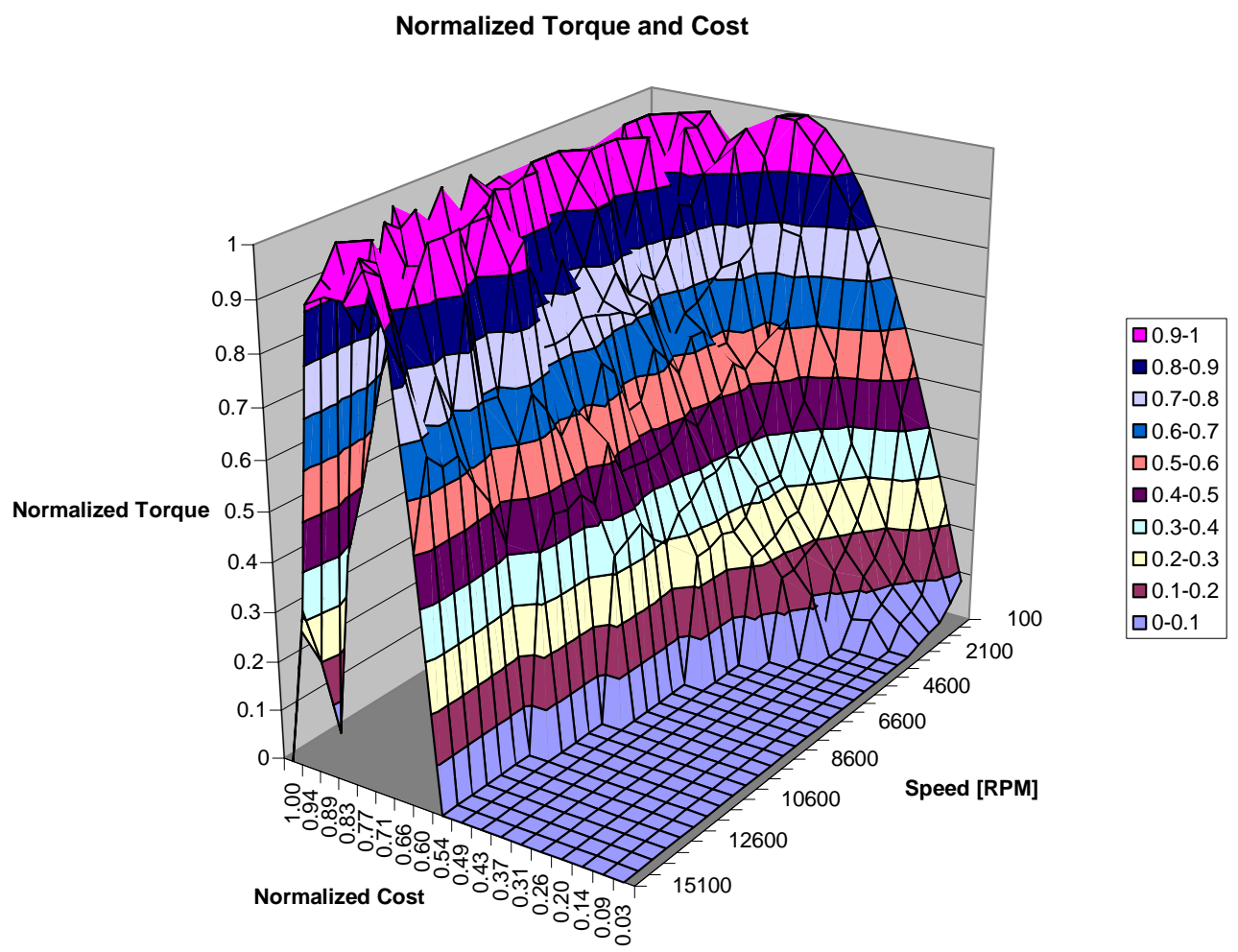

(a) Low-cost corner view.

Normalized Torque and Cost

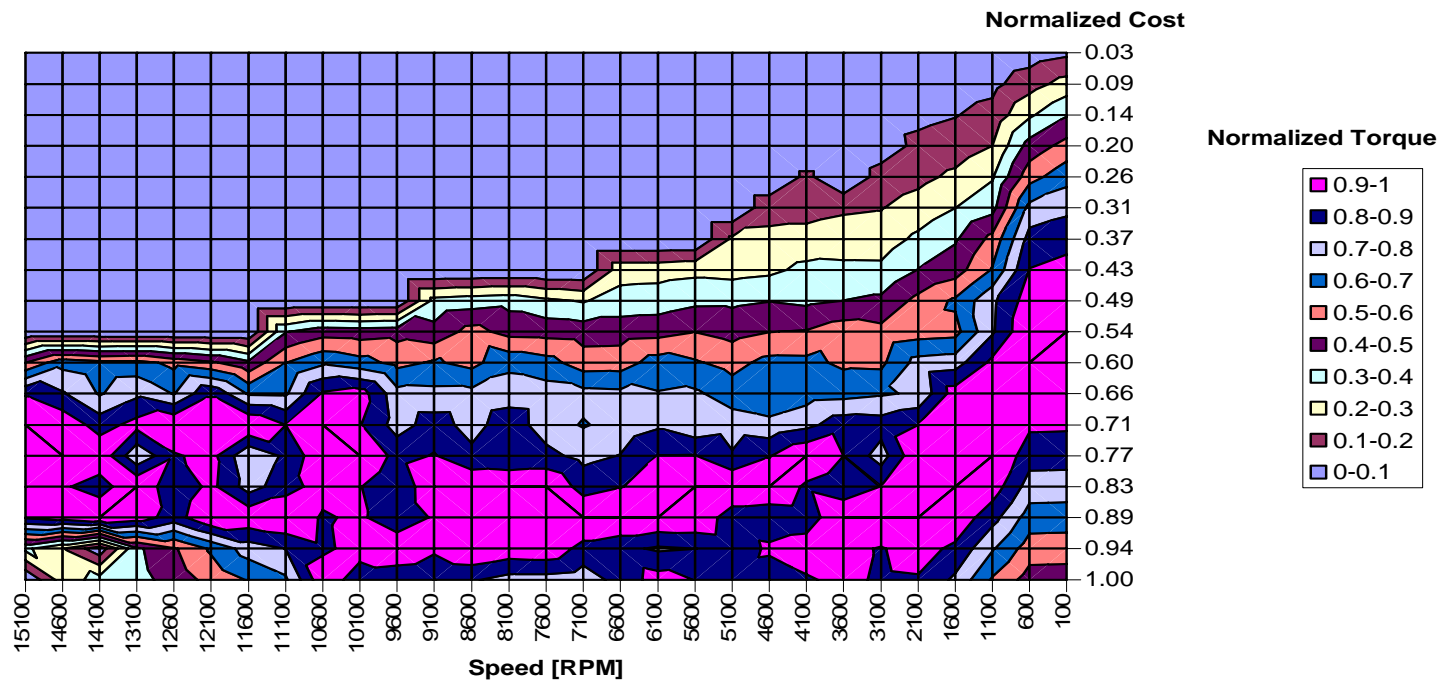

(b) Normalized torque contour view.

Fig. 13. Relationship between normalized torque, speed, and relative magnet cost for the inset PM motor. 
Figure 14(a) and 14(b) show a comparison of the torque and power vs. speed curves for the $\beta_{M}$ values considered to be the best for the inset PM with those for an equivalent surface-mounted $\mathrm{PM}$ that has no reluctance torque and is represented here by an inset PM with $\beta_{\mathrm{M}}=180^{\circ}$.

Zero Reluctance InsRel Motor

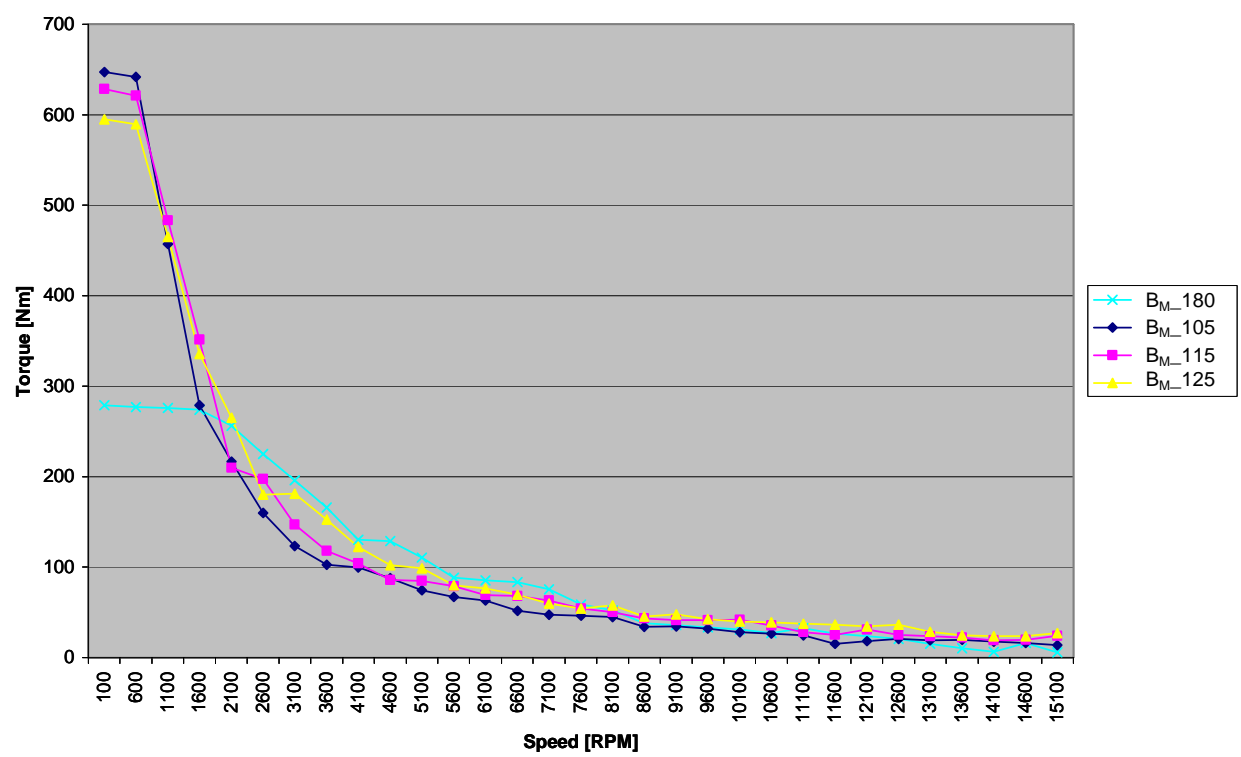

(a) Torque performance view.

Zero Reluctance InsRel Motor Power

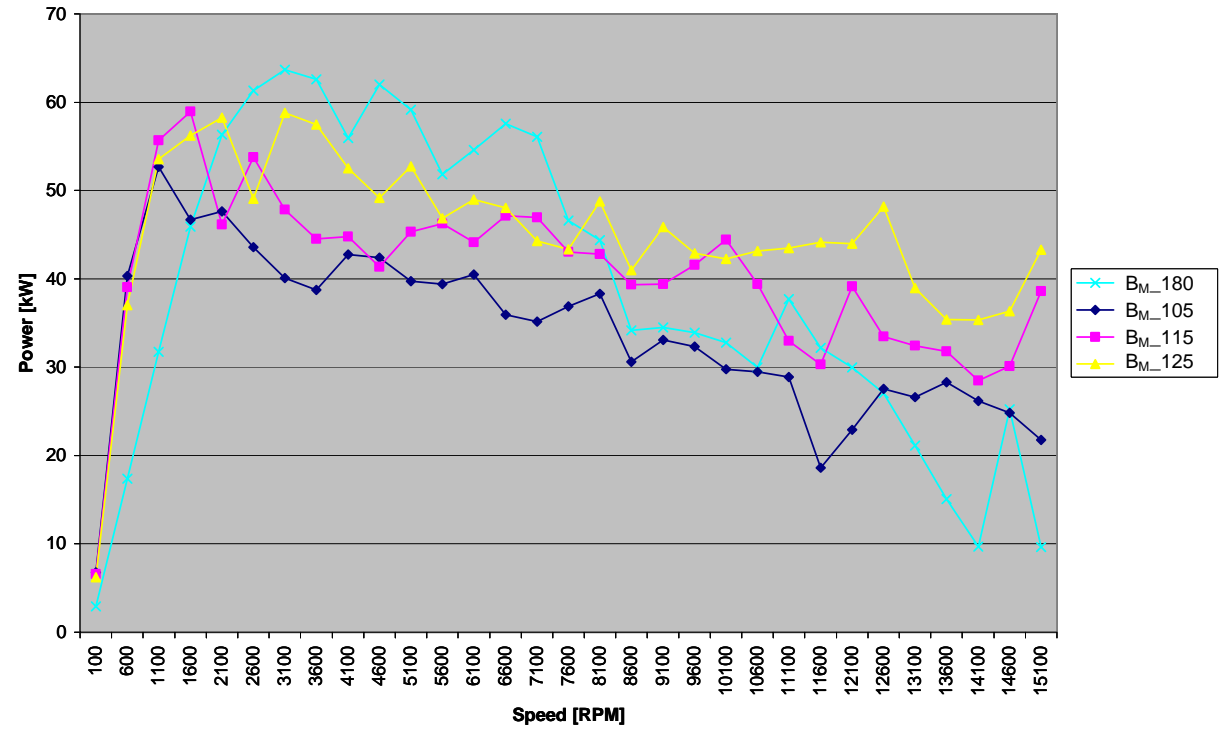

(b) Power performance view.

Fig. 14. Comparison of selected optimal (magnet pitches, $\beta_{M}=105,115$, and $125^{\circ}$ with highest CPSR) inset PM motor performance with surface-mounted PM motor $\left(\beta_{M}=180^{\circ}\right)$.

The surface-mounted PM not only has lower peak torques at low speeds, but also has a smaller speed range. 


\section{V-Shaped IPM Type-4 Results}

Figure 15(a) and 15(b) show the curves of efficiency and torque for the IPM type-4 motor topology. The curves have a "V" or inverted parabola shape, again due to the variation in $\beta_{\mathrm{M}}$. Note the drastic drop in efficiency in the 100-rpm range. This should be considered a limiting factor in determining the effective operating speed range. As shown previously for the inset PM motor, the torque vs. speed for each $\beta_{\mathrm{M}}$ is plotted in Fig. 16.

$\mathrm{B}_{\mathrm{M}}$ Variation Upon Torque and Efficiency

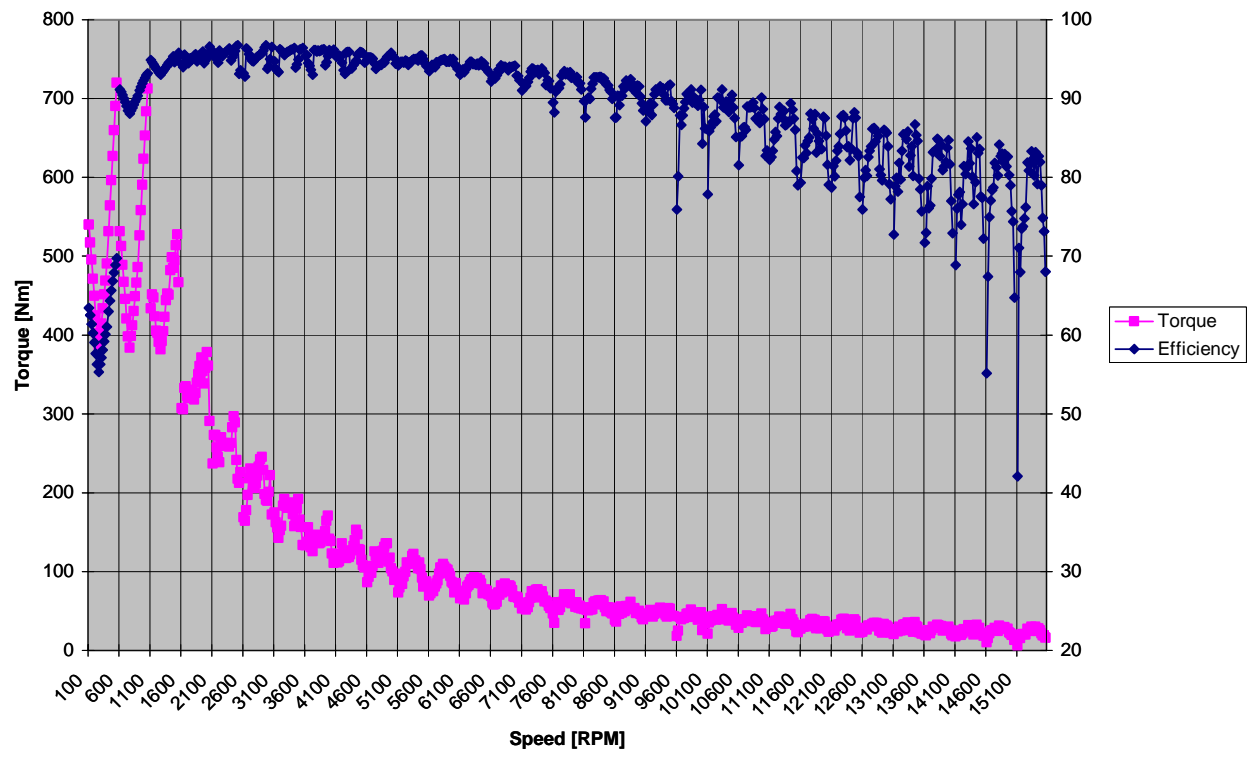

(a) Compact view for the full range of speeds.

Zoom of $\mathrm{B}_{\mathrm{M}}$ Variation Upon Torque and Efficiency

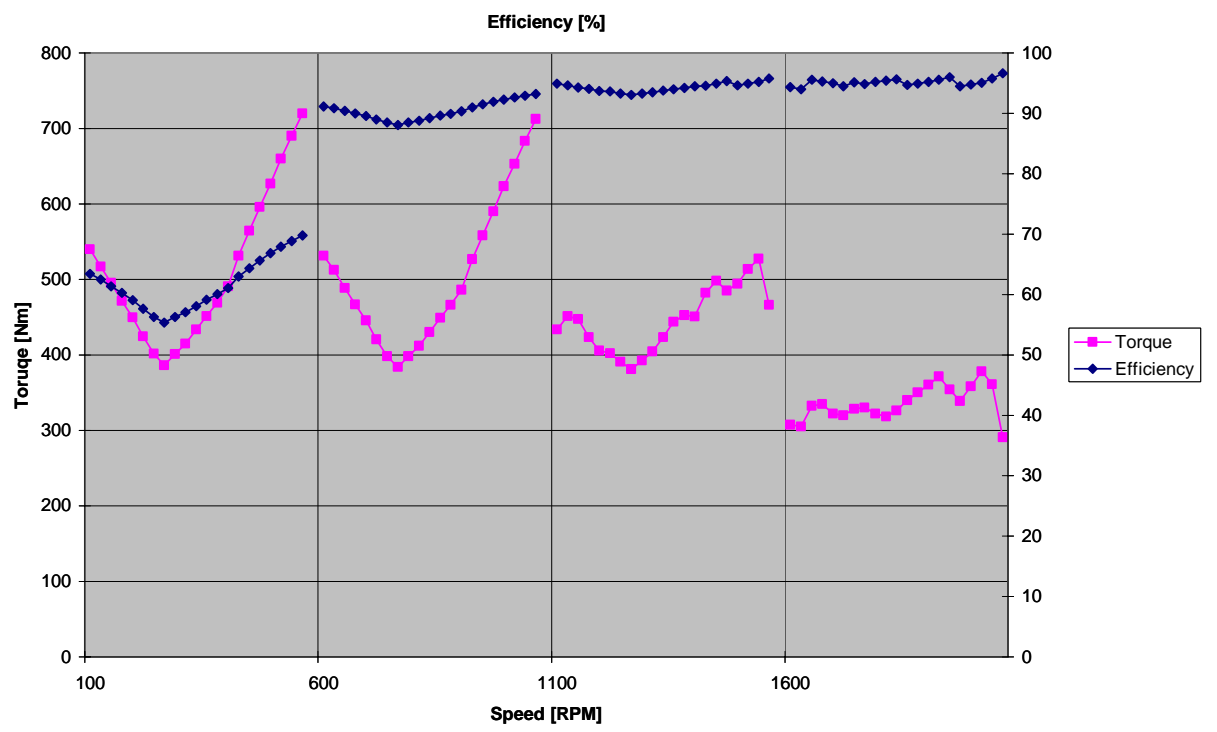

(b) Expanded view for a reduced set of speeds.

Fig. 15. V-shaped IPM motor torque and efficiency as a function of speed for a range of magnet pitches. 
Speed Variation Upon Torque for Each $B_{M}$

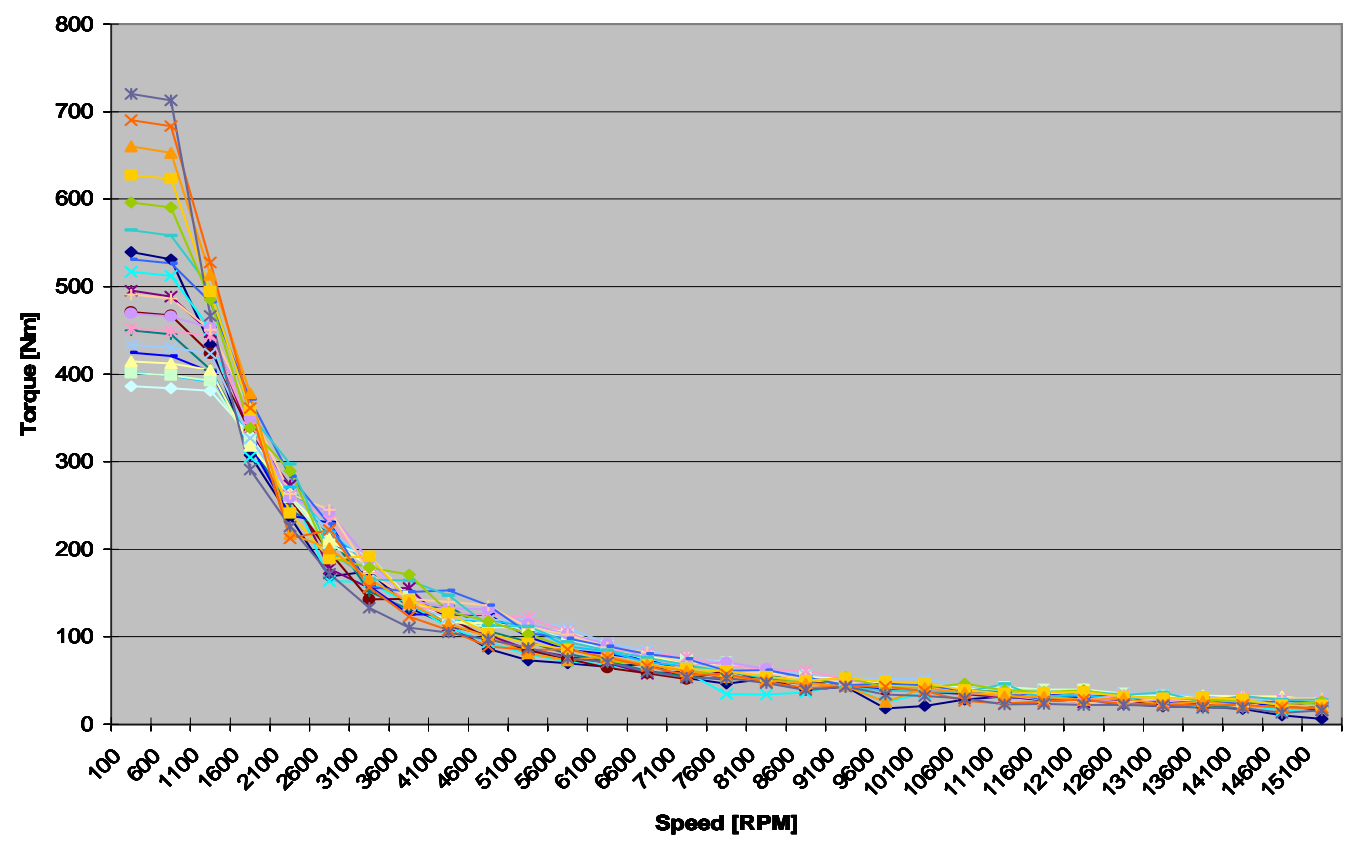

\begin{tabular}{|c|}
\hline \multirow{2}{*}{$\begin{aligned} \longrightarrow & \mathrm{B}_{\mathrm{M}} \text { 50 } \\
\leftarrow & \mathrm{B}_{\mathrm{M} \_} 56\end{aligned}$} \\
\hline \\
\hline$* \mathrm{~B}_{\mathrm{M} \_} 62$ \\
\hline$\longrightarrow B_{M} \_68$ \\
\hline - $\mathrm{B}_{\mathrm{M}_{2}} 74$ \\
\hline$=-B_{M} \_80$ \\
\hline$=B_{M \_} 86$ \\
\hline $\mathrm{B}_{\mathrm{M} \_} 92$ \\
\hline $\mathrm{B}_{\mathrm{M} \_} 98$ \\
\hline $\mathrm{B}_{\mathrm{M} \_104}$ \\
\hline$\times \quad B_{M} \_110$ \\
\hline$*-\mathrm{B}_{\mathrm{M}} \_116$ \\
\hline$-B_{M} \_122$ \\
\hline B $\mathrm{B}_{\mathrm{M} \_128}$ \\
\hline - $\mathrm{B}_{\mathrm{M} \_} 134$ \\
\hline$-B_{M} \_140$ \\
\hline$\because B_{M \_} 146$ \\
\hline$-B_{M} \_152$ \\
\hline$-\mathrm{B}_{\mathrm{M} \_} 158$ \\
\hline$x \quad B_{M} \_164$ \\
\hline$* \mathrm{~B}_{\mathrm{M}_{-}} 170$ \\
\hline
\end{tabular}

(a) Conventional torque performance view.

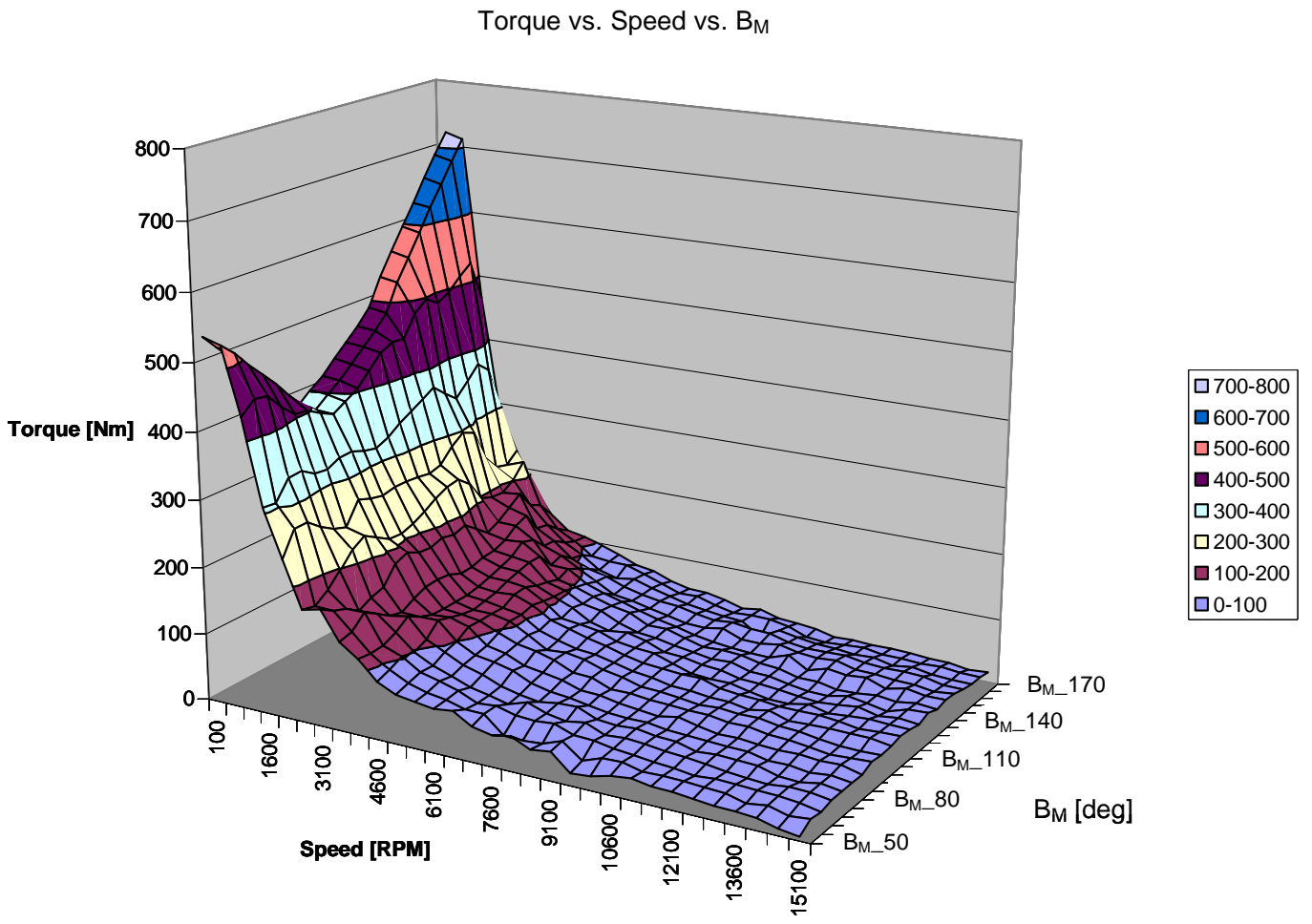

(b) Minimum magnet corner view.

Fig. 16. Relationship between magnet pitch, $\beta_{M}$, speed, and torque for the $V$-shaped IPM motor. 


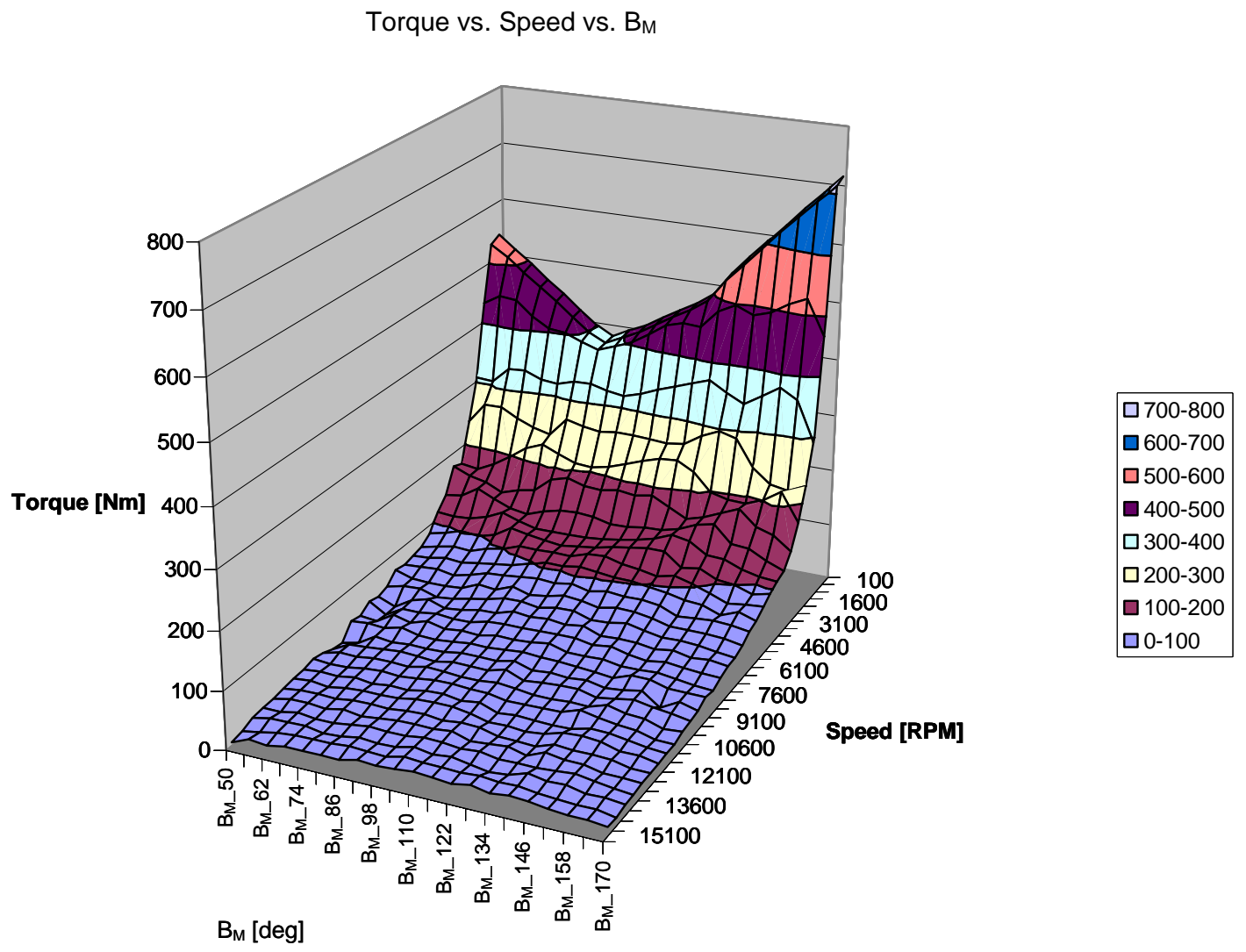

(c) Maximum magnet corner view.

Fig. 16. Relationship between magnet pitch, $\beta_{M}$, speed, and torque for the V-shaped IPM motor (cont'd).

Figures 16(a), 16(b), and 16(c) show the same informational relationship between $\beta_{\mathrm{M}}$, speed, and torque as Fig. 15 in classical formats. Figure 16(c), in particular, facilitates the determination of the amount of magnet required to achieve a level of torque through a given speed range. For use of the complete speed range with a torque output of above $500 \mathrm{~N}-\mathrm{m}, \beta_{\mathrm{M}}$ must be at least $116^{\circ}$.

Similarly, the complete relationship between $\beta_{\mathrm{M}}$ and speed upon advance and power is shown below in Figs. 17(a), 17(b), 18(a), and 18(b), respectively. 


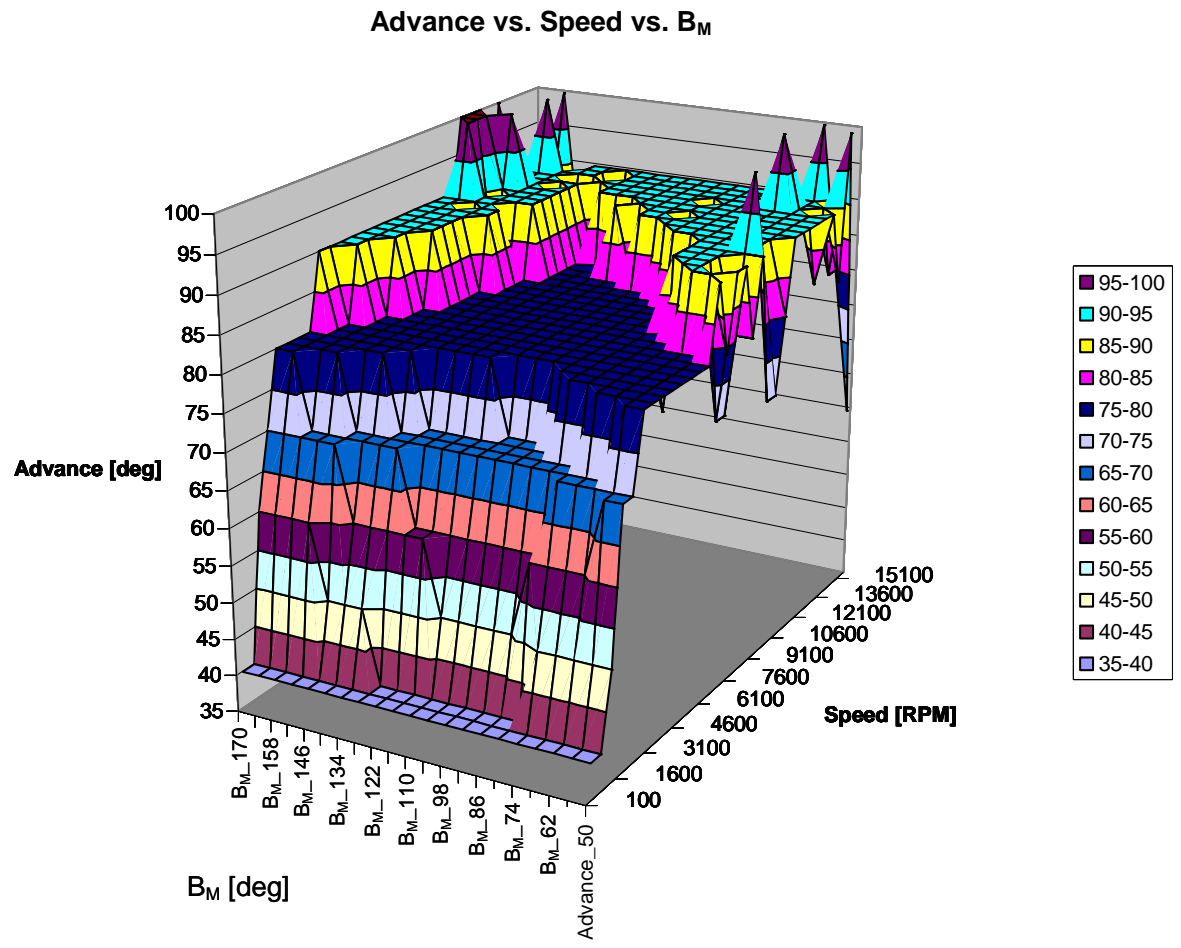

(a) Minimum magnet corner view.

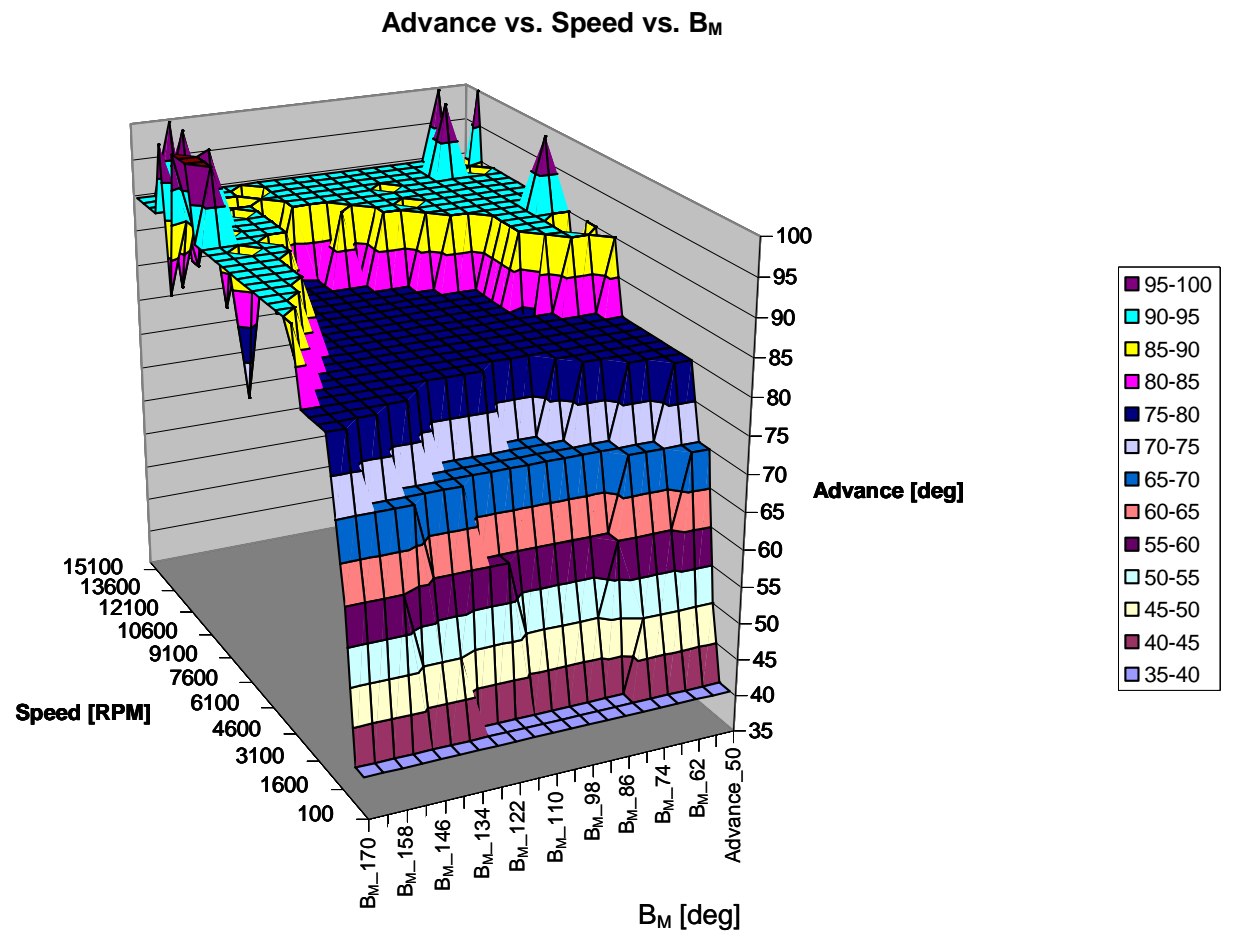

(b) Maximum magnet corner view.

Fig. 17. Relationship between magnet pitch, $\beta_{M}$, speed, and advance for the V-shaped IPM motor. 


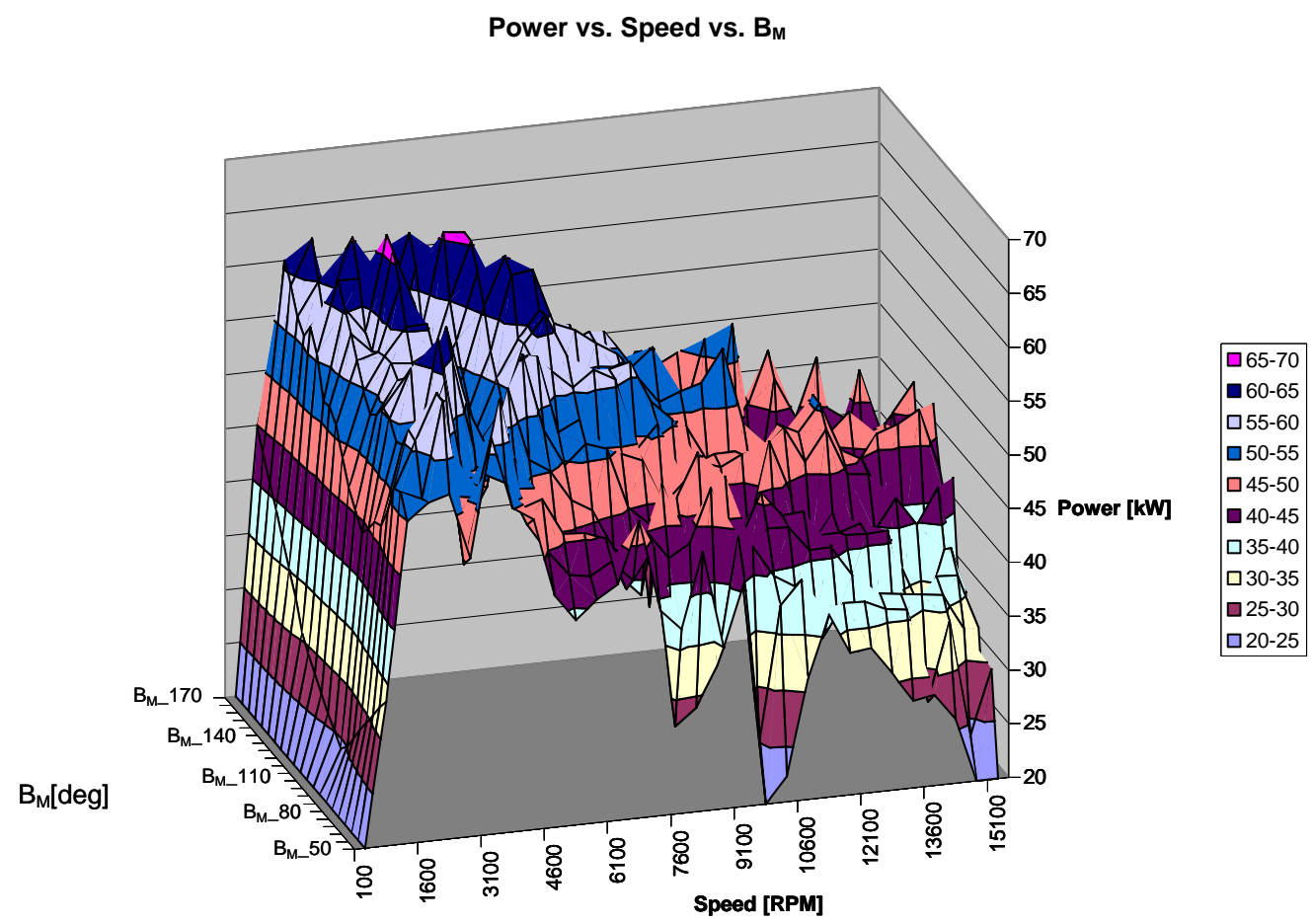

(a) Minimum magnet corner view.

Power vs. speed vs. $B_{M}$

\section{$B_{M}[\operatorname{deg}]$}

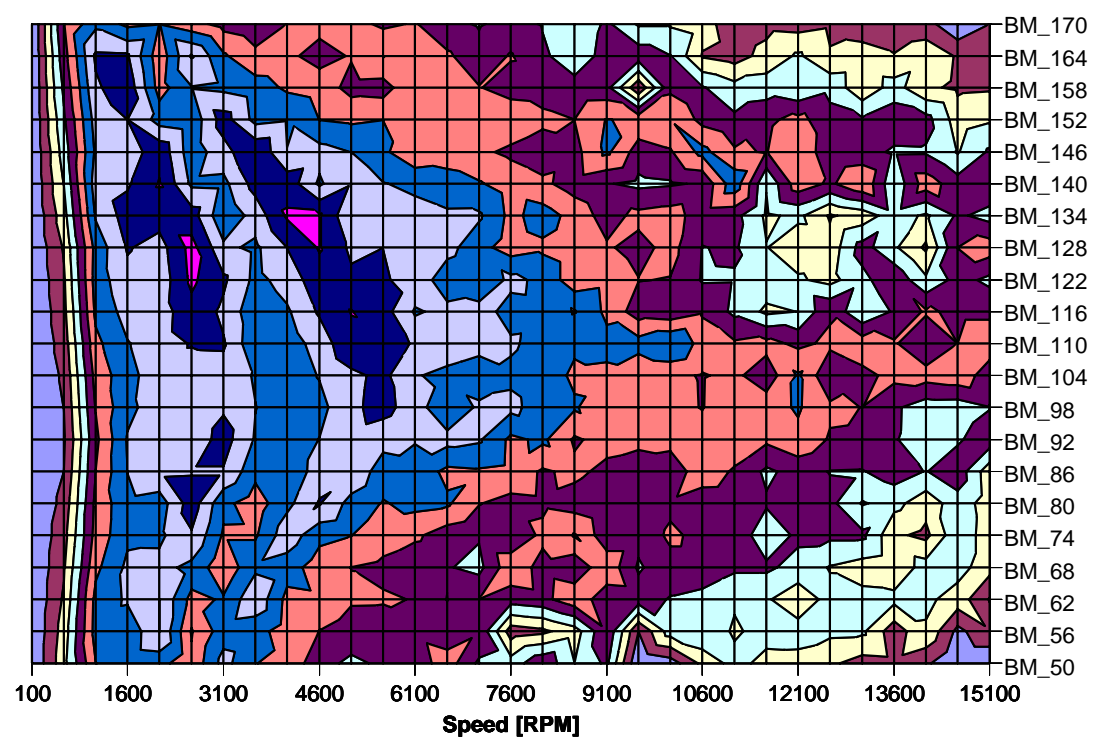

(b) Power contour view.

Fig. 18. Relationship between magnet pitch, $\beta_{\mathrm{M}}$, speed, and maximum power for the V-shaped IPM motor.

The contour plot in Fig. 18(b) clearly shows the general trend of higher power (dark blue) extending into higher speed ranges over the midrange of the $\beta_{M}$ variation. Figure 19 shows the percentage of torque produced by reluctance. 


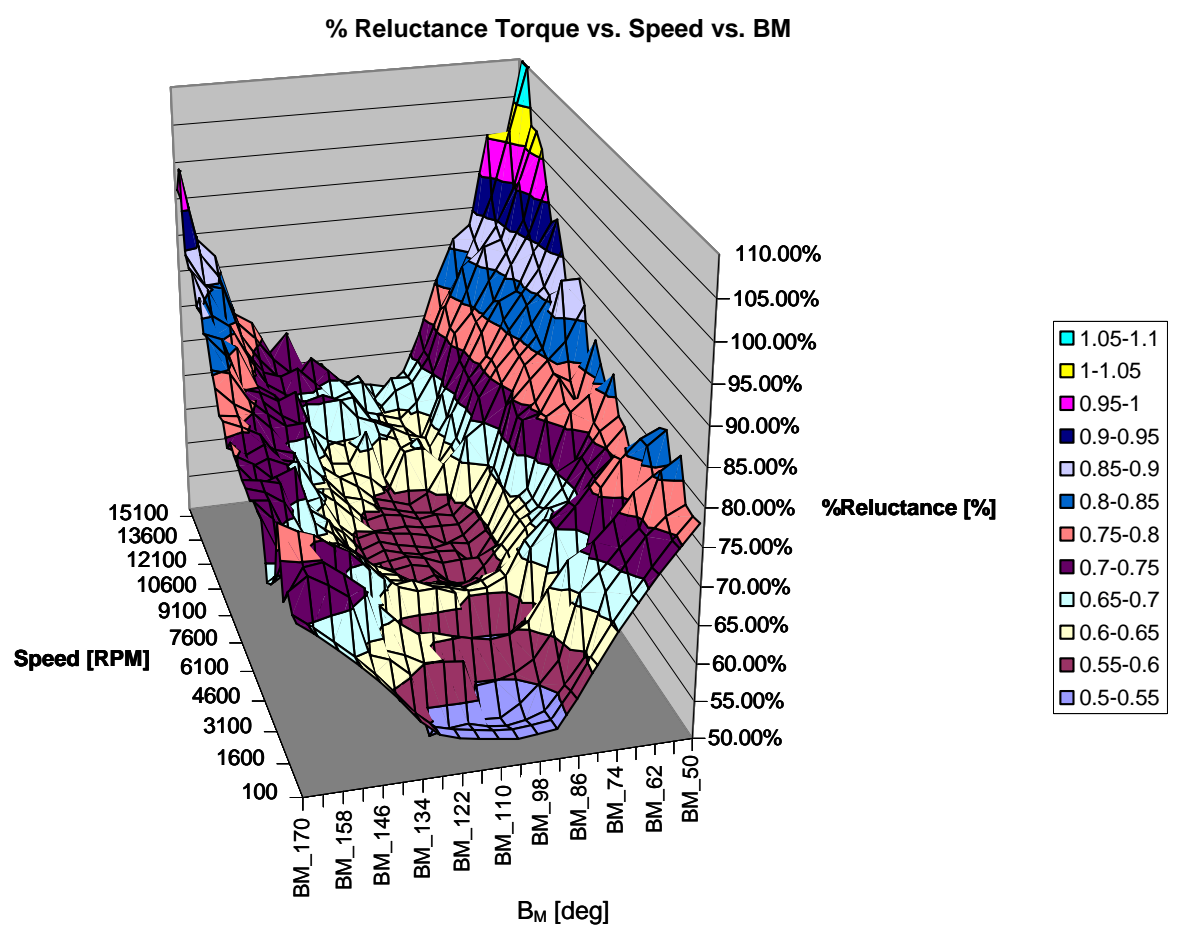

Fig. 19. Relationship between magnet pitch, $\beta_{\mathrm{M}}$, speed, and percentage of reluctance torque for the V-shaped IPM type-4 motor.

Figure 20 shows the CPSR for $40 \mathrm{~kW}$. The CPSR peaks at a value of 12 for a value of $\beta_{\mathrm{M}}$ between $110^{\circ}$ and $122^{\circ}$; a value of $\beta_{M}=77^{\circ}$ would be enough for a CPSR of 10 .

CPSR at $40 \mathrm{~kW}$

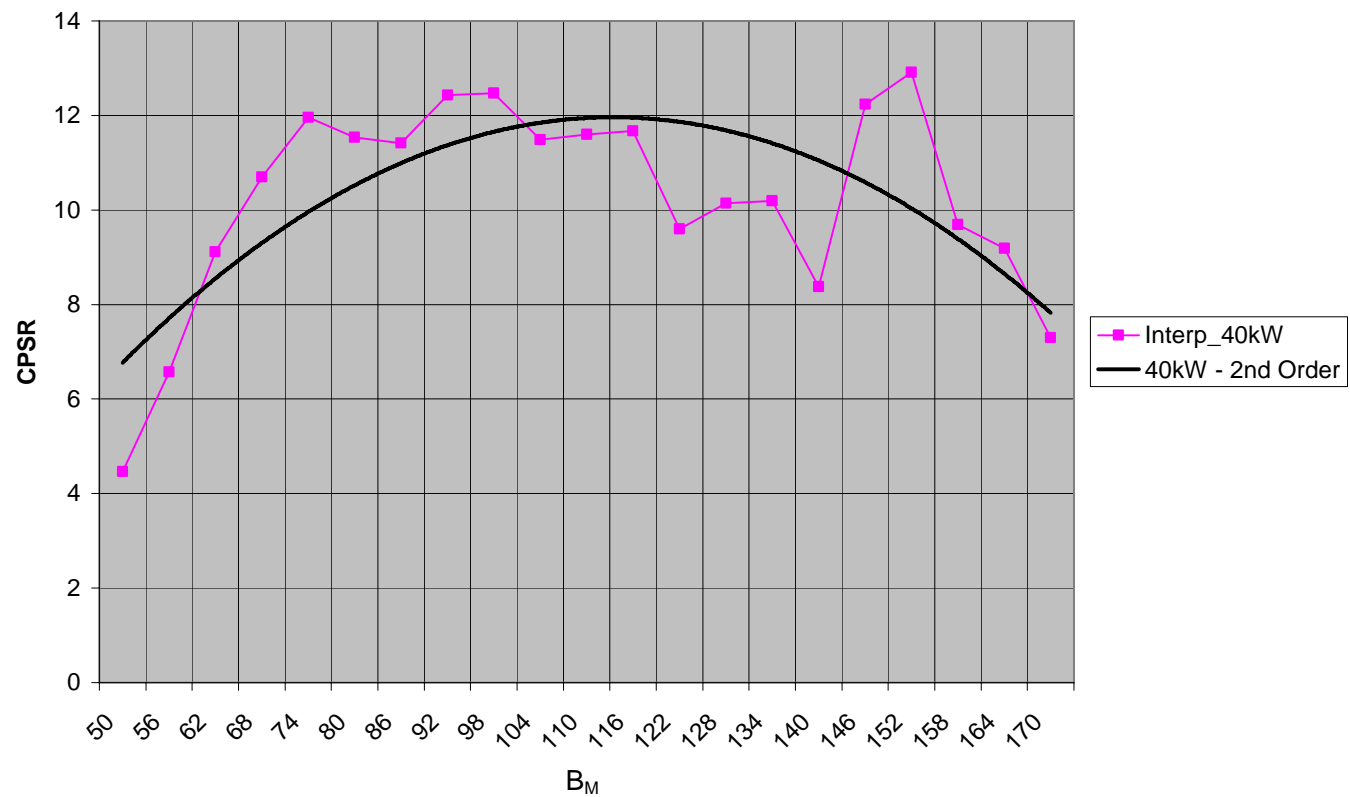

Fig. 20. CPSR as a function of magnet pitch, $\beta_{M}$, for the V-shaped IPM motor.

As with the InsRel motor, the relationship between normalized cost, torque, and speed is shown in Figs. 21(a) and 21(b). 

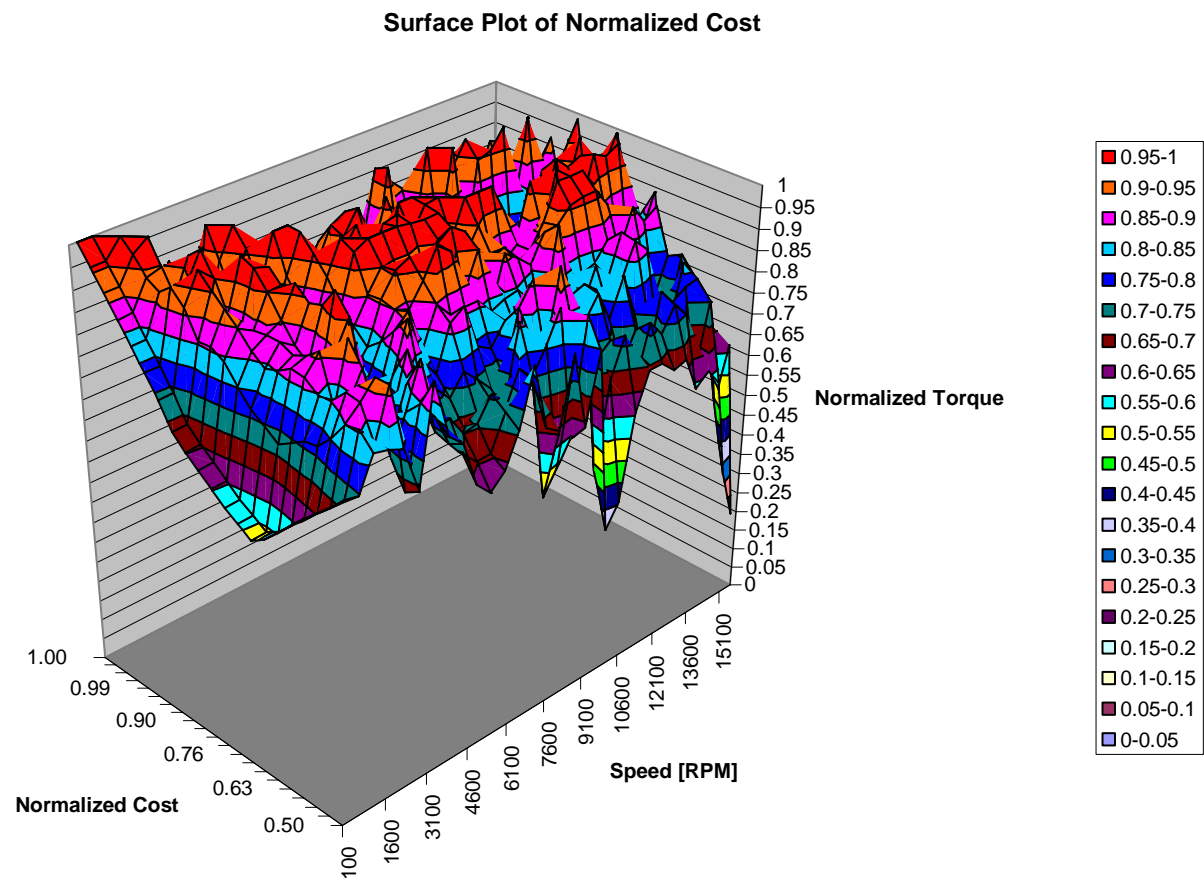

(a) Low-cost corner view.

Contour Plot of Normalized Cost and Torque

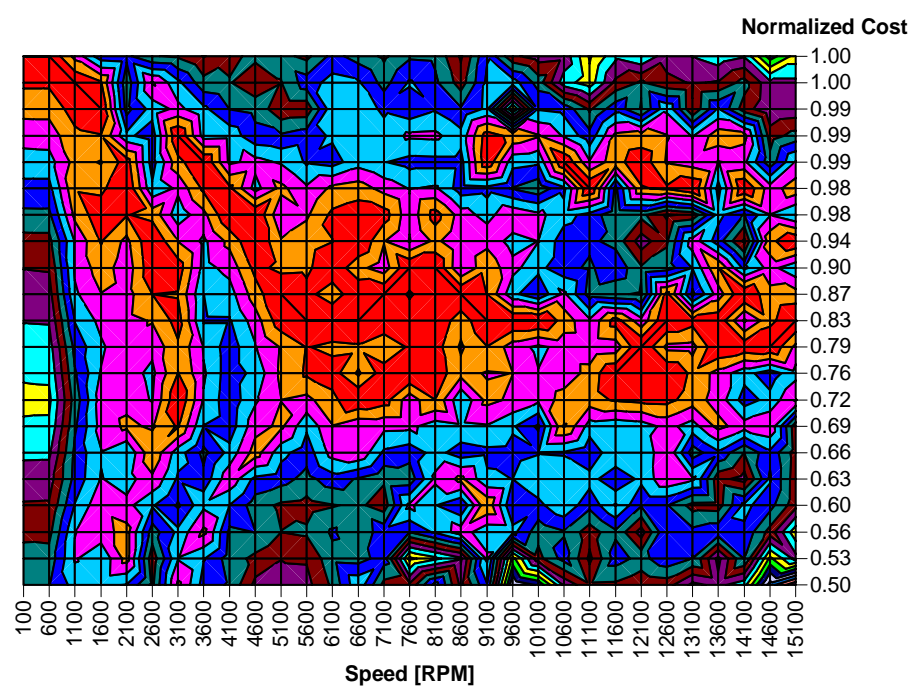

Normalized Torque

$\square 0.95-1$

$\square 0.9-0.95$

$\square 0.85-0.9$

$\square 0.8-0.85$

0.75-0.8

$\square 0.7-0.75$

๑0.65-0.7

- 0.6-0.65

$\square 0.55-0.6$

口0.5-0.55

$\square 0.45-0.5$

- $0.4-0.45$

$\square 0.35-0.4$

$\square 0.3-0.35$

$\square 0.25-0.3$

口0.2-0.25

$\square 0.15-0.2$

ㅁ.1-0.15

$\square 0.05-0.1$

口0-0.05

(b) Normalized torque contour view.

Fig. 21. Relationship between normalized torque, speed, and relative magnet cost for V-shaped IPM motor.

Figure 21(b) shows that the cost can vary from $100 \%$ to $50 \%$ and that the highest torque region (red, orange, purple, and blue) over the entire speed range appears to be centered at about $83 \%$ cost. 
Finally, Figs. 22(a) and 22(b) compare the torque and power vs. speed of the type-4 and the surface-mounted PM. As with the inset PM, the surface-mounted PM has an initial torque roughly half that of the motor with $\mathrm{V}$-shaped magnets. It marginally increased above the motor with V-shaped magnets before falling below at speeds above $7600 \mathrm{rpm}$. This illustration shows the positive impact of reluctance torque generation over the complete operating range.

Torque vs Speed Comparison

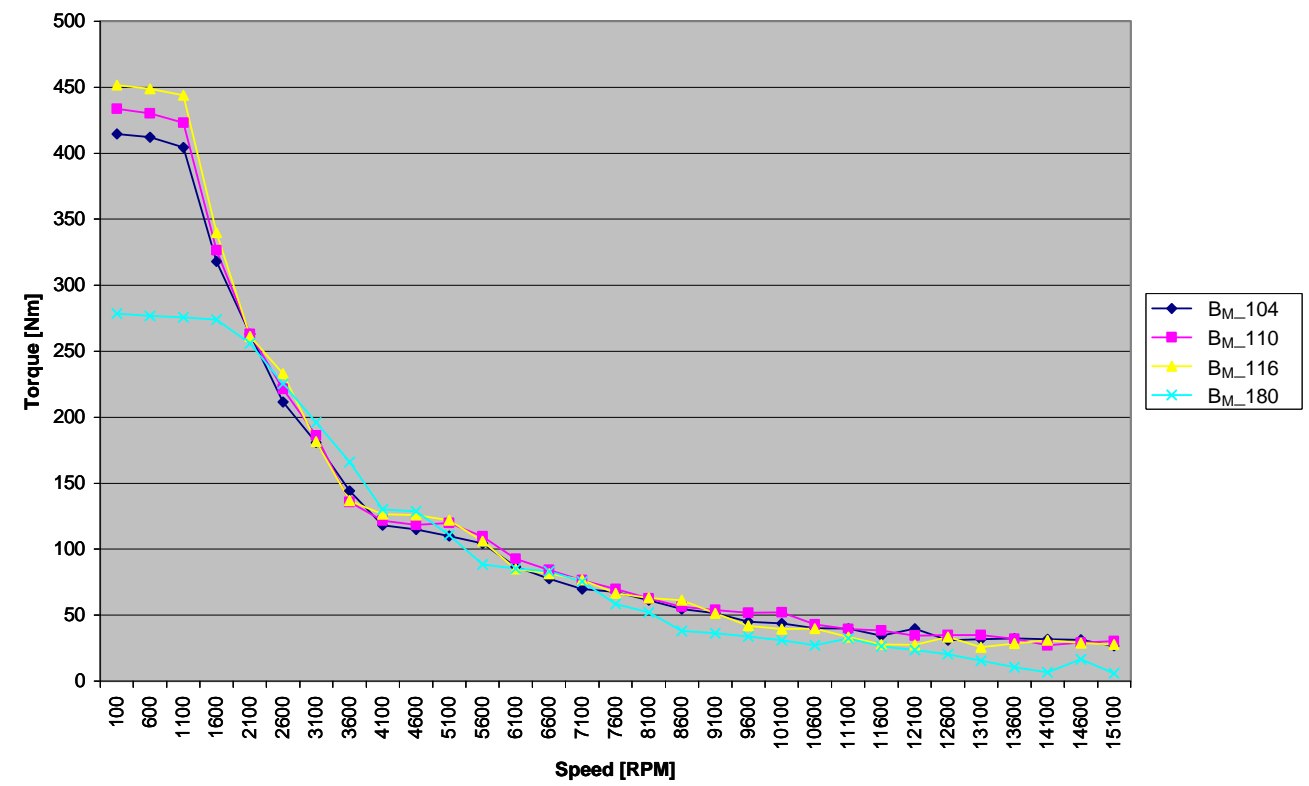

(a) Torque comparison view. Power vs Speed Comparison

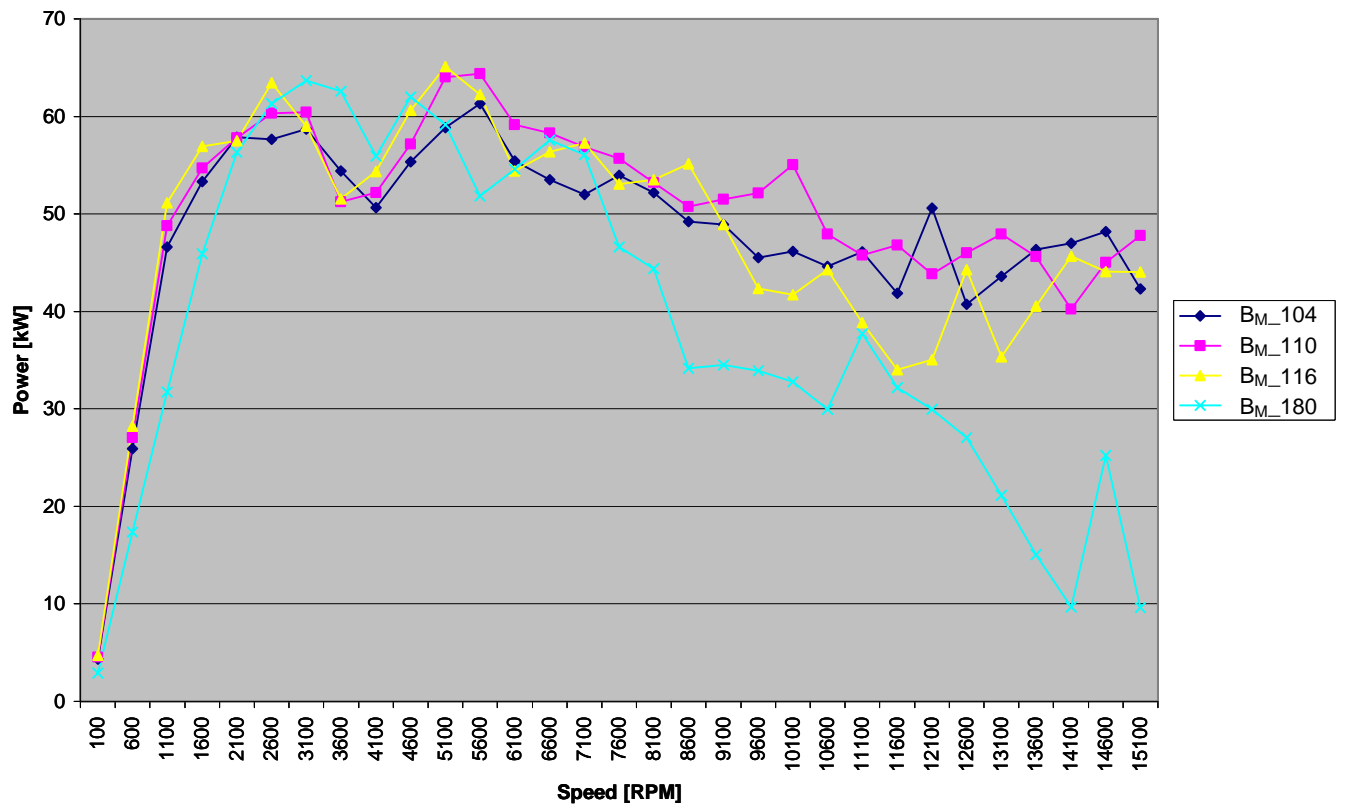

(b) Power comparison view.

Fig. 22. Comparison of selected optimal (magnet pitches, $\beta_{M}=104,110$, and $116^{\circ}$ with highest CPSR) $V$-shaped IPM motor performance with surface-mounted PM motor $\left(\beta_{M}=1^{\circ}{ }^{\circ}\right)$. 


\section{U-Shaped Dual-Layer IPM Type-6 Results}

In this geometry, the parameter determining the amount of magnet material, $\beta_{M}$, is replaced with the variable, yI_1, which is the length of the magnet in the bottom layer of the innermost part of the "U." The width of the silicon steel web at the air-gap boundary is kept constant. Thus, the only reluctance changes produced by the change of yI_1 are associated with the positioning of internal flux barriers. The main effect of yI_1 variation is the amount of PM material.

Figures 23(a) and 23(b) show that in the U-shaped dual-layer IPM type-6 motor, the variation in PM positioning and amount of magnet had little impact in the torque produced, as indicated by the horizontal segments in Fig. 23(a) and, especially, Fig. 23(b). Note the sharp roll-off of efficiency as speed increases. This efficiency roll-off may determine the optimal length of the innermost PM in this IPM type.

$B_{M}$ Variation Upon Torque and Efficienciy

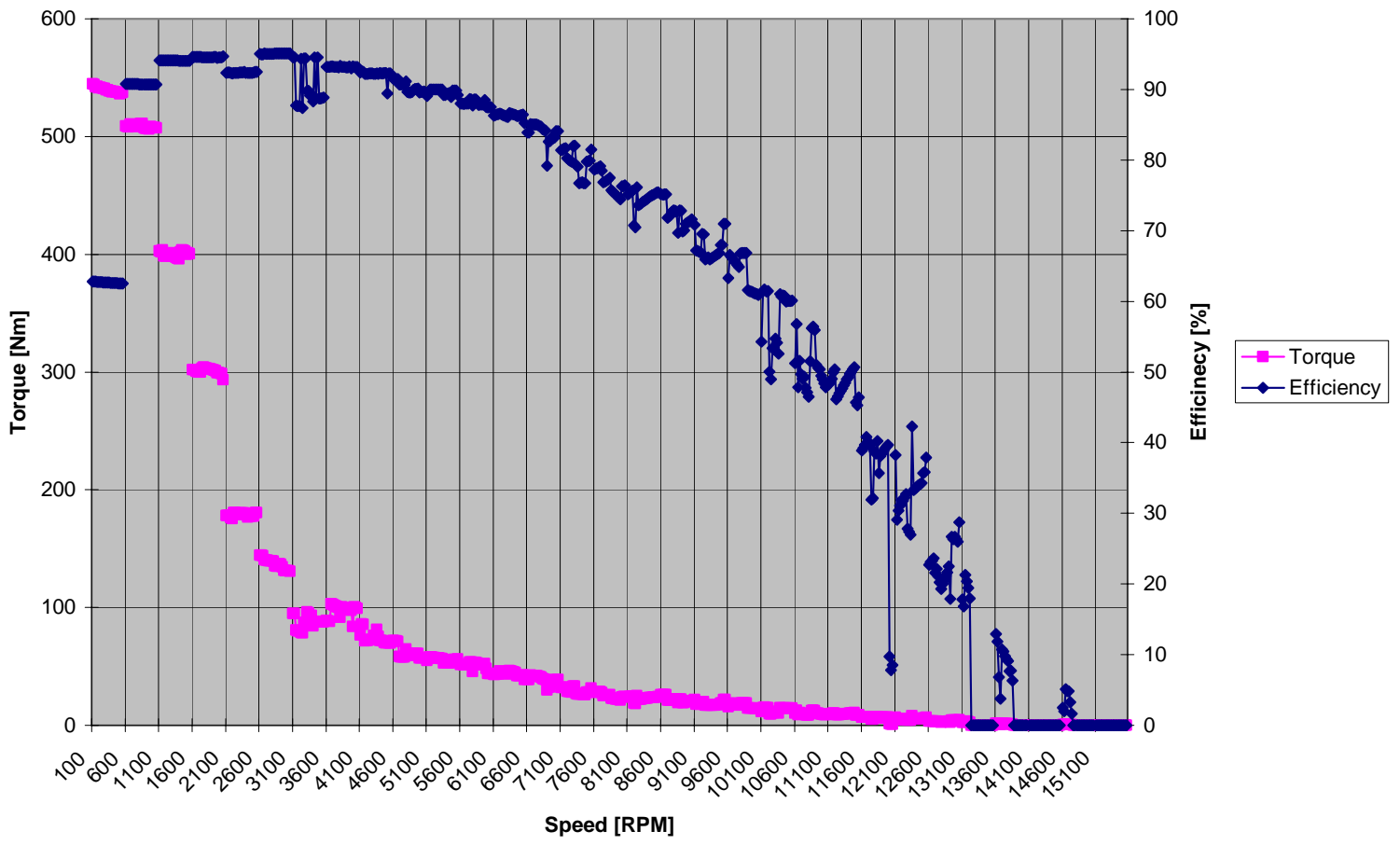

(a) Compact view for the full range of speeds.

Fig. 23. Torque and efficiency as a function of speed over a range of magnet pitches for the motor with dual-layer U-shaped IPMs. 


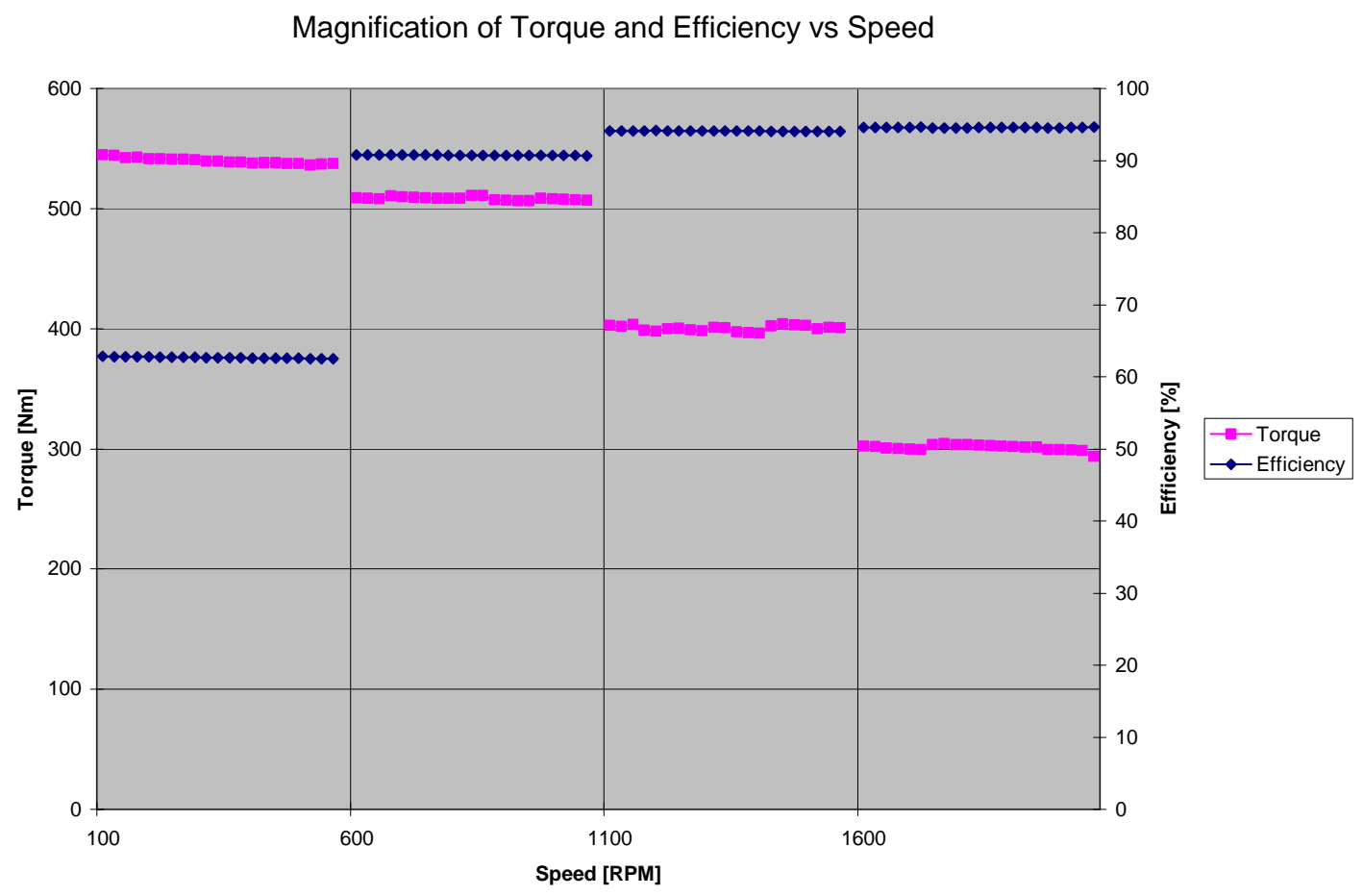

(b) Expanded view for a reduced set of speeds.

Fig. 23. Torque and efficiency as a function of speed over a range of magnet pitches for the motor with dual-layer U-shaped IPMs (cont'd).

Figures 24(a) and 24(b) show the relationship between yI_1, speed, and torque for this dual-layer U-shaped PM motor. The tightly packed set of torque vs. speed curves confirms that the torque is independent of changes in length of the U-shaped lower magnets.

Figures 25(a) and 25(b) are 3D views of the relationships between yI_1, speed, and phase advance for the dual-layer U-shaped PM motor type. Again, the values are nearly independent of variations in yI_1.

Figures 26(a) and 26(b) are 3D views of the relationships between yI_1, speed, and power output for the dual-layer U-shaped PM motor. Again, the values are nearly independent of variations in yI_1. 
Speed Variation Upon Torque for Each yl_1

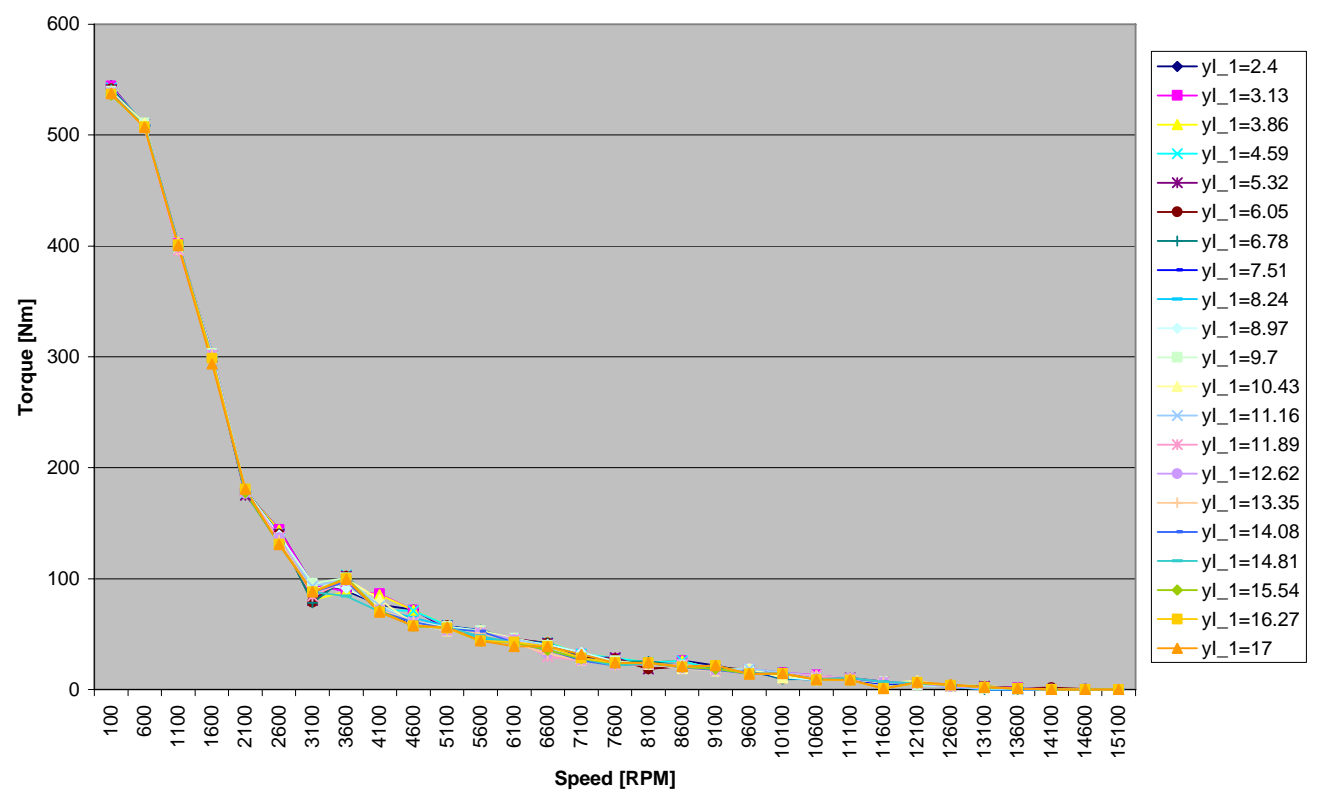

(a) Conventional torque performance view.

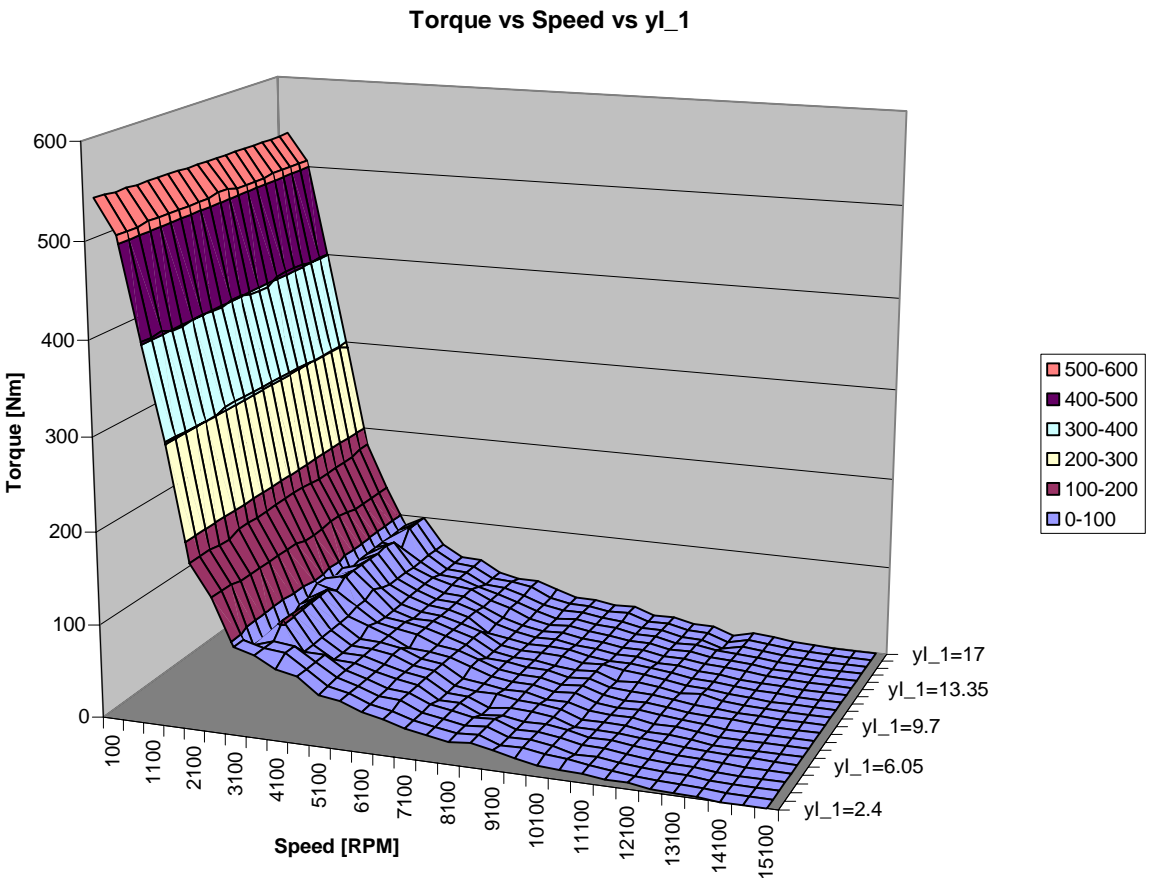

(b) Minimum magnet material corner view.

Fig. 24. Relationship between magnet amount, yI_1, speed, and torque for the motor having dual-layer U-shaped IPMs. 


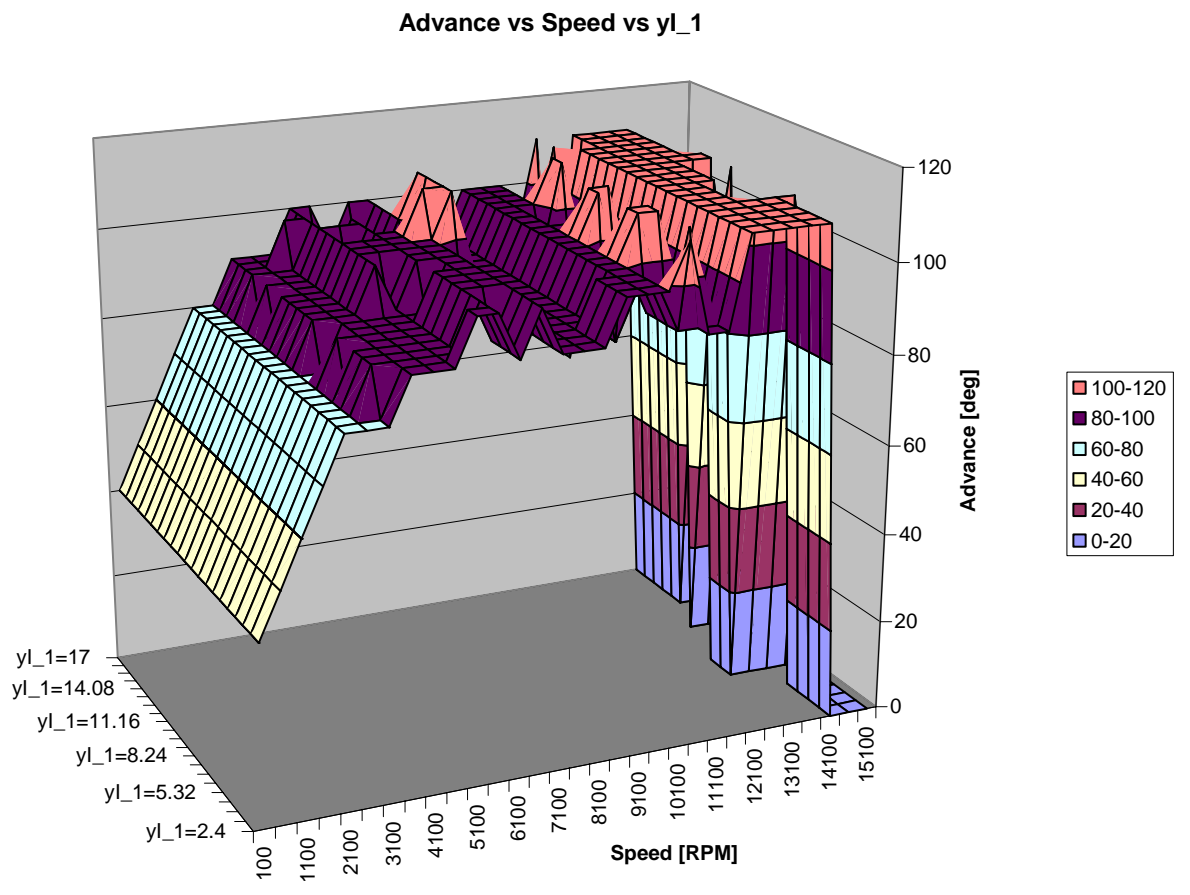

(a) Minimum magnet material corner view.

Advance vs Speed vs yl_1

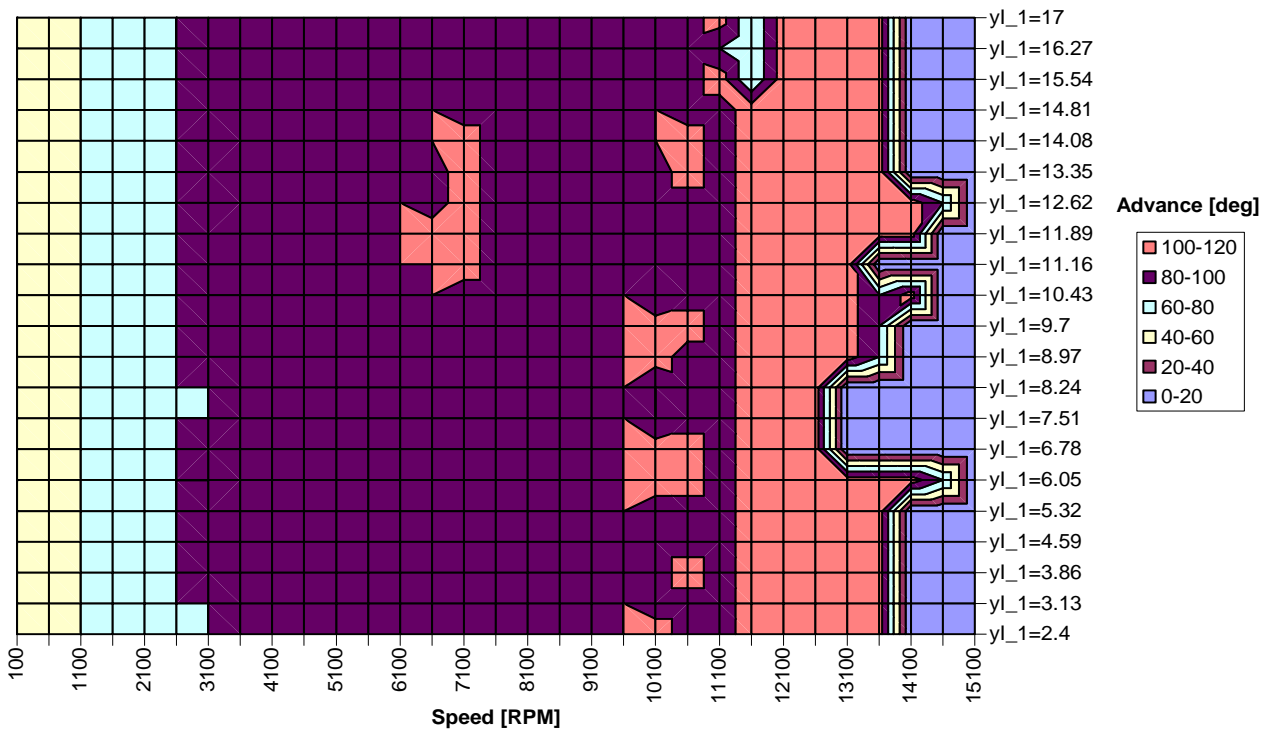

(b) Advance contour view.

Fig. 25. Relationship between magnet material, yI_1, speed, and advance for the motor having dual-layer U-shaped IPMs. 


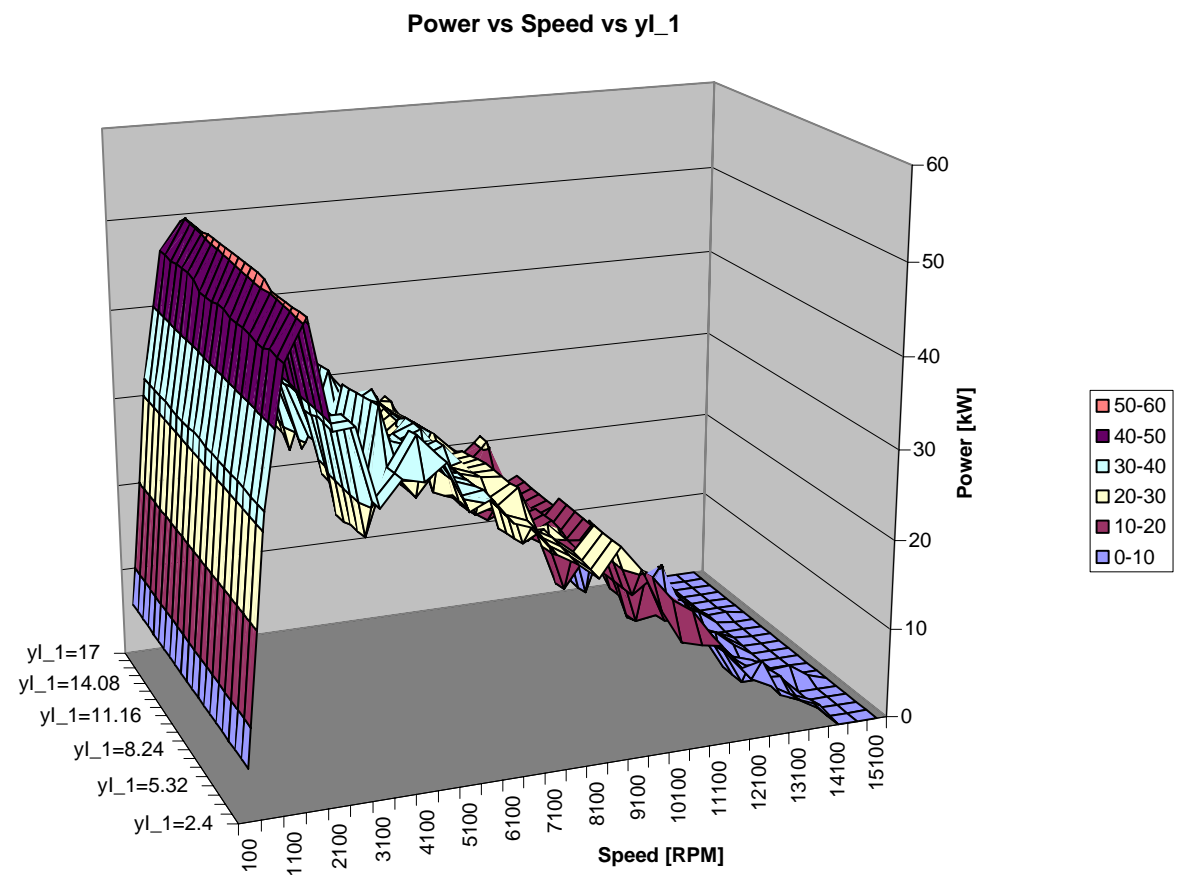

(a) Minimum magnet material corner view.

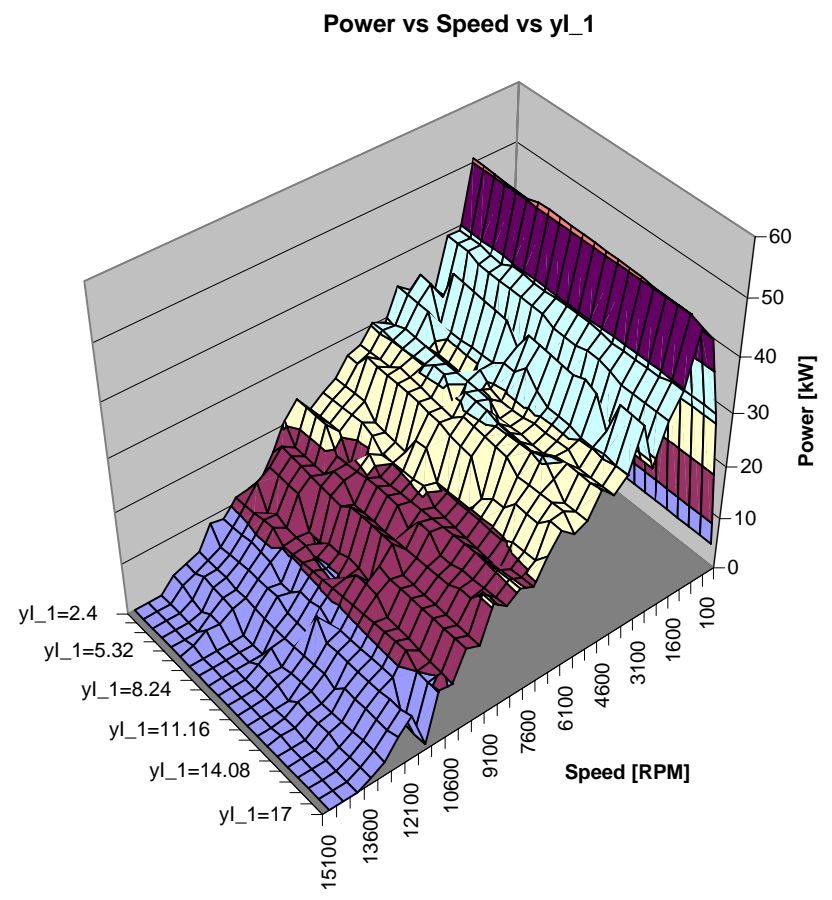

(b) Maximum magnet material corner view.

Fig. 26. Relationship between magnet amount, yI_1, speed, and power for the motor having dual-layer U-shaped IPMs.

Figure 27 shows the extreme contribution of reluctance at high speeds. Note that at these same high speeds this motor exhibits low efficiency, as shown earlier in Fig. 23. 


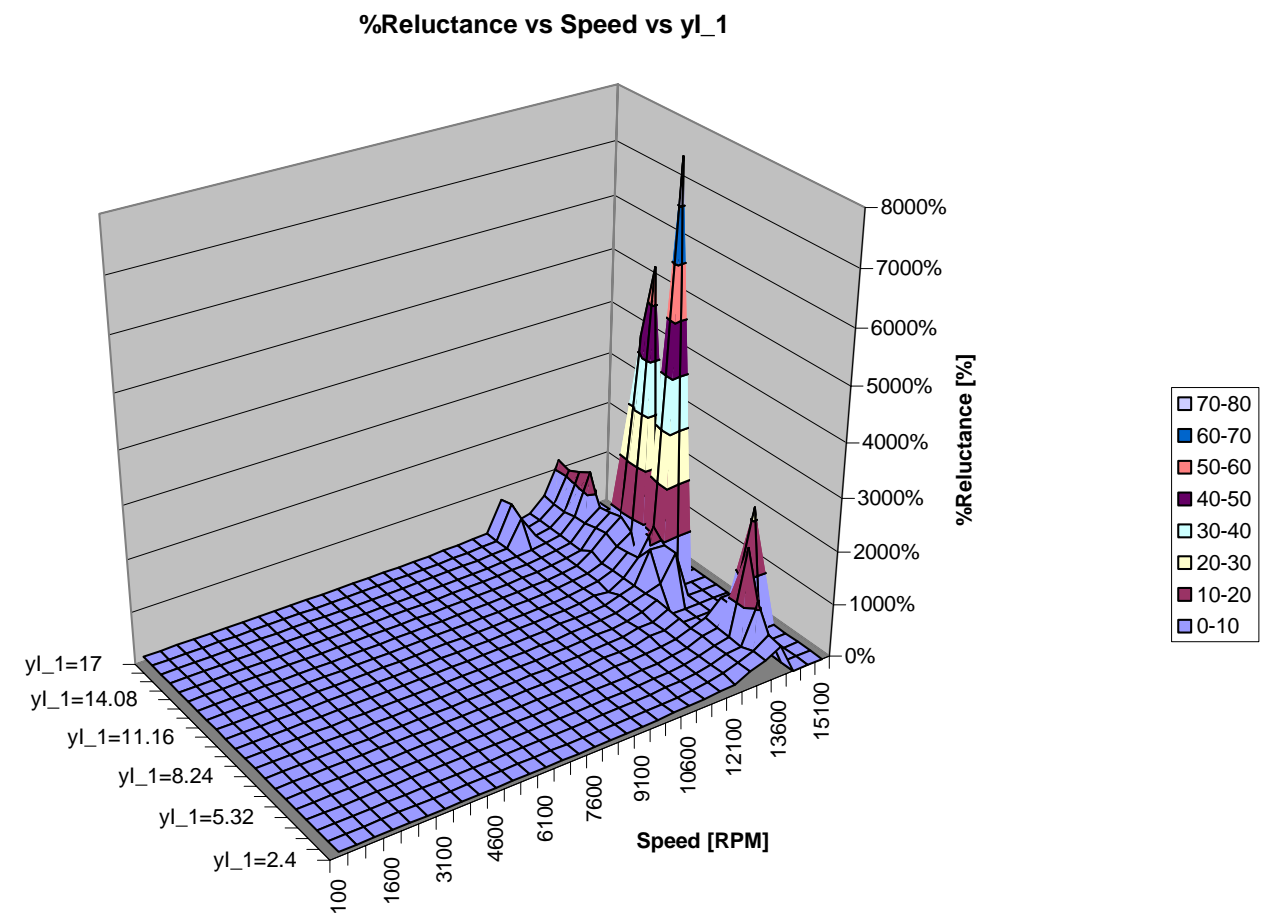

Fig. 27. Relationship between magnet amount, yI_1, speed, and percentage of reluctance torque for motor having dual-layer U-shaped IPMs.

Figure 28 shows that the CPSR for the motor topology is unaffected by changes in yI_1; consequently, the minimum value of yI_1 is best.

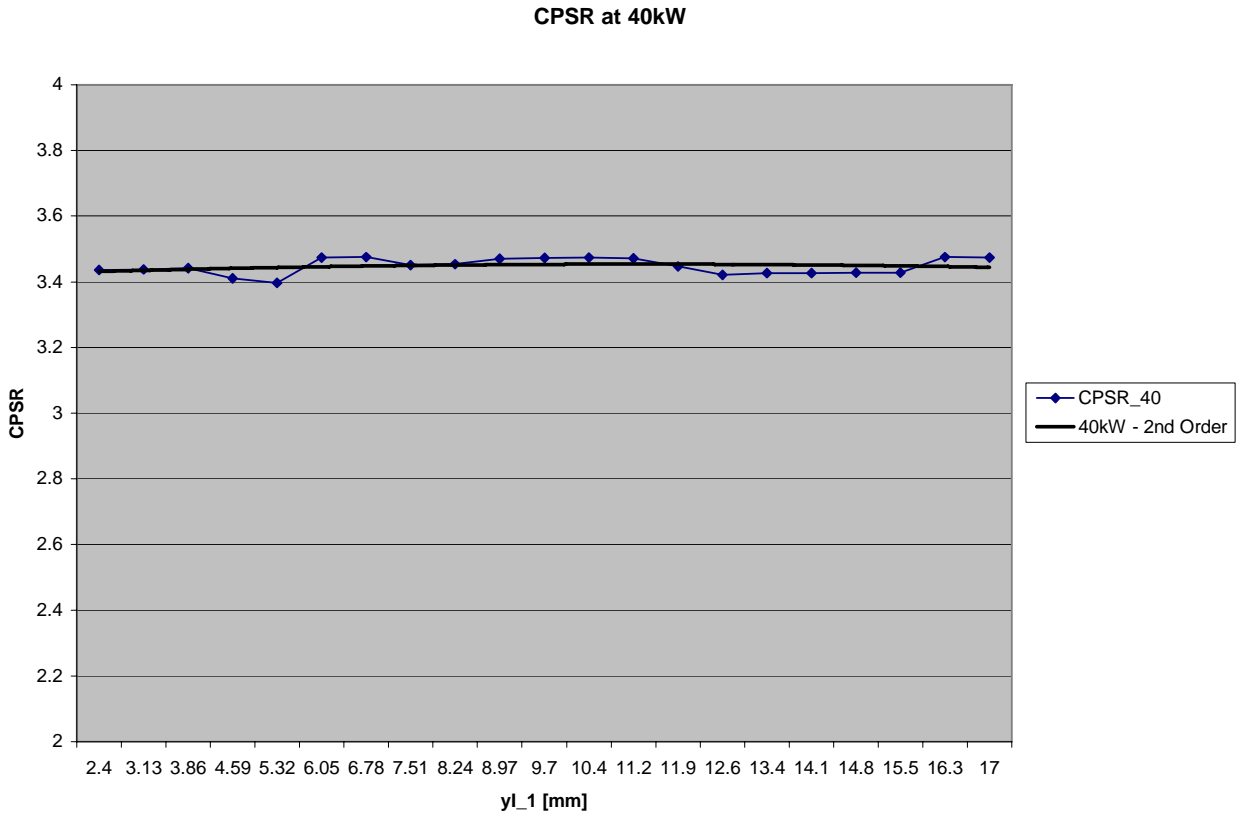

Fig. 28. CPSR as a function of magnet amount, yI_1, for the motor having dual-layer U-shaped IPMs. 
Figures 29(a) and 29(b) show the normalized costs of the magnet and torque generated at each speed.

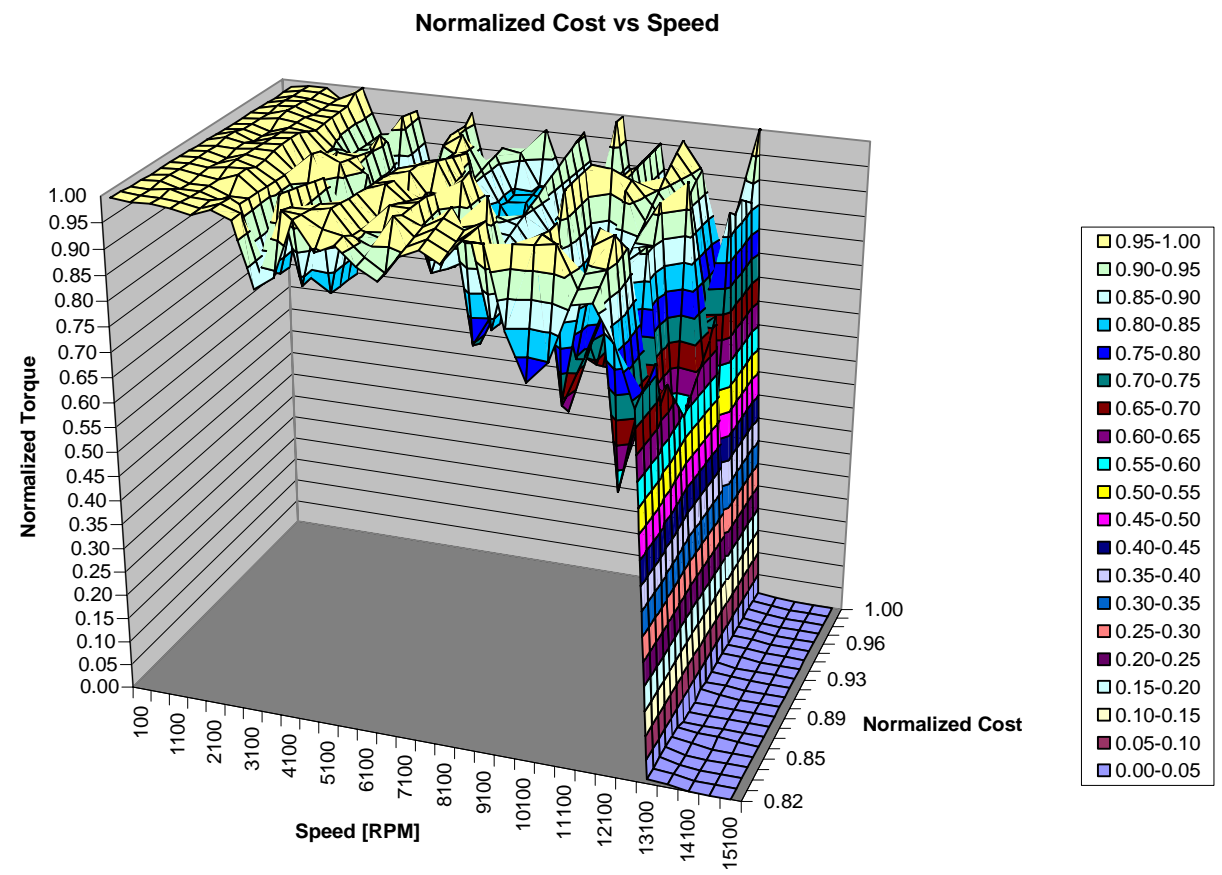

(a) View from low-cost corner.

Normalized Cost vs Speed

Normalized Cost
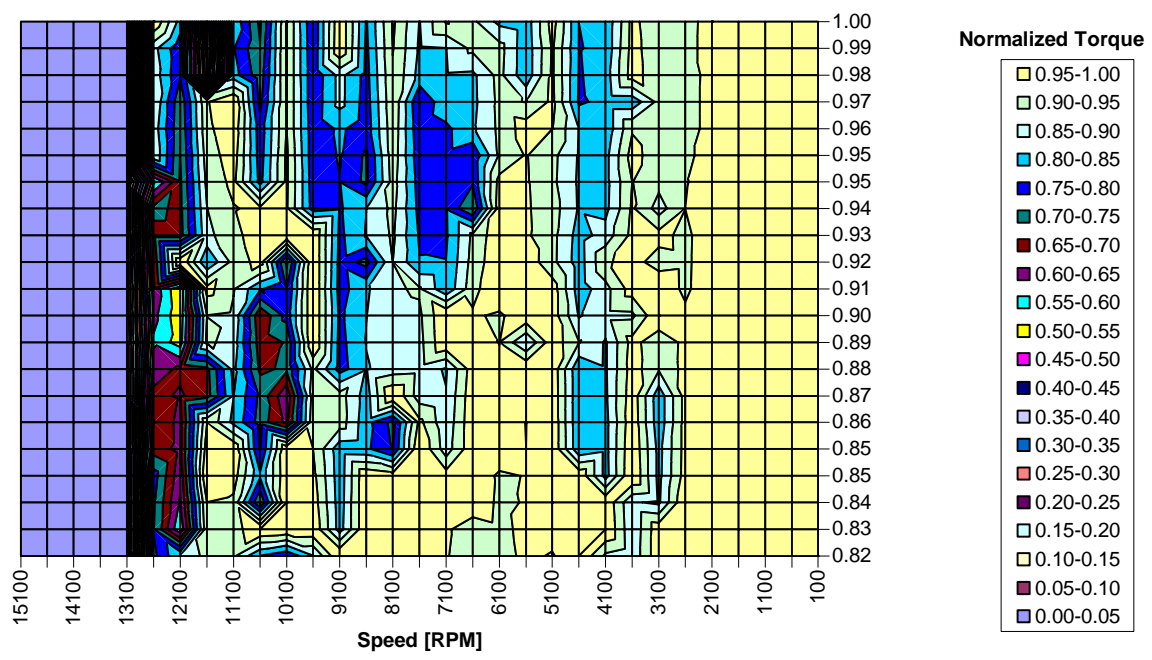

(b) Torque contour plot.

Fig. 29. Speed and normalized cost and torque for the motor having dual-layer U-shaped IPMs. 
Finally, Figs. 30(a) and 30(b) show the toque and power vs. speed curves for this topology and for the surface-mounted IPM, which is the inset PM motor with $\beta_{\mathrm{M}}=180^{\circ}$. The type- 6 motor has significantly higher torque up to $1600 \mathrm{rpm}$, but its speed range is lower. As shown by Fig. 30(b), the performance computed for this motor type is quite inferior to that of the surfacemounted PM motor.

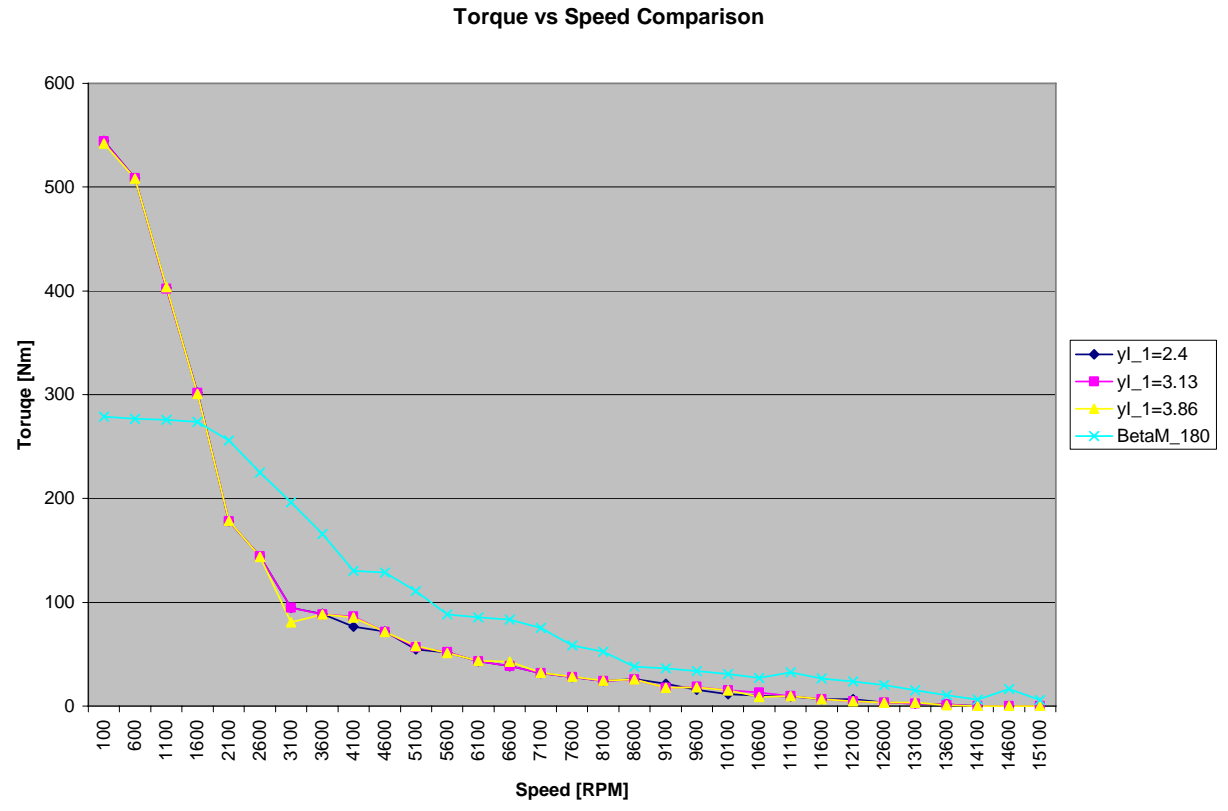

(a) Torque performance comparison.

Power vs Speed Comparison

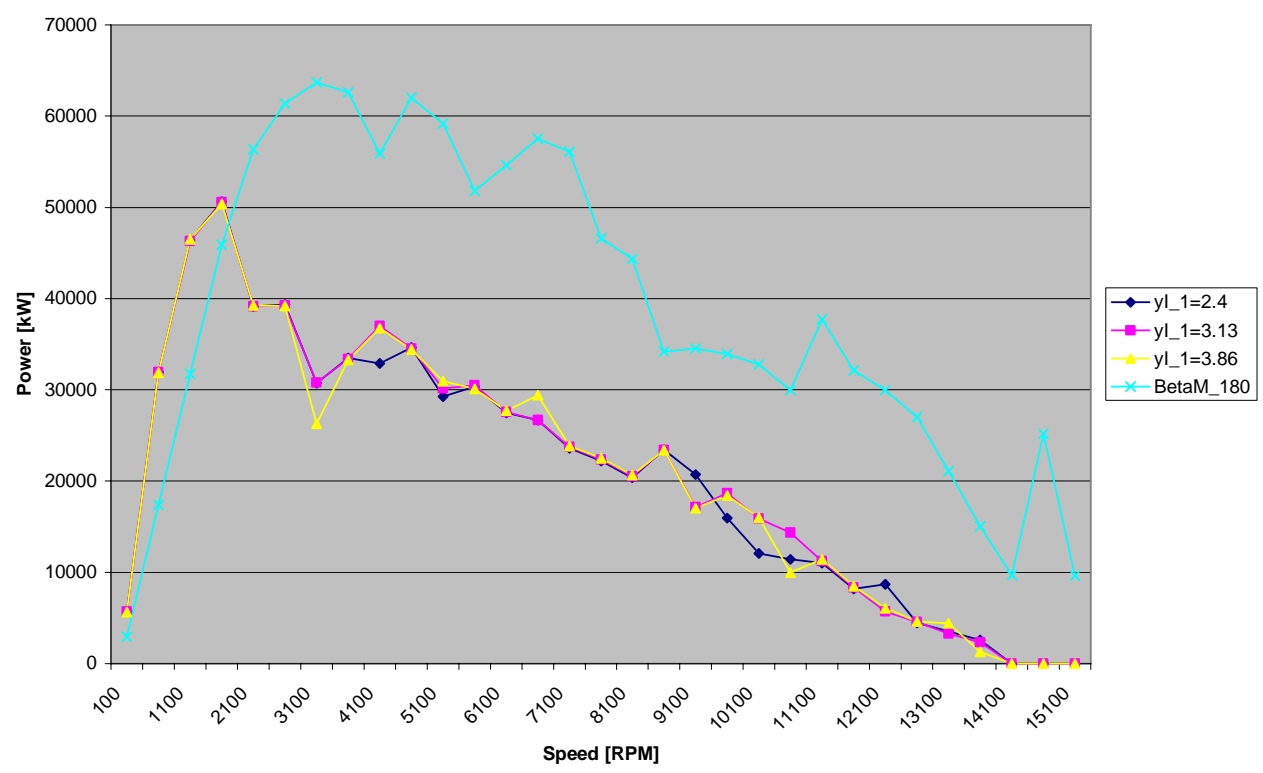

(b) Power performance comparison.

Fig. 30. Performance comparison of IPM motor having double-layer U-shaped magnets with surface-mounted PM motor having only PM torque. 


\section{Comparison of Best of Each Topology}

For reference and comparison, the torque and power plots for what we have chosen as the best in each of the three motor types have been plotted in Figs. 30(a) and 30(b). For completeness, the curves for the surface-mounted PM have also been included.

Torque Comparision for All Four Motor Types

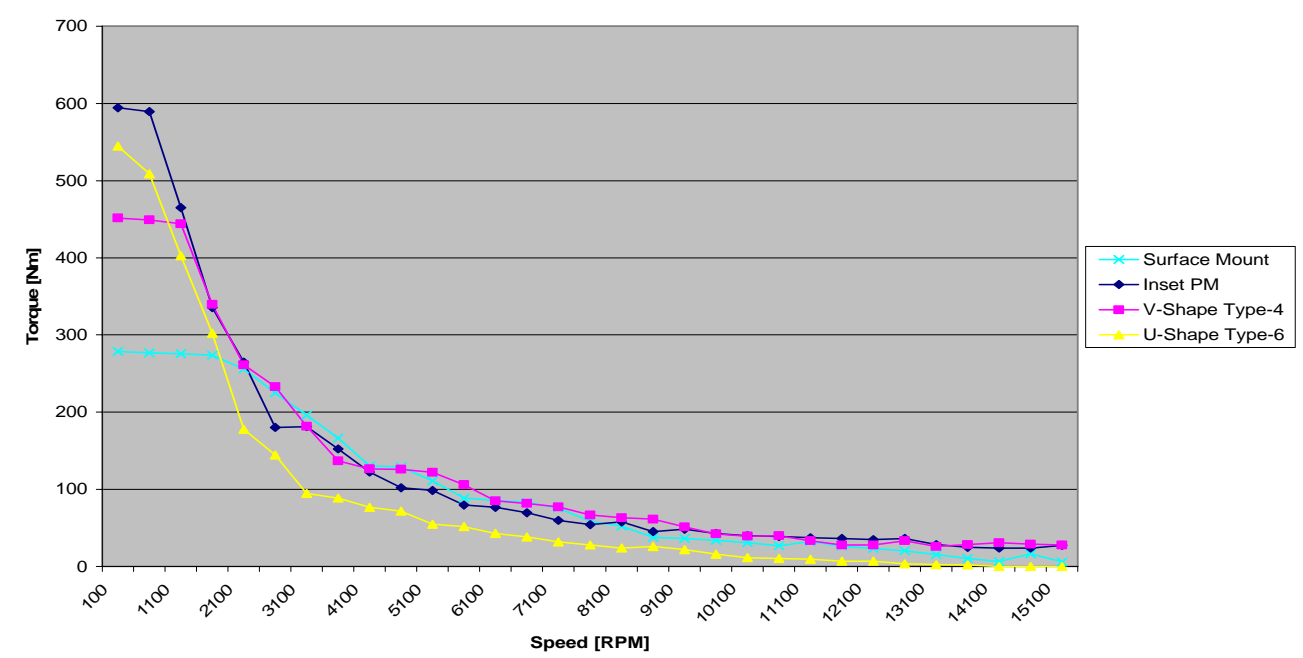

(a) Torque performance comparison.

Power Comparision for All Four Motor Types

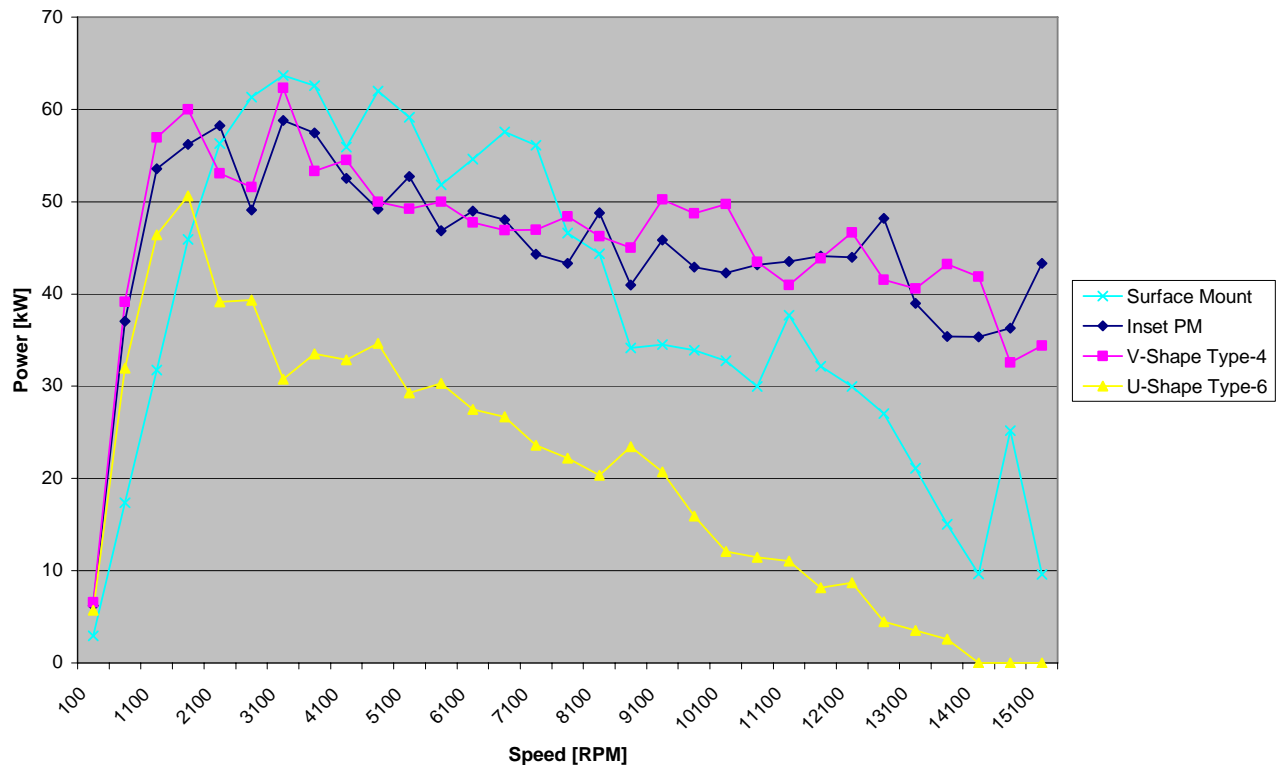

(b) Power performance comparison.

Fig. 31. Performance comparison of four motors with varying degrees of reluctance: (1) surface-mounted PM motor producing only PM torque; (2) inset PM/reluctance motor with magnet pitch, $\beta_{M}=125^{\circ}$; (3) V-shaped IPM motor with $\beta_{M}=116^{\circ}$; and (4) double-layer U-shaped IPM with yI_1 = $22.4 \mathrm{~mm}$. 
Figure 31(a) shows that the torque at low speeds is significantly higher for all the IPM motors than for the surface-mounted PM. The slopes of the curves in Fig. 31(b) show the impact of reluctance on lowering the rate of power drop-off with speed.

The best of the motors with inset and V-shape magnets have very similar performances. The Ushape type-6 motor has lower performance and shorter speed range, but comparison to the others may not be warranted because its base geometry is not necessarily optimal. The intended goal was to evaluate the impact of changing the amount of PM while keeping the geometry at the airgap surface constant. There is a need to continue studies in investigating the effect of changing the amount of PM closer to the periphery.

\section{CONCLUSIONS}

Through our preliminary analysis, we have shown the benefits of properly controlling reluctance and the need for saliency to further increase reluctance torque.

ORNL has investigated, by means of parametric studies, the performance of three PM designs which represent progressive approaches of using reluctance to improve the performance of PM motors for locomotion. The results obtained show the need for detailed finite-element simulations and indicate the direction of further research.

As expected, due to the reluctance torque component, all three types of IPM motors studied have significantly higher torque at low speeds than a similar surface-mounted PM motor (Fig. 31(a)) The rate of power drop as speed increases is lower in all the IPMs (Fig. 31(b)), as expected because they have weaker magnet strength, which reduces the value of $\omega_{\max }$ (Caption Fig. 1).

The inset PM introduces reluctance torque, causing saliency in the rotor by replacing some of the PM material in its surface with iron (Fig. 3). This study concludes that the optimal amount of PM material for a CPSR of 10 at $40 \mathrm{~kW}$ corresponds to an angular pitch of $\beta_{\mathrm{M}}=125^{\circ}$ (Fig. 12). This is $70 \%$ of the amount of PM material in a similar surface-mounted PM motor, which would result in lower cost for the motor in addition to improved performance.

The embedded V-shaped PM motor immerses the PMs into the rotor's iron (Fig. 4), creating soft-iron magnetic poles in addition to introducing saliency. It is concluded that the angular magnet pitch for optimal torque and speed range is $105^{\circ}$ (Fig. 18(b)). Then the motor can operate over the whole speed range at powers above $50 \mathrm{~kW}$. Note that for a CPSR $=10$ at $40 \mathrm{~kW}$, the motor would only require a magnet pitch of $\beta_{\mathrm{M}}=77^{\circ}$ (Fig. 20 using the 2 nd order line fit), which would be more economical.

The dual-layer U-shape PM motor (Fig. 5), in addition to creating soft-iron magnetic poles and saliency in the rotor, introduces multiple barriers to increase anisotropy in the magnetic path, thereby enhancing saliency. ORNL has not yet determined the operational benefits expected from the added design complexity. The intended goal was to evaluate the impact of changing the amount of PM in the inside while keeping the geometry at the air-gap surface constant. The conclusion is clear: there is no impact. As Fig. 24(a) shows, performance was essentially unaffected by changes in the length of the lower magnets. As a result, the obvious optimal 
geometry was the one with the shortest magnet possible. Comparison of power and torque outputs to those of the other optimized motor types is not warranted because the base geometry is not necessarily optimal. It is also possible that the computer model does not simulate this multilayer type of motor properly. Further studies will investigae this topology with more detailed variations of the width of the iron web between the PMs, as in the other two types, and using finite elements to study the impact of the multiple flux barriers on reluctance.

Although the performance curves of the inset and V-shaped types differ on most of the parametric calculations, the performance of each with the best combination of parameters, which is shown together in Fig. 31(b), is strikingly similar. Because of the air-gap flux skewing capability inherent to the IPM magnetic poles, it is expected that the V-shaped IPM will have higher output at the highest speeds. This will require further detailed analyses using finiteelement computations.

\section{REFERENCES}

1. A. E. Fitzgerald, C. Kingsley, Jr., and S. D. Umans, Electric Machinery, McGraw-Hill, 1990.

2. I. Boldea and S. A. Nasar, Electric Drives, CRC Press, 1999.

3. A. M. El-Refaie and T. M. Jahns, "Optimal Flux Weakening in Surface PM Machines Using Concentrated Windings," Record of the 2004 IEEE Industry Applications Society Annual Meeting, Seattle, Washington, October 2004. 


\section{DISTRIBUTION}

Internal

1. D. J. Adams

2. E. C. Fox

3. L. D. Marlino

4. J. W. McKeever
5. M. Olszewski

6. P. J. Otaduy

7-8. Laboratory Records

\section{External}

9. T. Q. Duong, U.S. Department of Energy, EE-2G/Forrestal Building, 1000 Independence Avenue, S.W., Washington, D.C. 20585.

10. R. R. Fessler, BIZTEK Consulting, Inc., 820 Roslyn Place, Evanston, Illinois 60201-1724.

11. K. Fiegenschuh, Ford Motor Company, Scientific Research Laboratory, 2101 Village Road, MD-2247, Dearborn, Michigan 48121.

12. V. Garg, Ford Motor Company, 15050 Commerce Drive, North, Dearborn, Michigan 48120-1261.

13. E. Jih, Ford Motor Company, Scientific Research Laboratory, 2101 Village Road, MD1170, Rm. 2331, Dearborn, Michigan 48121.

14. W. C. Johnson, University of Tennessee-Knoxville, ECE Department, 414 Ferris Hall, 1508 Middle Drive, Knoxville, Tennessee 37996.

15. A. Lee, Daimler Chrysler, CIMS 484-08-06, 800 Chrysler Drive, Auburn Hills, Michigan 48326-2757.

16. F. Liang, Ford Motor Company, Scientific Research Laboratory, 2101 Village Road, MD1170, Rm. 2331/SRL, Dearborn, Michigan 48121.

17. M. W. Lloyd, Energetics, Inc., 7164 Columbia Gateway Drive, Columbia, Maryland 21046.

18. Brenda Medellon, USCAR, brenda@uscar.org

19. M. Mehall, Ford Motor Company, Scientific Research Laboratory, 2101 Village Road, MD-2247, Rm. 3317, Dearborn, Michigan 48124-2053.

20. J. Rogers, Chemical and Environmental Sciences Laboratory, GM R\&D Center, 30500 Mound Road, Warren, Michigan 48090-9055.

21. S. A. Rogers, U.S. Department of Energy, EE-2G/Forrestal Building, 1000 Independence Avenue, S.W., Washington, D.C. 20585.

22. G. S. Smith, General Motors Advanced Technology Center, 3050 Lomita Boulevard, Torrance, California 90505.

23. E. J. Wall, U.S. Department of Energy, EE-2G/Forrestal Building, 1000 Independence Avenue, S.W., Washington, D.C. 20585.

24. B. Welchko, General Motors Advanced Technology Center, 3050 Lomita Boulevard, Torrance, California 90505.

25. P. G. Yoshida, U.S. Department of Energy, EE-2G/Forrestal Building, 1000 Independence Avenue, S.W., Washington, D.C. 20585. 